Marcelo Bacalini

\title{
Metodologia Experimental para Testes Padronizados de Confiabilidade em Dispositivos Indicadores de Faltas
}



Marcelo Bacalini

\section{Metodologia Experimental para Testes Padronizados de Confiabilidade em Dispositivos Indicadores de Faltas}

Dissertação apresentada à Escola de Engenharia de São Carlos da Universidade de São Paulo, sendo parte dos requisitos para obtenção do título de Mestre em Ciências, Programa de Engenharia Elétrica, Área de Concentração em Sistemas Elétricos de Potência.

Orientador: Prof. Dr. Ivan Nunes da Silva

\section{São Carlos}




\section{AUTORIZO A REPRODUÇÃO E DIVULGAÇÃO TOTAL OU PARCIAL DESTE TRABALHO, POR QUALQUER MEIO CONVENCIONAL OU ELETRÔNICO, PARA FINS DE ESTUDO E PESQUISA, DESDE QUE CITADA A FONTE.}

Bacalini, Marcelo.

Metodologia experimental para testes padronizados de confiabilidade em dispositivos indicadores de faltas. I Marcelo Bacalini ; orientador Ivan Nunes da Silva. São Carlos, 2011.

Dissertação - Mestrado (Programa de Pós-Graduação em Engenharia Elétrica e Área de Concentração em Sistemas Elétricos de Potência)-- Escola de Engenharia de São Carlos da Universidade de São Paulo, 2011.

1. Sistemas elétricos de potência. 2. Indicadores de continuidade. 3. Qualidade do serviço. 4. Indicadores de falta. I. Título. 


\section{FOLHA DE JULGAMENTO}

Candidato: Engenheiro MARCELO BACALINI

Título da dissertação: "Metodologia experimental para teses padronizados de confiabilidade em dispositivos indicadores de faltas."

Data da defesa: $12 / 12 / 2011$

\section{Comissão Julgadora:}

Prof. Associado Ivan Nunes da Silva (Orientador)

(Escola de Engenharia de São Carlos/EESC)

Prof. Dr. Julio Cesar Stacchini de Souza

(Universidade Federal Fluminense/UFF)

Prof. Dr. Rogério Andrade Flauzino

(Escola de Engenharia de São Carlos/EESC)
Resultado:
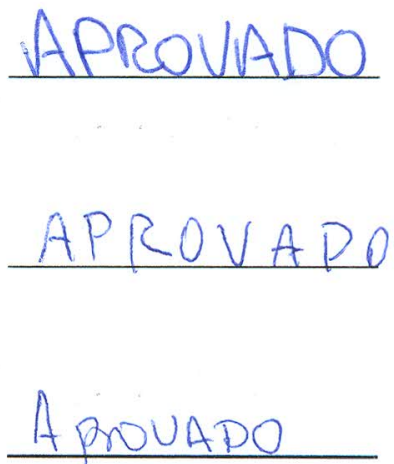

Coordenador do Programa de Pós-Graduação em Engenharia Elétrica:

Prof. Titular Denis Vinicius Coury

Presidente da Comissão de Pós-Graduação:

Prof. Associado Paulo Cesar Lima Segantine 

"Toda grande caminhada rumo ao conhecimento, começa sempre com um simples passo ..."

Provérbio Chinês 


\section{Agradecimentos}

Minha sincera gratidão ao nobre Mestre Prof. Dr. Ivan Nunes da Silva que sempre me incentivou na caminhada, orientando-me nos primeiros passos, sendo ainda incansável mestre, sempre genial e paciente para com todos.

Aos professores pelos ensinamentos que, com dedicação e carinho, nos proporcionaram ao longo da caminhada, em especial ao Prof. Dr. Rogério Andrade Flauzino e ao Dr. Danilo Hernane Spatti, pela incansável boa vontade para comigo.

À minha a minha querida companheira Cacá, sempre sincera e atenta para comigo, sendo essencial para realização de tal obra.

Aos meus pais Luiz e Izilda Luzia, meus sogros Abílio e Helena, e meu irmão Samuel Bacalini, que sempre estiveram presentes nos momentos essenciais.

Aos amigos Adélcio Assis, Alexandre José Pires, Débora, Fernanda, Geraldo Lupi Filho, José Carlos Brizola Jr., Josué dos Santos, Juracy Mamede, Luiz Carlos de Souza, Renato Machado Monaro, Ricardo Anacleto da Silva, Reginaldo Leopoldino, Ruy Aberto Corrêa Altafim e Sidney Mendes da Silva, os quais sempre me incentivaram na caminhada.

Aos caros amigos: Alemão, Calixto, Carlos, Diego,Jaqueline, João Marques, Júlio, Marcelo, Osvaldo, Rinaldo, Sergio, Valmir, Vera, Wesley, Wilson, Servidores da USP (Aparecida, Denise, José Carlos, Jussara, Marcelo, Marisa, Rosane), Equipe CPFL Energia (Agnaldo, André, Bartolo, Bossolani, Ben-Hur, Brizola, Casemiro, Carlos Aberto, Carlos Roberto, Chamas, Devanir, Elcio, Fábio, Financi, Gilmar, Ismael, Ivênio, Juninho, Lineu, Luciano, Marcelo, Márcia, Marcos, Maria Inês, Murilo, Ocimar, Paulo Vitor, Pastoreli, Riberto, Rogério), bem como à empresa CPFL Energia que me proporcionou a oportunidade de desenvolver tal trabalho. 


\section{Resumo}

BACALINI, M. (2011). Metodologia Experimental para Testes Padronizados de Confiabilidade em Dispositivos Indicadores de Faltas. Dissertação (Mestrado) Escola de Engenharia de São Carlos, Universidade de São Paulo, 2011.

Os dispositivos Indicadores de Faltas são utilizados para sinalizar a passagem de uma corrente de curto-circuito nos alimentadores de distribuição de energia elétrica. Tais dispositivos permitem uma redução significativa no tempo de inspeção das equipes de manutenção durante a busca pela região faltosa. Entretanto, associada a estes dispositivos, encontra-se uma elevada taxa de falhas de suas operações, que comprometem a confiabilidade do equipamento e, conseqüentemente, o tempo de localização de faltas. Neste trabalho é apresentada uma metodologia de ensaios laboratoriais a fim de complementar os testes padrões dos fabricantes de indicadores de faltas, buscando-se então identificar os fatores que colaboram para as falhas de tais equipamentos. Os resultados obtidos mostraram a eficiência da metodologia desenvolvida em detectar falhas de operação dos indicadores de faltas, as quais também não puderam ser detectadas por testes fornecidos por fabricantes.

Palavras chave: indicadores de continuidade, qualidade do serviço, indicadores de faltas, sistemas de distribuição de energia elétrica . 


\begin{abstract}
BACALINI, M.(2011). Experimental Methodology for Standardized Reliability Tests in Fault Indicator Devices. Dissertation (Master's Degree) - Escola de Engenharia de São Carlos, Universidade de São Paulo, 2011.

Fault Indicators are devices used to signal the passage of a short-circuit current in electricity distribution feeders. Such devices allow a significant reduction in patrol time by maintenance linemen during the search for the faulty region. However, associated with these devices, it is a high failure rate of operations that compromise the equipment reliability and, consequently, the time of fault location. This work presents a new methodology for single-phase laboratory tests in order to complement the standard tests accomplished by the manufacturers of fault indicators, aiming to then identify the factors that contribute to failures of such equipment. The results showed the efficiency of the methodology developed to detect operation failures of faults indicators that could not be detected by tests provided by manufacturers.
\end{abstract}

Keywords: indicators of continuity, quality of service, fault indicators, electric power distribution system . 


\section{Lista de Siglas e Abreviaturas}

$\begin{array}{ll}\text { ANEEL } & \text { Agência Nacional de Energia Elétrica } \\ \text { COD } & \text { Centro de Operação da Distribuição } \\ \text { IF } & \text { Indicadores de Faltas } \\ \text { SCADA } & \text { Supervisory Control and Data Acquisition } \\ \text { PRODIST } & \text { Procedimentos de Distribuição } \\ \text { TMA } & \text { Tempo Médio de Atendimento }\end{array}$




\section{Lista de Figuras}

FIGURA 2.1 - Presença de indicares de faltas em sistemas de distribuição. 14

FIGURA 2.2 - Pontos de instalação de indicadores de faltas.

FIGURA 2.3 - Modelos de indicadores de faltas.

FIGURA 2.4 - Diferentes modelos de indicadores de faltas de cabo.

FIGURA 2.5 - Sensor de indicador de falta.

FIGURA 2.6 - Indicadores de faltas instalados nas três fases. 22

FIGURA 2.7 - Esquema do indicador de faltas instalado no poste. 25

FIGURA 2.8 - Indicador de faltas de poste. 26

FIGURA 3.1 - Estrutura laboratorial de ensaios 39

FIGURA 3.2 - Montagem física da estrutura laboratorial de ensaios. 39

FIGURA 4.1 - Macro LRAMPI .44

FIGURA 4.2 - Macro PRAMPI .45

FIGURA 4.3 - Teste de evolução de corrente. 46

FIGURA 4.4 - Correntes pulsadas com amplitude variável e crescente. .47

FIGURA 4.5 - Exemplo de condição de trip com condição de carga na pré-falta.....48

FIGURA 4.6 - Simulação de uma condição de falta e tentativas de religamento .....49

FIGURA 4.7 - Situação de falta com religamento bem sucedido. 50

FIGURA 4.8 - Arranjo contendo apenas um indicador de faltas

FIGURA 4.9 - Arranjo considerando vários indicadores de falta

FIGURA 4.10 - Arranjo com variação no ângulo de instalação dos indicadores de falta.

FIGURA 4.11 - Arranjo considerando o teste de indicadores de poste 53

FIGURA 4.12 - Indicador de Falta Linetroll $110 \mathrm{E} \mu$ 54

FIGURA 4.13 - Banco de chaves para programação do Linetroll $110 \mathrm{E} \mu$ 55 
FIGURA 4.14 - Teste 1 - Evolução de Carga para o Linetroll 110E $\mu \ldots \ldots \ldots \ldots \ldots \ldots \ldots . . . . . .57$

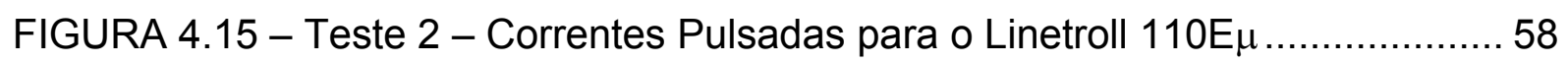

FIGURA 4.16 - Teste 3 - Religamento Sem Sucesso - Linetroll 110E $\mu$............... 59

FIGURA 4.17 - Teste 4 - Religamento Com Sucesso - Linetroll $110 \mathrm{E} \mu \ldots \ldots \ldots \ldots \ldots . . .60$

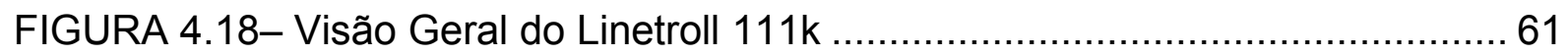

FIGURA 4.19 - Banco de chaves de programação do Linetroll 111k................... 62

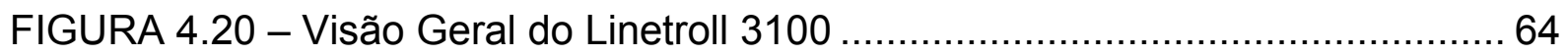

FIGURA 4.21 - Banco de chaves de programação do Linetroll 3100 .....................65

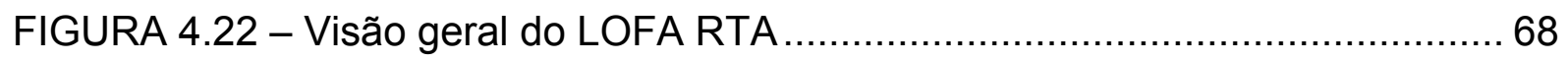

FIGURA 4.23 - Teste 1 - Evolução de Carga para o LOFA RTA-A ....................... 70

FIGURA 4.24 - Teste 2 - Correntes Pulsadas - LOFA RTA-A ............................71

FIGURA 4.25 - Teste 3 - Religamento Sem Sucesso - LOFA RTA-A .................. 72

FIGURA 4.26 - Teste 4 - Religamento Com Sucesso - LOFA RTA-A .................. 73

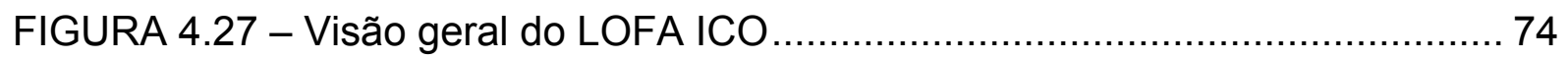

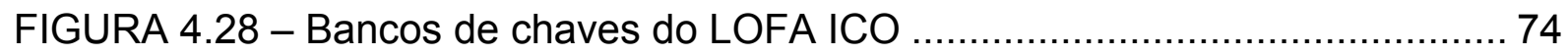

FIGURA $4 . .29$ - Bateria e sensor de tensão do LOFA ICO $\ldots \ldots \ldots \ldots \ldots \ldots \ldots \ldots \ldots \ldots \ldots . \ldots \ldots$

FIGURA 4.30 - Teste 1 - Evolução de Carga para o LOFA ICO .......................... 78

FIGURA 4.31- Teste 2 - Correntes Pulsadas - LOFA ICO ............................. 79

FIGURA 4.32 - Teste 3 - Religamento Sem Sucesso - LOFA ICO ..................... 80

FIGURA 4.33 - Teste 4 - Religamento Com Sucesso - LOFA ICO .................... 81

FIGURA 4.34 - Visão Geral do SEL Auto Ranger ....................................... 82

FIGURA 4.35 - Teste 1 - Evolução de Carga para o SEL AutoRanger ................... 84

FIGURA 4.36 - Teste 2 - Correntes Pulsadas - SEL Auto Ranger ...................... 85

FIGURA 4.37 - Teste 3 - Religamento Sem Sucesso - SEL Auto Ranger ............ 86

FIGURA 4.38 - Teste 4 - Religamento Com Sucesso - SEL AutoRanger ............. 87 
FIGURA 4.39 - Foto com quatro indicadores de falta próximos 91

FIGURA 4.40 - Foto com quatro indicadores de falta distanciados de $25 \mathrm{~cm}$ .92

FIGURA 4.41 - Diferentes posições de instalação do IFs .93

FIGURA 4.42 - Resultados dos ensaios referentes aos indicadores de cabo .... .96

FIGURA 4.43 - Resultados dos Ensaios referentes aos IFs de cabo por modelo ....96

FIGURA 4.44 - Resultados referentes aos indicadores de poste .99

FIGURA 4.45 - Resultados referentes aos indicadores de poste por modelo .99 


\section{Lista de Tabelas}

TABELA 2.1 - Comparação entre alguns fabricantes de Indicadores de faltas instalados em cabo.

TABELA 2.2 - Comparação entre alguns fabricantes de Indicadores de faltas instalados em poste

TABELA 3.1 - Parâmetros para o ensaio de suportabilidade de corrente. 33

TABELA 3.2 - Tabela padrão para registro dos ensaios de corrente de trip 37

TABELA 4.1 - Resumo das características do Linetroll 110E $\mu$ .55

TABELA 4.2 - Programação das chaves do Linetroll 110E $\mu$ 56

TABELA 4.3 - Indicadores de Falta Linetroll 110E $\mu$ 56

TABELA 4.4 - Parâmetros do Teste 1 - Evolução de Carga - Linetroll 110E $\mu$ 56

TABELA 4.5 - Parâmetros do Teste 2 - Correntes Pulsadas - Linetroll 110E $\mu$ 57

TABELA 4.6 - Parâmetros do Teste 3 - Religamento Sem Sucesso - Linetroll $110 \mathrm{E} \mu$ 59

TABELA 4.7 - Parâmetros do Teste 4 - Religamento Com Sucesso - Linetroll $110 \mathrm{E} \mu$ 60

TABELA 4.8 - Principais características do Linetroll 111k 63

TABELA 4.9 - Programação do Linetrol 111k. 63

TABELA 4.10 - Principais características do Linetroll 3100. 66

TABELA 4.11 - Programação do Linetrol 3100 (banco de chaves SW1) 66

TABELA 4.12 - Programação do Linetrol 3100 (banco de chaves SW2) 67

TABELA 4.13 - Programação do Linetrol 3100 (banco de chaves SW3) .... 67

TABELA 4.14 - Principais características do RTA-A 69

TABELA 4.15 - Ajuste dos Indicadores da LOFA 69

TABELA 4.16 - Parâmetros do Teste 1 - Evolução de Carga - LOFA RTA-A 69

TABELA 4.17 - Parâmetros do Teste 2 - Correntes Pulsadas - LOFA RTA-A ........70

TABELA 4.18 - Parâmetros do Teste 3 - Religamento Sem Sucesso - LOFA RTA-A 
TABELA 4.19 - Parâmetros do Teste 4 - Religamento Com Sucesso - LOFA RTA-A.

TABELA 4.20 - Principais características do ICO ….............................................. 76

TABELA 4.21 - Programação do LOFA ICO (banco de chaves DIP Switch 1) ........ 76

TABELA 4.22 - Programação do LOFA ICO (banco de chaves DIP Switch 2) ........ 77

TABELA 4.23 - Parâmetros do Teste 1 - Evolução de Carga - LOFA ICO.............. 77

TABELA 4.24 - Parâmetros do Teste 2 - Correntes Pulsadas - LOFA ICO............ 78

TABELA 4.25 - Parâmetros do Teste 3 - Religamento Sem Sucesso - LOFA

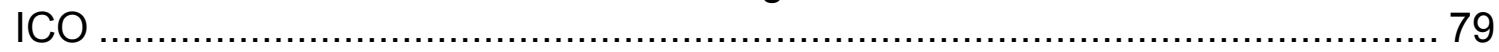

TABELA 4.26 - Parâmetros do Teste 4 - Religamento Com Sucesso - LOFA ICO 80

TABELA 4.27 - Principais características do SEL Auto Ranger. 83

TABELA 4.28 - Parâmetros do Teste 1 -Evolução de Carga - SEL Auto Ranger... 84

TABELA 4.29 - Parâmetros do Teste 2-Correntes Pulsadas - SEL Auto Ranger... 85

TABELA 4.30 - Parâmetros do Teste 3 - Religamento Sem Sucesso - SEL Auto Ranger.

TABELA 4.31 - Parâmetros do Teste 4 - Religamento Com Sucesso - SEL Auto

Ranger. 87

TABELA 4.32 - Ajuste dos Indicadores da Linetroll 110E $\mu$ 89

TABELA 4.33 - Resultados dos testes dos IFs Linetroll 110E $\mu$............................. 90

TABELA 4.34 - Resultados de testes para indicadores muito próximos .................. 91

TABELA 4.35 - Resultados para IFs considerando uma distância entre eles .......... 92

TABELA 4.36 - Variação da posição angular de instalação..................................... 93

TABELA 4.37 - Variação na defasagem angular entre a tensão e corrente de $0^{\circ} \ldots 93$

TABELA 4.38 - Variação na defasagem angular entre a tensão e corrente de $90^{\circ}$

TABELA 4.39 -Variação na defasagem angular entre a tensão e corrente de $180^{\circ}$

TABELA 4.40 - Variação na defasagem angular entre a tensão e corrente de $270^{\circ}$ 94

TABELA 4.41 - Resultados de teste para o SEL Auto Ranger. 95 
TABELA 4.42 - Resultados de teste para o LOFA RTA-A .................................95

TABELA 4.43 - Conjunto de ajuste para o IF Linetroll $111 \mathrm{k} \ldots \ldots \ldots \ldots \ldots \ldots \ldots \ldots \ldots . . . . . . \ldots 7$

TABELA 4.44 - Resultados referentes ao indicador de poste Linetroll $111 \mathrm{k} \ldots \ldots \ldots . . .98$

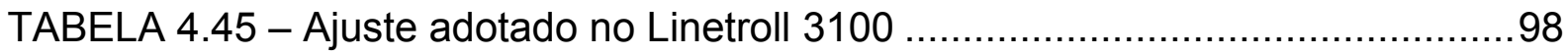

TABELA 4.46 - Resultados referentes ao indicador de poste Linetroll 3100 ...........98 


\section{Sumário}

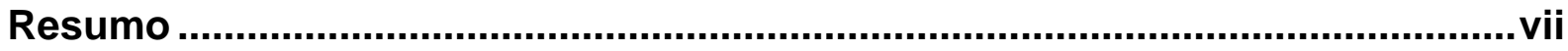

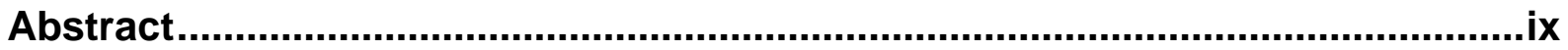

Lista de Siglas e Abreviaturas ............................................................................

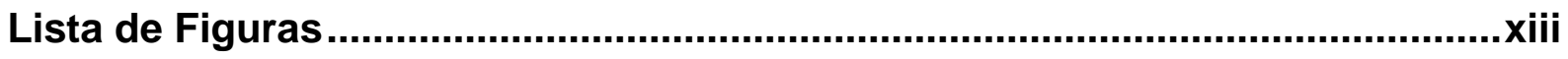

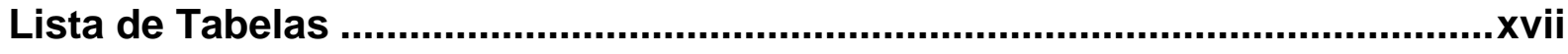

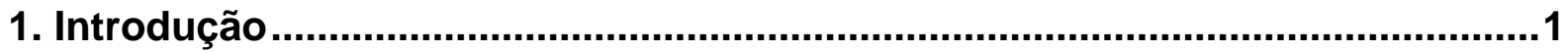

1.1 Motivação e Relevância do Trabalho ……………………………........

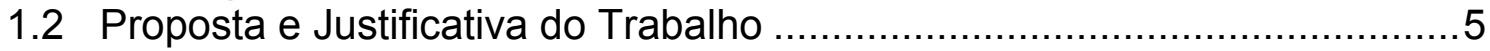

1.3 Organização da Dissertação .............................................................11

2. Aspectos Técnicos Relacionados aos Indicadores de Faltas em Sistemas de Distribuição de Energia Elétrica ...............................................................13

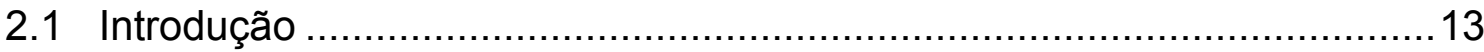

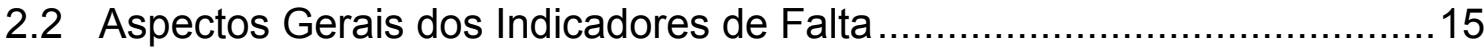

2.2.1 Descrição Funcional ........................................................... 15

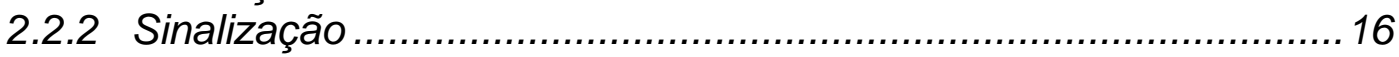

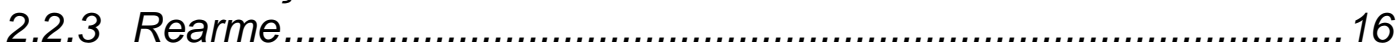

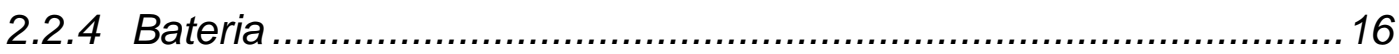

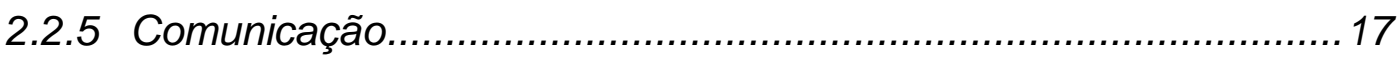

2.2.6 Programação ...................................................................17

2.2.7 Pontos de Aplicação de Indicadores de Falta............................... 18

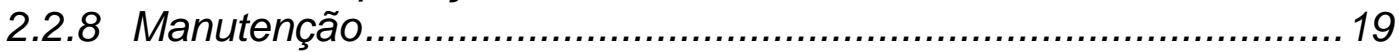

2.3 Indicadores de Faltas Instalados no Cabo Condutor-Fase ......................20

2.4 Indicadores de Faltas Instalados em Poste ..........................................2

2.5 Novas Tecnologias Construtivas para Indicadores de Faltas...................26

3. Aspectos Metodológicos para Ensaios de Indicadores de Faltas .................29

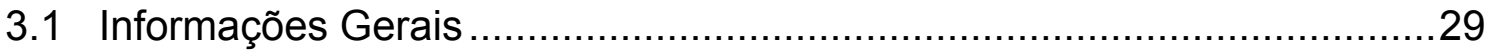

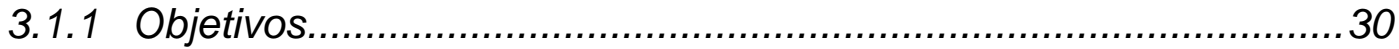

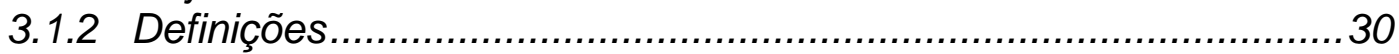

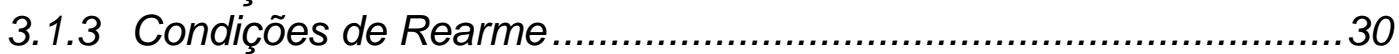

3.1.4 Dispositivo de Rearme ........................................................... 31

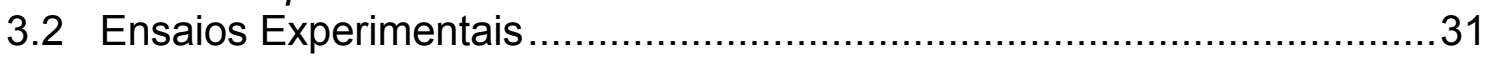

3.2.1 Planejamento de Ensaios ........................................................ 31 
3.2.2 Ensaio Para a Corrente de Trip ............................................. 31

3.2.3 Ensaios Para as Formas de Rearme ...................................... 32

3.2.4 Teste de Suportabilidade de Corrente ..................................... 33

3.2.5 Efeito da Corrente de Condutores Adjacentes............................ 33

3.3 Preparativos do Indicador de Faltas ................................................ 34

3.4 Determinando as Condições Elétricas do Ensaio ................................ 35

3.5 Análise dos Resultados Para a Corrente de Trip................................ 37

3.6 Considerações Acerca dos Indicadores de Faltas do Tipo Poste.............. 38

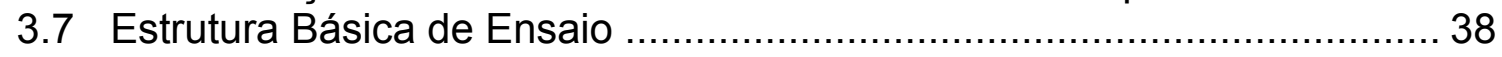

3.7.1 Transformador de Corrente (TC) ........................................ 40

3.7.2 Transformador de Potencial (TP)..................................... 40

3.7.3 Carga Fantasma ................................................................. 40

3.7.4 Softwares ......................................................................... 40

3.7.5 Microcomputador ...................................................... 40

3.7.6 Oscilógrafo................................................................ 41

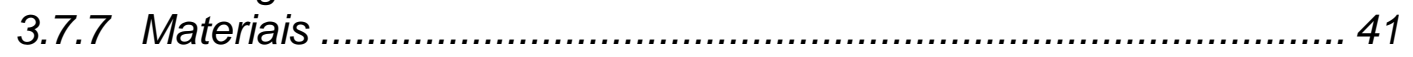

4. Metodologia Experimental e Estudos de Caso ......................................... 43

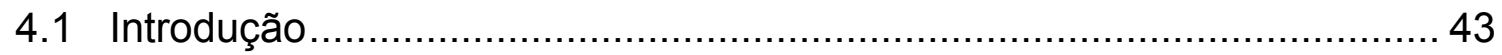

4.1.1 Macro LRAMPI.............................................................. 44

4.1.2 Macro PRAMPI ........................................................... 45

4.2 Teste de Evolução de Corrente .................................................. 45

4.3 Teste de Correntes Pulsadas com Amplitude Variável e Crescente.......... 46

4.4 Teste de Religamento sem Sucesso ............................................... 48

4.5 Teste de Religamento com Sucesso ............................................. 49

4.6 Arranjo Considerando Apenas Um Indicador de Faltas .......................... 50

4.7 Variação da Quantidade de Indicadores de Faltas .............................. 51

4.8 Variação do Ângulo de Instalação .................................................... 52

4.9 Indicador de Faltas do Tipo Poste .............................................. 52

4.10 Indicadores de Faltas Selecionados Para Teste Laboratorial................... 53

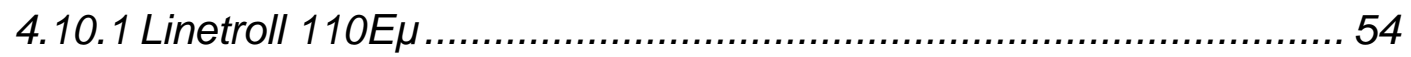

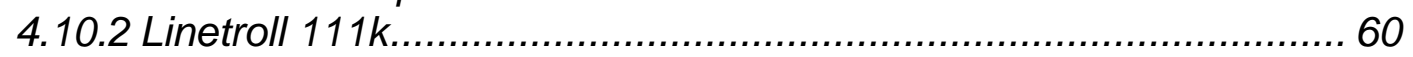

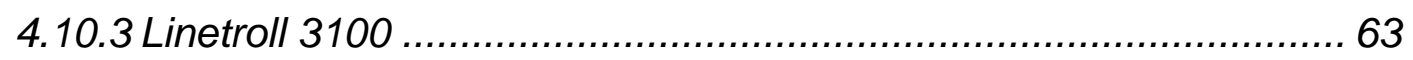

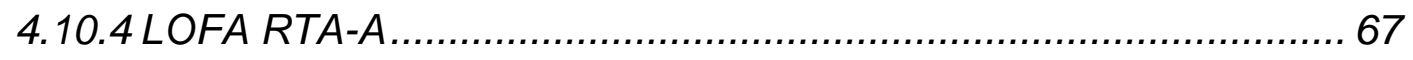

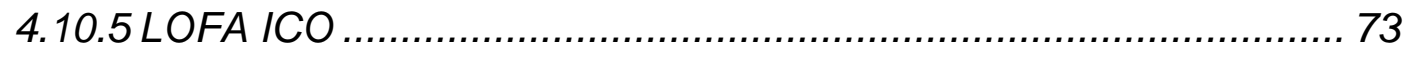

4.10.6 SEL Auto Ranger ........................................................... 81

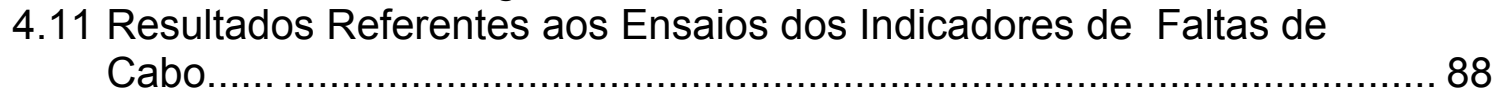

4.12 Resultados Referentes aos Ensaios dos Indicadores de Faltas de Poste................................................................................. 97

5. Conclusões .............................................................................................. 101

Referências Bibliográficas............................................................................. 103 


\section{Introdução}

\subsection{Motivação e Relevância do Trabalho}

A disponibilidade da energia elétrica representa um incremento na qualidade de vida das populações. No momento em que se implanta um sistema de distribuição de energia elétrica, a população local imediatamente passa a contar com inúmeros benefícios, tanto do ponto de vista do conforto doméstico, como de melhores possibilidades de emprego e produção.

À medida que os benefícios da energia elétrica passam a fazer parte do diaa-dia das pessoas, é então natural que se inicie um processo de discussão quanto à qualidade desse produto.

Inicialmente, há a preocupação com a continuidade do serviço, já que fica evidente que qualquer interrupção do fornecimento implicará em transtornos de toda ordem. Em seguida, mas menos evidente, é a questão da qualidade da energia elétrica como um produto comercial, mesmo que não ocorram interrupções; o que normalmente só é percebido, de forma um pouco difusa, por meio de falhas de funcionamento em alguns equipamentos.

Portanto a questão da qualidade da energia elétrica só aparece, a partir do momento em que os consumidores constatam interrupções no fornecimento que são aferidas mediante indicadores de continuidade do serviço de distribuição de energia elétrica. Entretanto, à medida que tais consumidores tornam-se mais 
sofisticados sob o ponto de vista tecnológico, outros fatores começam a ser considerados.

A demanda por energia elétrica é cada vez maior em nossa sociedade. Juntamente com uma grande procura por energia elétrica, torna-se então necessário o constante investimento no setor, tendo-se sempre como objetivo primeiro que a qualidade do serviço oferecido não seja comprometida.

Em contexto mais atual, a qualidade da energia está intimamente ligada ao fornecimento ininterrupto dessa. Indicadores de continuidade da energia elétrica fornecida determinam a energia de boa qualidade como àquela fornecida ininterruptamente.

Nos sistemas elétricos de potência, um dos principais fatores para a interrupção do serviço é a ocorrência de faltas. Estas demandam os maiores esforços das equipes de inspeção, pois exigem uma inspeção minuciosa, seja nos sistemas de distribuição ou de transmissão, a fim de mitigar definitivamente o agente causador da falta, refletindo-se aqui diretamente no TMA (Tempo Médio de Atendimento), o qual contribui significativamente para os indicadores de continuidade, assim como para a qualidade do serviço.

Para que a energia elétrica entregue pelas Distribuidoras sofra menos distúrbios em conseqüência da ocorrência de uma falta, cada vez mais grupos de pesquisa estudam formas de modernizar os sistemas de proteção e melhorar o tempo de resposta dos mesmos diante de tal situação. Tanto isto é uma realidade que, na literatura técnico-científica, a presença de ferramentas inovadoras atuando na proteção dos sistemas elétricos de potência sempre é uma tônica em diversos trabalhos recentes, como pode ser observada nas referências bibliográficas que 
envolvem automação da proteção e localização inteligente de uma falta nos sistema (Souza et al., 2009).

A metodologia experimental de testes de confiabilidade de indicadores de faltas objetiva fornecer subsídios a fim de incrementar ainda mais o desempenho do sistema distribuição de energia elétrica, visando-se reduzir o tempo das interrupções no fornecimento de energia elétrica.

Os modernos sistemas elétricos de potência são caracterizados, dentre outros aspectos, pela alta disponibilidade temporal do fornecimento de energia elétrica com qualidade adequada ao correto funcionamento dos equipamentos supridos por esse sistema. A busca pela viabilidade técnico-financeira desse tipo de sistema guia o desenvolvimento de equipamentos e ferramentas computacionais que auxiliem no projeto, no estudo e no planejamento de expansão dedicada ao contexto dos sistemas elétricos de potência.

Preocupadas com a evolução da proteção dos sistemas elétricos de potência, as empresas do setor investem cada vez mais na inserção de dispositivos, tais como os indicadores de faltas, os quais são instalados nos sistemas de distribuição e são também os objetos principais deste estudo. Tais equipamentos já fazem parte do sistema elétrico de potência, tendo grande importância na identificação dos locais de falta, pois por meio de sua sinalização, quando da ocorrência dessas, seria possível percorrer e inspecionar o caminho que o distúrbio seguiu pelo sistema e assim mitigar sua origem.

Em virtude da complexidade decorrente do número e da diversidade topológica, verifica-se então grande aporte de recursos, especialmente atribuídos ao desenvolvimento de ferramentas de suporte para os sistemas de distribuição de energia elétrica. Dessas ferramentas, destaca-se o projeto automático de sistemas 
de proteção contra sobretensões de origem atmosférica (Santos et al., 2009), a avaliação do comportamento em freqüência para transformadores (Silva et al., 2005), bem como a especificação da melhor topologia de aterramento para os equipamentos inseridos no sistema de distribuição (Silva et al., 1999), a qual influencia diretamente no desempenho dos sistemas de distribuição de energia elétrica.

Além dessas linhas de pesquisas, outra que tem merecido destaque no cenário compreendido pelas Distribuidoras de energia elétrica diz respeito às ações que permitam uma proteção eficiente ao longo das linhas de distribuição. Um exemplo desse tipo de pesquisa é a busca dos melhores pontos para alocação de dispositivos de proteção em redes de distribuição de energia elétrica (Soudi \& Tomsovic, 1998, 1999, 2001; Wang \& Thorp, 2001). Nesses trabalhos, a alocação dos dispositivos é realizada de maneira estratégica a fim de garantir que, diante de uma condição de falta e da operação adequada do sistema de proteção, o menor número de consumidores ou de cargas ficará abstido do fornecimento de energia elétrica. Em outras palavras, esses dispositivos de proteção são alocados de forma a contribuir para a melhora dos índices de desempenho da concessionária de energia elétrica.

Nessa mesma linha de investigação, mais recentemente, destaca-se o estudo dos indicadores de faltas (Krajnak, 2000) e sua alocação ótima junto à rede de distribuição de energia elétrica (Duc-Pham et al., 2005). Os indicadores de faltas são dispositivos instalados ao longo do sistema de distribuição e possuem como funcionalidade a capacidade de indicar se o sistema foi submetido algum tipo de falta à jusante de sua instalação (Angerer, 2001. Em função dos ganhos promovidos pela alocação desses dispositivos nos sistemas de distribuição de energia elétrica, o 
número de indicadores de faltas instalados nos mesmos encontra-se em franco crescimento.

Assim, em virtude desse crescimento expressivo e dos ganhos decorrentes de sua utilização, o interesse pelo desenvolvimento de metodologias e de ferramentas computacionais capazes de auxiliar no planejamento de sua instalação é latente, conforme se verifica por meio da comunidade especializada internacional (Tang et al., 2000).

Um exemplo é a investigação do ponto ótimo de inserção desses equipamentos no sistema (Duc-Pham et al., 2005). Partindo-se do fato que o número de dispositivos indicadores de faltas é limitado nas distribuidoras de energia elétrica, sua inserção em pontos estratégicos ou ótimo deve levar em conta o histórico de ocorrências de faltas permanentes em pontos da rede de distribuição de energia elétrica.

\subsection{Proposta e Justificativa do Trabalho}

Se um equipamento de proteção não atuar de forma correta, toda uma cadeia de eventos pode ser disparada, culminando com a interrupção do fornecimento de energia elétrica. Como a mitigação de faltas requer conhecimento de todos os equipamentos envolvidos na proteção, considerando ainda como utilizálos em conjunto e aproveitando também suas características e minimizando suas limitações, além de um número considerável de informações vindas do ambiente em estudo, deve-se então lançar mão de todas as ferramentas disponíveis visando enquadrar a solução ótima para o problema.

Como o setor de energia elétrica está em constante expansão e mudanças, um estudo sobre a inserção adequada de dispositivos de proteção como um indicador de faltas se faz essencial, já que não existem regras e metodologias 
definidas que melhor expliquem os pontos de alocação, bem como a quantidade mais adequada da instalação desses equipamentos em Sistemas de Distribuição de Energia Elétrica (Souza et al., 2009).

Assim, para a realização deste trabalho, foram levantadas informações sobre a ocorrência de faltas em uma empresa de distribuição de energia elétrica, bem como as características dessas e da rede onde os indicadores de faltas foram instalados.

De fato, o desenvolvimento dos sistemas elétricos de potência, desde seus primórdios, se deu de forma paralela e compassada à evolução dos sistemas de proteção dedicados aos mesmos (Zahra et al., 2000). Com o advento de novas tecnologias, diversas foram as filosofias de proteção que emergiram no escopo dos sistemas elétricos de potência. Porém, mesmo em face das diferenças conceituais entre tais filosofias, o objetivo primordial de cada uma dessas é a correta identificação de faltas e, em face de sua identificação, disponibilizar o controle adequado para os dispositivos de seccionamento responsáveis por isolarem o setor defeituoso do restante do sistema. Além disso, o sistema de proteção deve atuar de maneira seletiva, proporcionando a minimização do número de clientes que se encontrarão desprovidos do fornecimento de energia elétrica quando da ocorrência de uma falta (Cho \& Ha, 1998; Tang et al., 2000).

Assim, diante de uma falta no sistema elétrico de potência e mesmo frente à correta operação do sistema de proteção, existirá um determinado número de clientes que provisoriamente estarão sob uma condição de não fornecimento de energia elétrica. Esse cerceamento da energia elétrica, mesmo que por curtíssimos intervalos de tempo, podem decorrer em danos a equipamentos de consumidores, conduzir à situações de riscos e, de uma maneira geral, gerar prejuízos financeiros 
(Choi et al., 1999). Dessa forma, a localização rápida e precisa de uma falta torna-se imprescindível para a operação segura e econômica do sistema e, motivada por esses aspectos, a comunidade técnico-científica e especializada solidificou linhas de pesquisas correlatas ao tema.

No entanto, mesmo diante de pesquisas voltadas ao tema de localização de faltas, o procedimento adotado, na maioria dos casos em sistemas de distribuição, para se identificar o ponto onde a falta ocorreu é baseado em inspeção visual. Procedendo segundo essa metodologia convencional, a equipe de inspeção responsável deve então inspecionar visualmente a linha de distribuição a fim de identificar anomalias estruturais que possam ter desencadeado a falta. Esta técnica, dependendo da extensão da rede de distribuição, pode elevar o tempo em que o sistema fica sem energia elétrica a níveis capazes de depreciar significativamente os índices de desempenho da Distribuidora (Zhang et al., 2004).

Contornando a precariedade da metodologia convencional para localização de faltas, inúmeros dispositivos, denominados indicadores de faltas, bem como "identificadores de circuitos faltosos" ou "indicadores de corrente de falta", foram desenvolvidos desde meados dos anos quarenta. Esses dispositivos, os quais são instalados ao longo da rede de distribuição de energia elétrica, têm por funcionalidade indicar se alguma condição de falta, identificada seja por corrente, ou por tensão, ocorreu à sua jusante. Assim, tais dispositivos objetivam agregar maior desempenho ao sistema de distribuição de energia elétrica, pois sua correta operação proporcionaria uma redução do tempo de inspeção da rede, frente à localização de eventuais defeitos, por parte da equipe responsável pela inspeção da linha após uma falta (Baker et al., 2001). 
O emprego de indicadores de faltas em sistema elétricos de potência tem nos seus primórdios a iniciativa da Companhia Horstmann, a qual em 1946 desenvolvera na Alemanha os primeiros indicadores de faltas (Angerer, 2001). Esses primeiros dispositivos possuíam sinalização mecânica, a qual era comandada pela rotação de um disco mediante a passagem de uma corrente elétrica acima do ajuste programado. Uma vez que esses dispositivos sinalizassem uma falta, a indicação da mesma permanecia até que, manualmente, o dispositivo indicador de faltas fosse rearmado.

Dessa forma, quando diante da ocorrência de uma falta no sistema de distribuição de energia elétrica, todos os indicadores de faltas à montante do ponto de incidência necessitavam ser rearmados, pois, em tese, todos esses dispositivos estavam em estado de indicação de falta. Esse tipo de operação de rearme manual decorre em um maior número de procedimentos para restabelecimento do sistema após a identificação da falta. Além desse inconveniente, esses dispositivos possuíam uma taxa de erros relativamente elevada, principalmente no que se refere à não identificação de faltas. Esse aspecto frustrou inicialmente as Distribuidoras quanto ao seu emprego em larga escala.

Mesmo diante das limitações observadas nos primeiros modelos de indicadores de falta, sua aplicação não caiu em desuso em função da demanda latente por esse tipo de dispositivo e os primeiros avanços logo se deram, iniciandose quando o rearme deixou de ser manual e passou a ser automático. $O$ rearme automático se dava após um determinado tempo, contado a partir do momento em que a corrente voltava a patamares pré-ajustados ou após a normalização da tensão no sistema (Angerer, 2001). 
Outro avanço tecnológico de merecida citação se deu em meados dos anos setenta. A companhia Horstmann introduziu em 1976 uma bateria de lítio em seus indicadores de faltas. A utilização de uma fonte externa de energia permitiu aumentar a vida útil dos equipamentos, bem como testar os mecanismos de funcionamento, sem maiores intervenções físicas. Além disso, um sistema de fornecimento de energia autônomo dedicado aos indicadores de faltas garantia o funcionamento desses mesmos quando, em virtude da atuação do sistema de proteção, a tensão no ponto de instalação do indicador fosse nula. Esse aspecto permitiu então melhorar a operação dos indicadores de faltas, reduzindo-se as condições nas quais as indicações de falta eram impossibilitadas pela ausência de alimentação.

Dessa forma, os indicadores de faltas poderiam ser rearmados e colocados em operação, independentemente da intervenção humana, pois se poderia atestar o funcionamento deles. Esse avanço e a disponibilidade de novas tecnologias na área da eletrônica impulsionaram as empresas do setor a investirem em novos desenvolvimentos. Assim, com o advento de indicadores de faltas implementados por meio de circuitos eletrônicos, e não mais de forma eletromecânica, os erros de operação e as atuações indevidas foram minimizados significativamente e novos horizontes foram traçados para os dispositivos indicadores de faltas (Krajnak, 2000).

Atualmente, novos adventos científicos estão sendo propostos para a elaboração de indicadores de faltas que venham a contribuir para o aumento de sua sensibilidade e robustez de sua operação. Dentre as técnicas e metodologias citadas, destaque especial se verifica para aquelas inseridas no contexto da inteligência computacional, tais como as redes neurais artificiais e os sistemas de inferência fuzzy (Souza, 2009). Essas ferramentas computacionais possuem como 
características atraentes a possibilidade de generalização, a robustez de operação mesmo em face de um ambiente com incertezas e a capacidade de se adaptar, acompanhando-se as modificações que o sistema elétrico de potência venha por ventura a experimentar (Tang et al., 2000).

As ferramentas advindas da inteligência computacional estão sendo empregadas não apenas para elaboração de identificadores de faltas mais precisos, mas também para determinar em quais pontos do sistema de distribuição esses dispositivos devem ser inseridos a fim de possibilitar uma melhor operação global.

Diversos aspectos podem ser levados em consideração quando da localização ótima de identificadores de faltas como, por exemplo, o menor custo de instalação, ao mesmo tempo em que se garanta a total cobertura de monitoramento do sistema.

Portanto, frente ao desenvolvimento de metodologias e ferramentas computacionais que venham a auxiliar a Distribuidora de energia elétrica na alocação de dispositivos para identificação de faltas, bem como uma metodologia para ensaios de indicadores de falta, obtêm-se então subsídios para uma maior confiabilidade do dispositivo e do sistema de distribuição de energia elétrica, proporcionando-se então uma redução significativa da duração das interrupções de fornecimento aos clientes do sistema e, conseqüentemente, a melhoria do serviço oferecido. De fato, apenas fundamentado em informações seguras e confiáveis é que se pode atuar no restabelecimento da energia elétrica, sem comprometer toda uma série de entidades que dependem diretamente dos sistemas de distribuição e transmissão, desde a unidade geradora até o consumidor final. 
Este trabalho tem como objetivo a proposta de se realizar um minucioso estudo do funcionamento dos indicadores de faltas e sua aplicação no sistema de distribuição de energia elétrica.

Devido ao fato de muitos indicadores de faltas já se encontrarem instalados no sistema de distribuição de energia elétrica, torna-se ainda mais crucial que seja pesquisado o comportamento deste como equipamento do sistema de proteção, pois a busca por uma proteção eficiente e robusta, que seja capaz de restabelecer o serviço o mais rapidamente possível, sem danos para os clientes e para as Distribuidoras, envolve a operação de equipamentos distintos que devem atuar de forma coesa e complementar.

Uma indicação errônea do equipamento pode trazer como consequência a demora no restabelecimento, assim como manobras desnecessárias no sistema elétrico de distribuição de energia elétrica, as quais podem diretamente afetar a qualidade da energia.

Assim sendo, o objetivo deste trabalho consiste em elaborar uma metodologia experimental para o ensaio prático padrão de dispositivos indicadores de faltas, de modo que contribua para uma a eficiência dos dispositivos indicadores de faltas em sistema de distribuição de energia elétrica.

\subsection{Organização da Dissertação}

Esta dissertação será desenvolvida em 5 capítulos conforme se segue.

O detalhamento dos indicadores de falta, pesquisas envolvendo o uso de indicadores de faltas e, também, a proposta de trabalho foram registrados neste Capítulo 1.

No Capítulo 2 serão apresentados os aspectos técnicos relacionados aos indicadores de faltas e sua aplicação nos sistemas de distribuição. 
No Capítulo 3 serão apresentados aspectos metodológicos para ensaios de indicadores de faltas.

No Capítulo 4 serão apresentados os estudos de caso.

No Capítulo 5 serão feitas as considerações finais a respeito deste trabalho, enfatizando quais os ganhos desta pesquisa para os sistemas de distribuição. Propostas para a continuidade da pesquisa também serão delineados neste capítulo. 


\section{Aspectos Técnicos Relacionados aos Indicadores de Faltas em Sistemas de Distribuição de Energia Elétrica}

\subsection{Introdução}

É muito importante que os elementos responsáveis em detectar faltas sejam sensibilizados por qualquer tipo de falta, imediatamente após a ocorrência desta, para que prejuízos humanos e financeiros não ocorram.

A aplicação de dispositivos indicadores de faltas na rede permite às distribuidoras de energia elétrica melhorar o desempenho e a qualidade no fornecimento de energia elétrica aos consumidores, uma vez que esses identificam e sinalizam a ocorrência de curtos-circuitos. Além disso, tais dispositivos permitem a redução do tempo de desligamento das redes elétricas, provenientes de faltas transitórias ou permanentes, pois diminui o tempo de inspeção das equipes de restabelecimento, facilitando o trabalho de isolamento da seção submetida a uma falta e restauração do sistema (Falaghi et al., 2005).

Estudos apontam que as presenças de indicadores de faltas em sistemas de distribuição subterrâneos ou aéreos podem reduzir em até $60 \%$ o tempo de interrupção, agilizando rapidamente o reparo de uma seção faltosa pela equipe, assim como melhorando os índices que contabilizam o tempo e a freqüência em que o consumidor fica sem energia elétrica (Krajnak, 2000). Além disso, existem índices que avaliam a continuidade no fornecimento de energia, conforme estabelecido pela ANEEL. 
Na Figura 2.1 é ilustrada uma representação de um circuito de distribuição com um único indicador de faltas instalado.

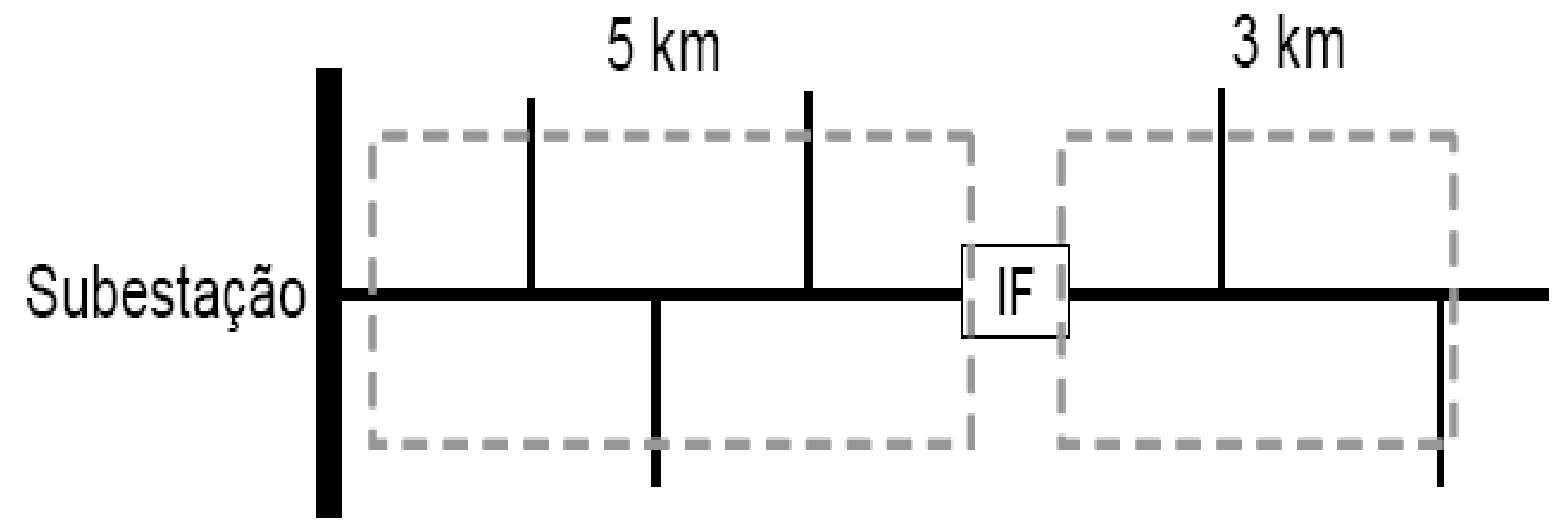

FIGURA 2.1 - Presença de indicador de faltas em um sistema de distribuição.

Em um sistema de distribuição como este da Figura 2.1 é possível reduzir o tempo de busca pela falta utilizando-se o Indicador de Faltas (IF) como referencial. Conforme metodologia apresentada em Usida (2011), supondo-se que o tempo médio para se localizar uma falta no alimentador da Figura 2.1 sem um indicador de faltas seja de 0,75 horas, o tempo para se localizar uma falta com a presença do indicador de faltas poderá ser então reduzido, pois agora a equipe (inspeção / manutenção) de restabelecimento pode percorrer antes do ponto de instalação do indicador, ou após, conforme as Expressões (2.1) e (2.2).

$$
\begin{aligned}
& \text { Tempo }_{\text {DepoisDolF }}=\frac{3}{3+5} \times 0,75=0,28 \text { horas } \\
& \text { Tempo }_{\text {AntesDolF }}=\frac{5}{3+5} \times 0,75=0,47 \text { horas }
\end{aligned}
$$


Em certos casos, onde a ocorrência da falta que fez a proteção atuar, a ausência de um dispositivo de sinalização de faltas para orientar as equipes de restabelecimento requererá um tempo elevado para percorrer toda extensão da rede até encontrar e restaurar os pontos danificados. Esse procedimento geralmente ocasiona elevados custos operacionais à concessionária distribuidora, além de grandes dificuldades para o restabelecimento do sistema. Tal problema se torna mais crítico em redes rurais (devido a suas grandes extensões) e em alimentadores urbanos com elevado número de consumidores.

Em 1987, iniciou-se a produção de dispositivos indicadores de faltas para linhas aéreas com transmissão via radiofreqüência, enviando-se as informações via SCADA (Supervisory Control and Data Acquisition) para um centro de controle COD (Centro de Operação da Distribuição).

\subsection{Aspectos Gerais dos Indicadores de Falta}

Nas subseções seguintes serão detalhados os aspectos funcionais dos indicadores de falta.

\subsubsection{Descrição Funcional}

$\mathrm{Na}$ ocorrência de uma falta o dispositivo sinaliza se houver passagem de corrente de curto-circuito pelo circuito monitorado. A detecção da situação de falta é por meio de sensores que monitoram a passagem de corrente pela rede primária de distribuição, diferenciando situações de carga de uma falta, os quais são sensibilizados pelo campo magnético produzido pela corrente de carga fluindo através do sistema. 


\subsubsection{Sinalização}

Se a corrente que flui pelo circuito monitorado excede o ajuste de disparo do indicador, o mesmo sinaliza, indicando-se a falta. Essa indicação ocorre de várias maneiras: por uma bandeirola colorida (geralmente sinalizados por lâmpadas de Gás Xenon), LED, ou uma combinação dos dois tipos, etc. Muitos fabricantes de IFs utilizam a sinalização para faltas transitórias diferente das permanentes.

\subsubsection{Rearme}

Uma vez localizado o defeito, reparado a linha e restaurado o fornecimento, o indicador precisa ser rearmado. Esse rearme pode ser automático ou manual. Os rearmes automáticos podem ser por tensão, por tempo, por corrente de carga, entre outros, variando de acordo com a aplicação e com a duração da falta.

\subsubsection{Bateria}

A alimentação do IF é feita por meio de bateria interna. A presença de uma fonte independente do circuito monitorado revolucionou a operação dos IFs, pois passaram a ter autonomia no seu funcionamento.

Alguns dispositivos IFs têm indicação de baixa capacidade de carga da bateria, ou seja, quando ela deve ser substituída. É importante lembrar que o correto funcionamento dos IFs depende do nível de carga da bateria. Geralmente, os fabricantes disponibilizam dados mais detalhados sobre a vida útil da bateria. 


\subsubsection{Comunicação}

Atualmente, há a disponibilidade de IFs com opção de comunicação remota, possibilitando a integração com o Centro de Operação da Distribuição (COD) e com outros equipamentos de proteção. Tal comunicação fornece o status operativo do IF no sistema SCADA do COD.

Existem modelos de IFs que emitem um sinal de radiofreqüência ou via GSM (Global System for Mobile Communication) quando há ocorrência de uma falta. Este sinal auxilia na alocação das equipes de manutenção ( equipes de inspeção e manutenção) através da identificação dos IFs que sinalizaram na ocorrência da falta.

\subsubsection{Programação}

O IF detecta curtos-circuitos quando a corrente excede o nível de detecção ou um limiar pré-estabelecido. As programações variam de acordo com o fabricante, mas geralmente os ajustes dos sensores e de rearme aparecem em todos eles.

Para evitar sinalizações em situações de manobra do sistema, como por exemplo, corrente de energização (inrush) da linha, o sensor de corrente $\frac{d i}{d t}$ é bloqueado durante um período de tempo suficiente para energização da rede. Enquanto o tempo de bloqueio transcorre, a corrente na linha se estabiliza e não há disparo do sensor. A programação é feita por meio de banco de chaves (switches) ou via software. Existem modelos que utilizam corrente de trip para sensibilizar os sensores de indicação de falta. 


\subsubsection{Pontos de Aplicação de Indicadores de Falta}

Geralmente, os IFs são instalados em pontos estratégicos do sistema de distribuição. Tais pontos, como mostra a Figura 2.2, são derivações do alimentador e ao longo de grandes trechos de alimentadores rurais, pois quando estes possuem extensões elevadas a localização do defeito pelas equipes de restabelecimento (inspeção / manutenção) pode demorar. Neste exemplo é evidenciado como o correto posicionamento dos IFs pode auxiliar a tomada de decisão para o rápido restabelecimento. Outro ponto a ser observado no posicionamento dos IFs é a característica dos equipamentos instalados à jusante e a contribuição para a corrente capacitiva, garantindo que esteja abaixo no nível de trip pré-definido para evitar que o indicador se ative indevidamente. Outra dificuldade é o posicionamento considerando pontos de deslocamento da equipe.

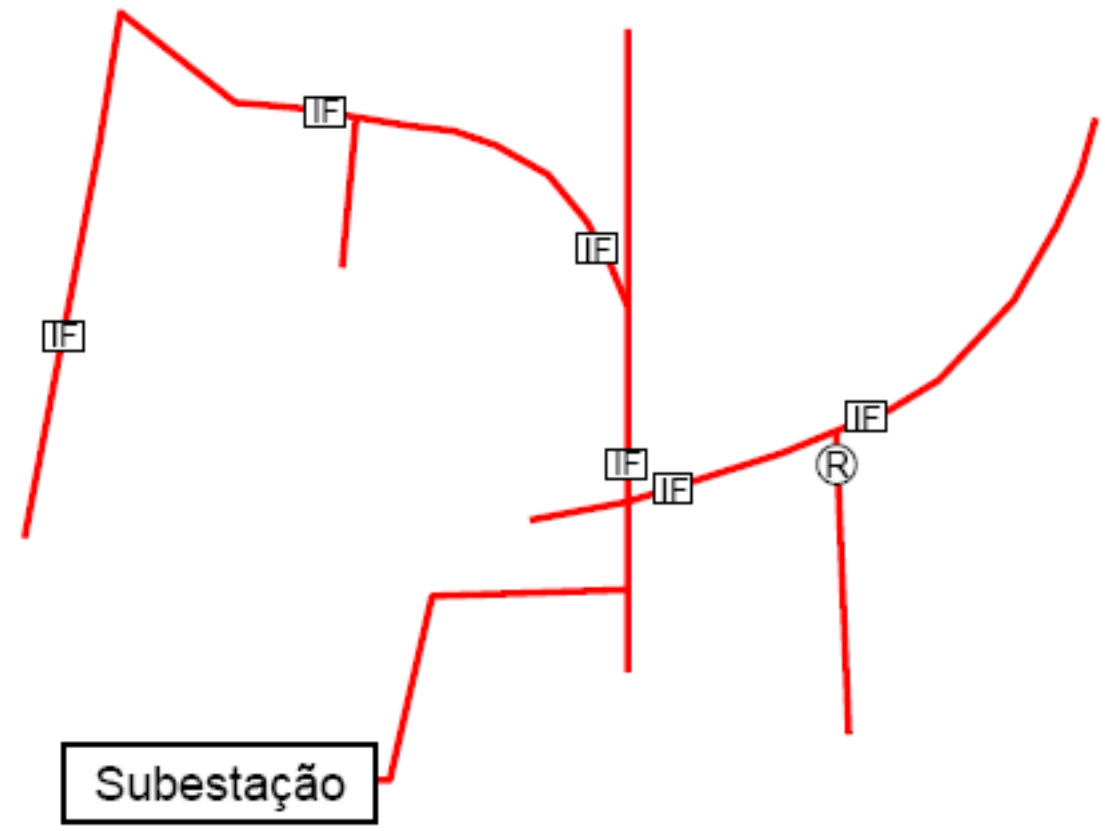

FIGURA 2.2 - Pontos de instalação de indicadores de faltas. 
Os IFs podem ser aplicados em redes de distribuição subterrâneas ou aéreas. Nas redes aéreas, estes podem ser instalados de duas formas:

- Condutor-fase;

- Poste.

Na Figura 2.3 encontram-se representados estes dois tipos.
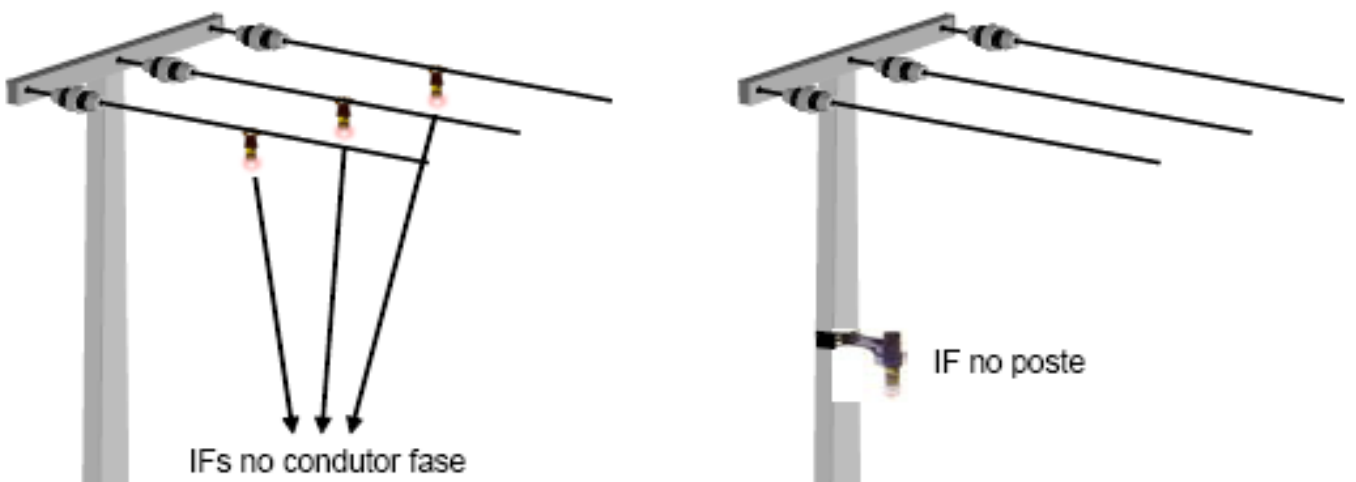

IFs no condutor fase

FIGURA 2.3 - Modelos de indicadores de faltas.

\subsubsection{Manutenção}

Quanto à manutenção dos IFs, os mesmos devem ser inspecionados periodicamente. Geralmente, os fabricantes recomendam a cada intervalo de um ano, com testes de verificação do funcionamento da bateria.

No entanto, este teste não garante seu funcionamento adequado. Foi observado que em alguns modelos podem ocorrer: alteração da posição das chaves de ajuste ao se fechar o equipamento, rompimento do cabo do sensor, problemas estes que somente serão observados quando esses IF forem retirados da rede para verificação. 


\subsection{Indicadores de Faltas Instalados no Cabo Condutor-Fase}

Como já descrito anteriormente, os IFs não localizam o ponto de falha, sendo que os mesmos apenas sinalizam a seção da falta. Após ter identificado a seção faltosa, as equipes de restabelecimento se dirigem ao local para correção do defeito. Com isso, ajudam a restabelecer a energia de forma mais rápida e eficiente, diminuindo-se a duração e freqüência das interrupções. Portanto, os IFs são dispositivos eficazes não só para a melhoria dos índices de qualidade das Distribuidoras, como também para o relacionamento da Distribuidora junto a seus clientes, ou seja, interrupções de energia cada vez menos freqüentes e mais curtas significam consumidores mais satisfeitos e menos reclamações.

O IF instalado no condutor-fase de redes primárias de distribuição de energia elétrica tem papel fundamental nesse contexto. Tal dispositivo é instalado de forma fácil e segura diretamente no cabo energizado da linha de distribuição e tem por finalidade monitorar a corrente e a tensão da fase da linha e também identificar a passagem de uma corrente de curto-circuito por esse local, com conseqüente desligamento da tensão elétrica dessa linha pelos equipamentos automáticos de proteção. Isso caracteriza a chamada falta permanente e requer atuação da equipe de manutenção.

Identificada a falta permanente, o IF começa a piscar e pode ser facilmente visto de dia ou de noite pela equipe que percorre o alimentador buscando o defeito. Quando identificado um ramal do alimentador principal por onde circulou a corrente de curto-circuito, a equipe de restabelecimento ( inspeção / manutenção ) tem a certeza de que é por ali que terá que seguir para localizar o ponto exato do defeito.

Os IFs instalados no cabo condutor-fase são também conhecidos por IFs de cabo ou IFs de linha, ou ainda, por sinalizadores de falta. Estes são pequenos dispositivos pinçados (presos) em torno de um cabo como ilustrado na Figura 2.4. 


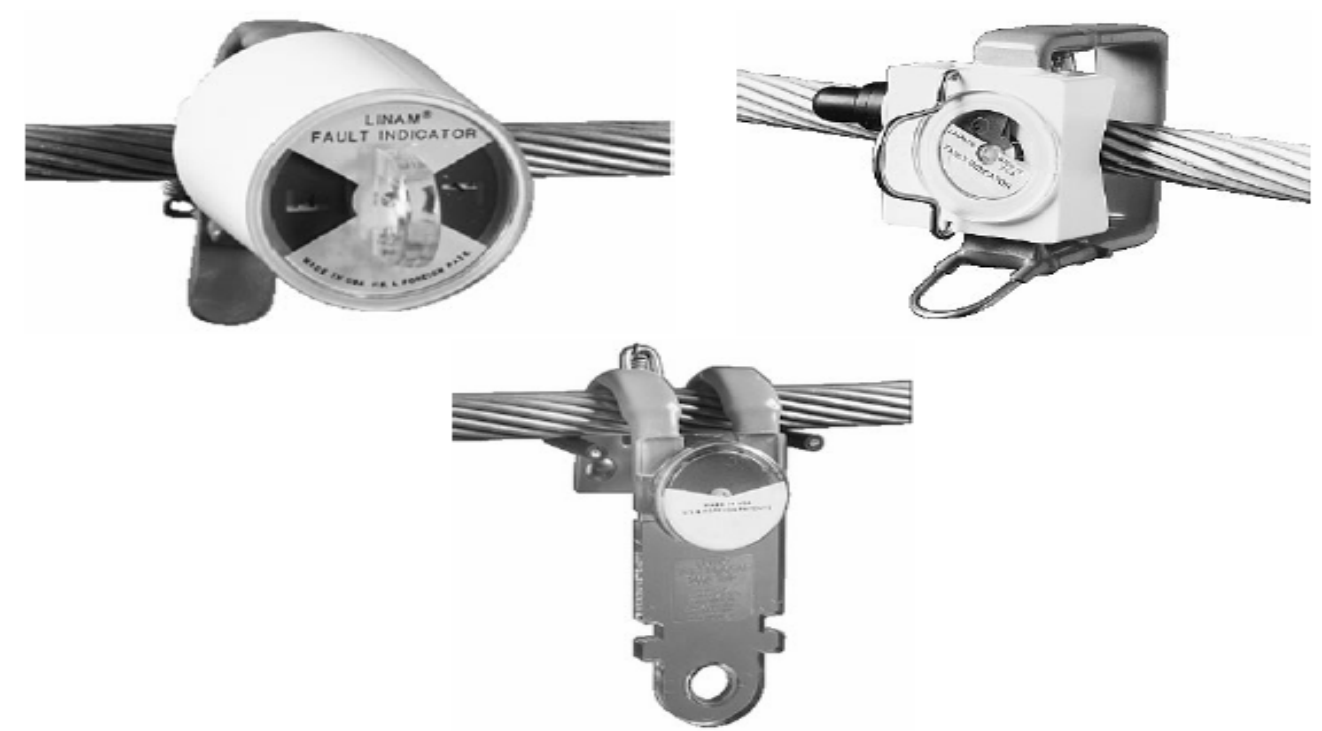

FIGURA 2.4 - Diferentes modelos de indicadores de faltas de cabo.

$\mathrm{Na}$ ocorrência de uma falta, o dispositivo sinaliza se houver passagem de corrente de curto-circuito pelo condutor monitorado. A detecção da corrente de falta é por meio de um sensor que monitora a variação da corrente no tempo, ou seja, $\frac{d i}{d t}$. Esse sensor diferencia uma corrente de carga em relação à corrente de falta fluindo através do condutor como mostra a Figura 2.5.

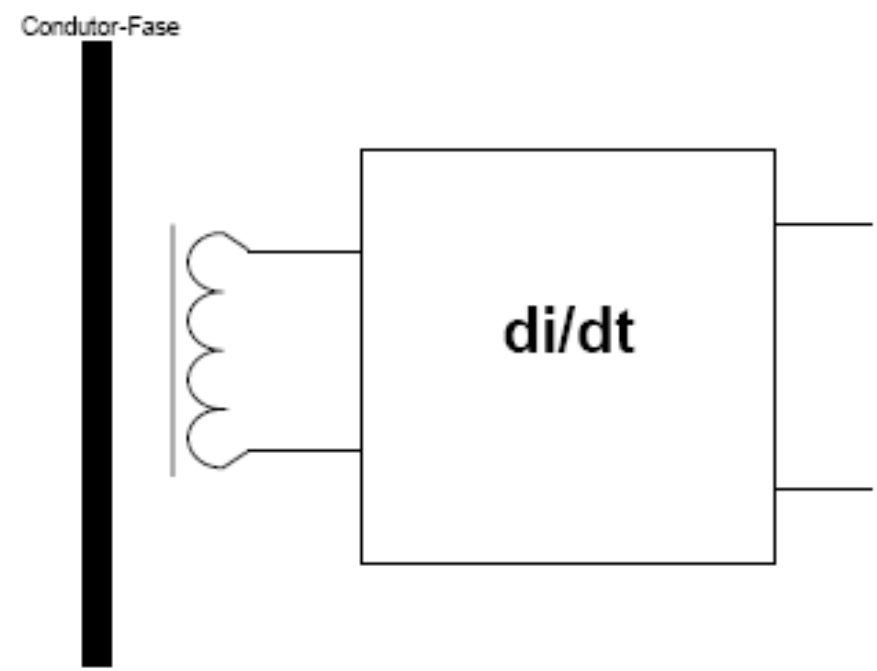

FIGURA 2.5 - Sensor de indicador de falta. 
A Figura 2.6 ilustra o esquema de instalação de IF na rede aérea. Geralmente, instala-se um IF para monitorar cada fase.

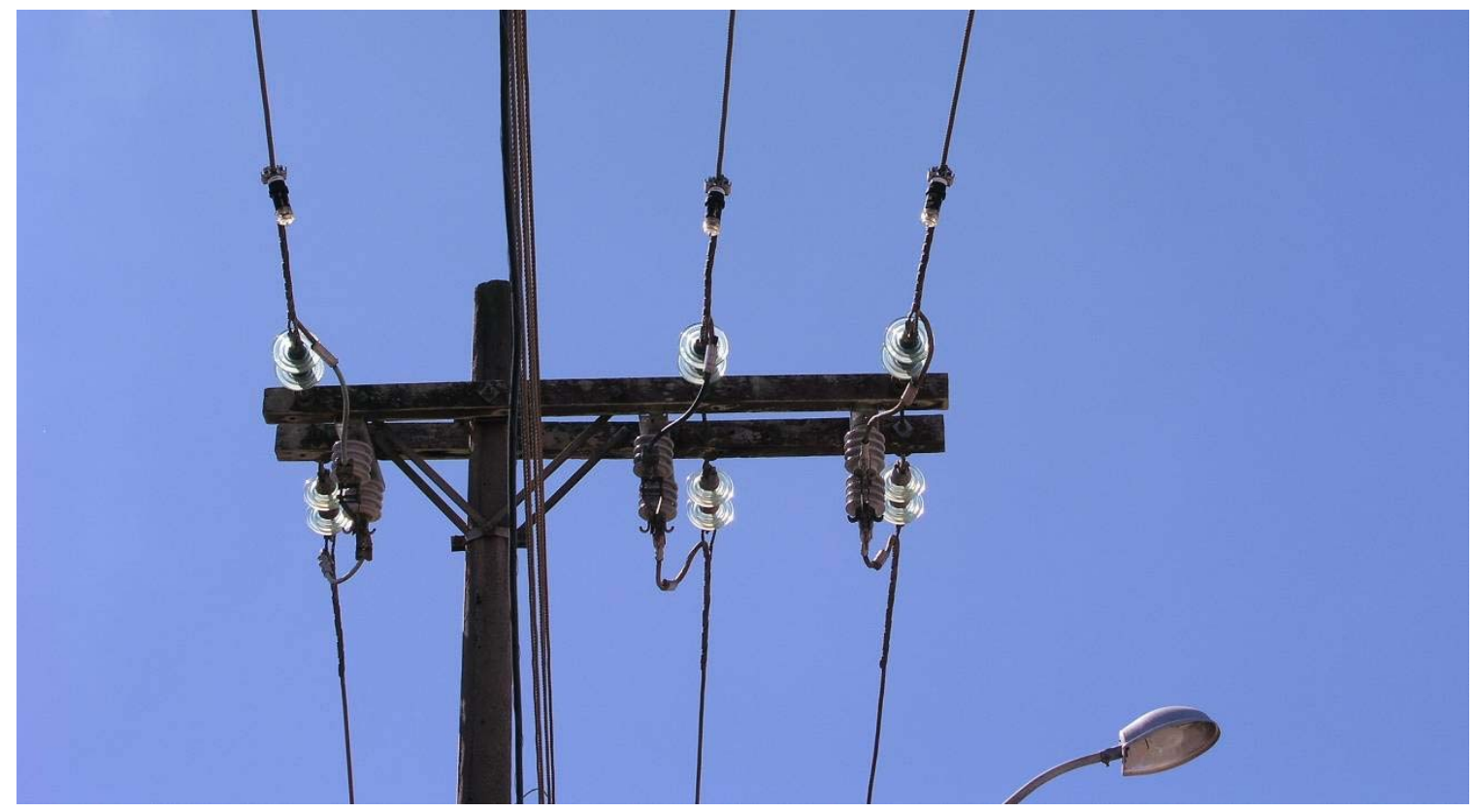

FIGURA 2.6 - Indicadores de faltas instalados nas três fases.

Os principais fabricantes de IFs de linha são:

- Schweitzer - www.selinc.com.br

- Schneider Electric - www.schneider-electric.com

- Nortroll - www.nortroll.com

- LOFA - www.lofa.net

- Bowden Bros - www.bowden-bros.com

$\mathrm{Na}$ Tabela 2.1, tem-se uma comparação entre os principais fornecedores de indicadores de falta para instalação em cabo com descrição dos seguintes ajustes: tipo de rearme, sinalização, bloqueio de corrente de inrush, faixa de trip, programação e tempo de vida útil da bateria. 
TABELA 2.1 - Comparação entre alguns fabricantes de Indicadores de faltas instalados em cabo.

\begin{tabular}{|c|c|c|c|c|c|c|c|c|c|c|}
\hline & $\begin{array}{c}\text { Indicadores } \\
\text { de Falta }\end{array}$ & 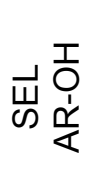 & $\underset{\omega}{\stackrel{\frac{n}{\alpha}}{\frac{\underline{x}}{m}}}$ & 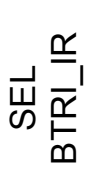 & 岀岳 & 岀点 & 岀号 & 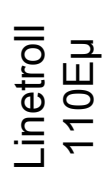 & 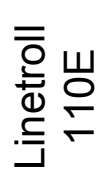 & 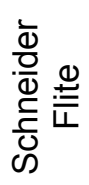 \\
\hline \multirow{4}{*}{ 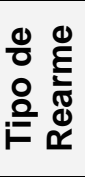 } & Eletrostático & & & & $X$ & $X$ & & & & \\
\hline & Corrente & & & & & & $x$ & & & \\
\hline & Tensão & & & & & & & $X$ & $x$ & $x$ \\
\hline & Tempo & $X$ & $x$ & $x$ & & & & $X$ & $X$ & $X$ \\
\hline \multirow{2}{*}{ 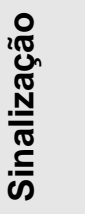 } & $\begin{array}{l}\text { Falta } \\
\text { Transitória }\end{array}$ & $x$ & & $x$ & & & & $x$ & $x$ & $x$ \\
\hline & $\begin{array}{l}\text { Falta } \\
\text { Permanente }\end{array}$ & $x$ & $x$ & $x$ & $x$ & & & $x$ & $x$ & $x$ \\
\hline \multicolumn{2}{|c|}{ Bloqueio de Inrush } & $x$ & $x$ & $x$ & $x$ & $x$ & $x$ & $x$ & $x$ & $x$ \\
\hline \multicolumn{2}{|c|}{ Faixa de Trip (A) } & $\begin{array}{l}50- \\
1.2 \mathrm{k}\end{array}$ & $\begin{array}{l}50- \\
1.2 \mathrm{k}\end{array}$ & $\begin{array}{l}50- \\
1.2 \mathrm{k}\end{array}$ & $\begin{array}{l}50- \\
1.2 \mathrm{k}\end{array}$ & $\begin{array}{l}50- \\
1.2 \mathrm{k}\end{array}$ & $\begin{array}{l}100- \\
1.2 \mathrm{k}\end{array}$ & $250-1 k$ & $250-1 k$ & \\
\hline \multirow{2}{*}{ 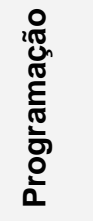 } & Switchs & \multirow{2}{*}{ 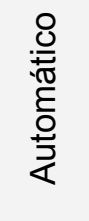 } & $x$ & $x$ & & & & $x$ & $x$ & $X$ \\
\hline & Software & & & & & & & & & $x$ \\
\hline \multicolumn{2}{|c|}{$\begin{array}{l}\text { Tensão Nominal } \\
\text { de Operação (kV) }\end{array}$} & $\begin{array}{c}4.16- \\
69\end{array}$ & $\begin{array}{l}4.16- \\
69\end{array}$ & $\begin{array}{l}8.66- \\
38\end{array}$ & $\begin{array}{c}8.66- \\
69\end{array}$ & $\begin{array}{c}8.66- \\
69\end{array}$ & $>38$ & $6-66$ & $6-66$ & $5-25$ \\
\hline \multicolumn{2}{|c|}{$\begin{array}{l}\text { Vida Útil da Bateria } \\
\text { (anos) }\end{array}$} & 20 & 20 & & & 20 & & $5-10$ & $5-10$ & 10 \\
\hline
\end{tabular}

$\mathrm{Na}$ Tabela 2.2, tem-se uma comparação dos principais fornecedores de indicadores de falta para instalação em poste. 
TABELA 2.2 - Comparação entre alguns fabricantes de Indicadores de faltas instalados em poste.

\begin{tabular}{|c|c|c|c|c|c|c|}
\hline & $\begin{array}{c}\text { Indicadores } \\
\text { de Falta }\end{array}$ & 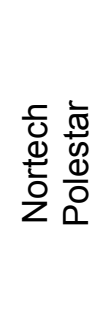 & 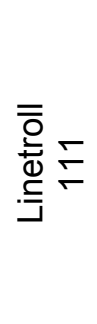 & 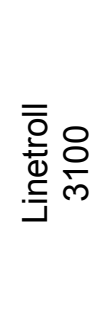 & 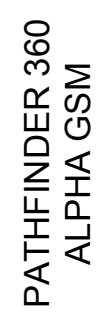 & 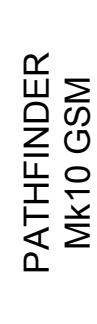 \\
\hline \multirow{4}{*}{ 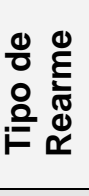 } & Manual & $\mathrm{X}$ & $\mathrm{X}$ & $x$ & $x$ & $x$ \\
\hline & Corrente & & & & & \\
\hline & Tensão & $x$ & $x$ & $\mathrm{X}$ & $x$ & \\
\hline & Tempo & $\mathrm{X}$ & $\mathrm{X}$ & $\mathrm{X}$ & $\mathrm{X}$ & \\
\hline \multirow{2}{*}{ 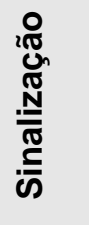 } & $\begin{array}{l}\text { Falta } \\
\text { Transitória }\end{array}$ & $x$ & $x$ & $x$ & $x$ & $x$ \\
\hline & Falta Permanente & $\mathrm{X}$ & $x$ & $\mathrm{X}$ & $x$ & $x$ \\
\hline \multicolumn{2}{|c|}{ Bloqueio de Inrush } & & $\mathrm{X}$ & $x$ & $x$ & $x$ \\
\hline \multirow{2}{*}{ 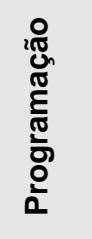 } & Switchs & & $\mathrm{x}$ & $x$ & & $x$ \\
\hline & Software & & & & & \\
\hline \multicolumn{2}{|c|}{$\begin{array}{l}\text { Tensão Nominal } \\
\text { de Operação (kV) }\end{array}$} & $11-275$ & $6-66$ & $6-132$ & $6-132$ & $6-132$ \\
\hline \multicolumn{2}{|c|}{ Vida Útil da Bateria (anos) } & 10 & $5-10$ & $7-8$ & $10-15$ & $6-10$ \\
\hline \multicolumn{2}{|c|}{ Comunicação } & $\mathrm{x}$ & & $x$ & $x$ & $x$ \\
\hline
\end{tabular}

\subsection{Indicadores de Faltas Instalados em Poste}

Conforme pode ser observado na Figura 2.7, o IF instalado no poste monitora as 3 fases do sistema de distribuição. 


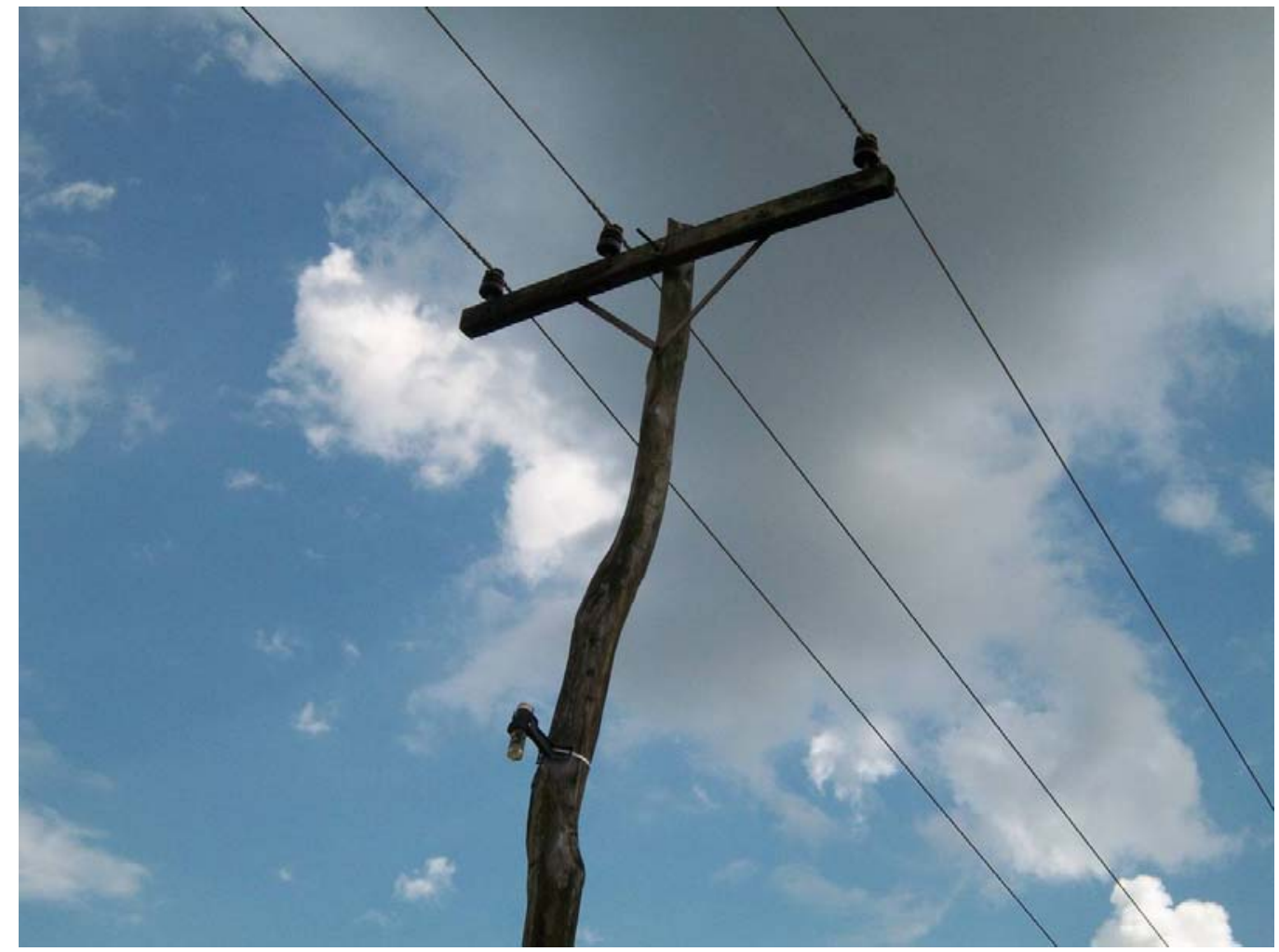

FIGURA 2.7 - Esquema do indicador de faltas instalado no poste.

Os indicadores de poste são empregados para detectar faltas Fase-Fase e Fase-Terra e também utilizam o princípio da variação da corrente para detectar uma falta. Há modelos que possuem sensores elétricos e magnéticos que monitoram constantemente a tensão e a corrente. Os sensores magnéticos $\frac{d i}{d t}$ se adaptam à presença de corrente na linha e são sensibilizados quando há um aumento abrupto de corrente quando ocorre uma falta. Já os sensores elétricos monitoram a presença de tensão na linha, por intermédio de uma antena localizada dentro do indicador.

Estes dispositivos podem sinalizar faltas permanentes, indicando iluminação de alerta principal, e também a passagem de faltas transitórias por intermédio de indicadores luminosos secundários. Na Figura 2.8, tem-se uma visualização de um IF instalado em um poste. 


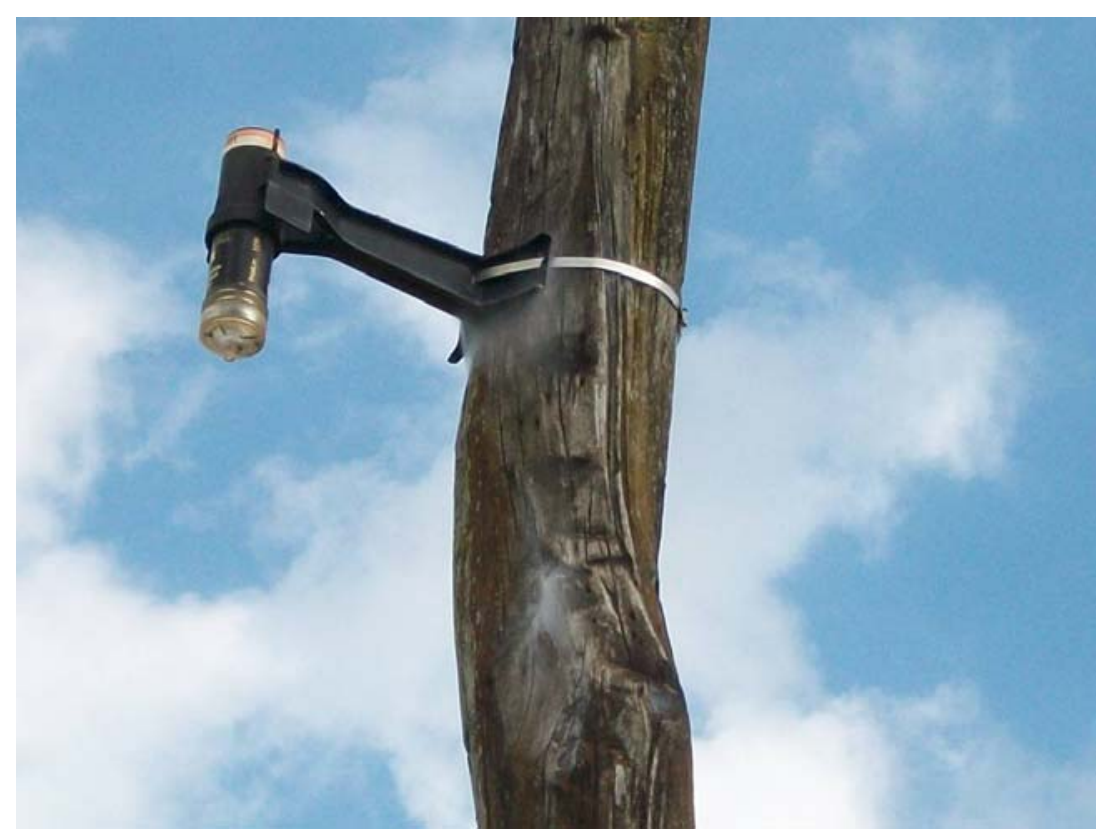

FIGURA 2.8 - Indicador de faltas de poste.

Como citado anteriormente, os indicadores de faltas instalados em postes monitoram as 3 fases simultaneamente com um único dispositivo. No entanto, estão sujeitos a interferências, tais como a presença da rede secundária no mesmo poste, o que torna o IF de linha mais adequado para esta situação.

Os principais fabricantes de IFs de poste são: Nortech, Nortroll e Bowden Bros.

\subsection{Novas Tecnologias de Aplicação para Indicadores de Faltas}

Diversas linhas de pesquisa vêm sendo desenvolvidas com o intuito de melhorar o desempenho dos indicadores de faltas. Destaca-se uma grande tendência no uso de ferramentas inteligentes e de transformadas wavelet.

O crescimento de aplicações envolvendo a transformada wavelet na detecção e localização de faltas é devido às dificuldades em se detectar uma falta de alta impedância (Kim et al., 2002).

A transformada wavelet tem um elevado poder de tratamento de sinais, pois permite realizar uma análise multiresolução considerando-se o domínio do tempo e da freqüência simultaneamente. Há também abordagens híbridas, que utilizam redes 
neurais artificiais combinadas com transformada wavelet, em que a decomposição do sinal é apresentada a uma estrutura neural para a tomada de decisão da sinalização de uma falta (Aravena \& Chowdhury, 1996).

As faltas de alta impedância representam um desafio para a proteção dos sistemas elétricos, principalmente devido às baixas magnitudes das correntes, que na maioria das vezes são menores que as de carga. Métodos para deixar os indicadores de faltas mais robustos com relação a este tipo de distúrbio, e que utilizam componentes fundamentais de correntes e tensões, são objetos de pesquisa .

Nestes casos, utilizam-se as componentes de seqüência zero para distinguir as correntes de falta daquelas de carga. Este é o caso da proposta apresentada em Baldwin et al. (2003), que traz também um modelo para detectar a direção da falta por meio de técnicas de processamento de sinais. Essa proposta se mostra atraente pelo fato de empregar um único dispositivo (microprocessado) capaz de detectar a passagem de uma falta, bem como o seu sentido de propagação.

Os indicadores de faltas também poderiam ser sensibilizados por união dos ruídos de altas freqüências produzidos pela passagem de uma falta. A proposta apresentada em Tang et al. (2000) consiste de rejeitar ou deixar passar uma banda específica de freqüências, detectando-se apenas os sinais de faltas da rede. Este tipo de abordagem necessita de uma elevada taxa de aquisição para que as componentes de altas freqüências possam ser corretamente representadas. 


\section{Aspectos Metodológicos para Ensaios de Indicadores de Faltas}

\subsection{Informações Gerais}

O plano de ensaios proposto é aplicável a equipamentos indicadores de falta empregados em sistemas de distribuição de energia elétrica operados em níveis de tensão não superiores a $46 \mathrm{kV}$ fase-fase. Ainda, esse plano abrange ensaios de natureza eletromagnética e não compreendem ensaios físicos, mecânicos, térmicos e de naturezas outras não correlatas à corrente de trip, formas de rearme e efeitos de correntes de condutores adjacentes. Casos omissos a esse plano de ensaios podem ser cobertos pela Norma ANSI/IEEE 495-2007, publicada em 28 de dezembro de 2007 (ANEXO A), bem como, conforme prevista na referida norma, deverão ser seguidas as condições sob as quais o indicador de falta será empregado.

Por meio da metodologia experimental proposta foi possível verificar que dez repetições, por ajuste do dispositivo, representam a quantidade ideal de ensaios a fim de se constatar defeitos construtivos e operativos, sob diferentes cenários, sendo também esta uma grande diferença em relação à referida norma, que sugere apenas duas repetições. 


\subsubsection{Objetivos}

Os dispositivos indicadores de faltas podem ser empregados em sistemas de distribuição de energia aéreos ou subterrâneos. De maneira específica, o objetivo desse Plano de Ensaios é apresentar metodologias de ensaios que sejam adequados às especificidades da distribuidora de energia elétrica. Assim, serão apresentadas as metodologias de ensaios dedicadas aos indicadores de falta empregados no sistema aéreo de distribuição de energia elétrica. Nesse contexto, serão abordadas alternativas para a condução de ensaios que sejam coerentes tanto para indicadores de falta do tipo cabo, como para indicadores do tipo poste.

De maneira ampla, pode-se então consolidar os objetivos desse plano de ensaio como sendo o conjunto de ensaios os quais os indicadores de falta deverão atender de maneira satisfatória e validar a sua eficácia.

\subsubsection{Definições}

Esta seção se destina a orientar os interessados quanto à interpretação dos termos mais utilizados neste plano de ensaios experimentais .

\subsubsection{Condições de Rearme}

A condição de rearme é a circunstância ou ação pela qual se modifica a sinalização do indicador de falta de uma condição de falta para um estado de nãofalta ou de operação normal. O rearme pode ser manual ou automático dependendo do tipo de programação, tipo e fabricante. 


\subsubsection{Dispositivo de Rearme}

O dispositivo de rearme é uma ferramenta ou equipamento para uso manual com o objetivo de se modificar a sinalização do indicador de falta de uma condição de falta para um estado de não-falta ou de operação normal.

\subsection{Ensaios Experimentais}

\subsubsection{Planejamento de Ensaios}

Os ensaios aplicáveis aos indicadores de falta devem ser planejados de maneira a possibilitar inferir sobre sua funcionalidade, segundo dados de projeto e manual, nas condições sob as quais os mesmos deverão operar.

Esses ensaios devem também ser realizados quando da instalação dos indicadores de falta e de maneira periódica com aqueles já instalados, com o intuito de monitorar a degradação dos parâmetros de funcionamento em relação do tempo e das adversidades atmosféricas. O acompanhamento periódico objetiva não apenas a retirada de serviços daqueles indicadores de faltas com tolerâncias acima do recomendado, mas também visa o levantamento de informações que permitam contribuir para o planejamento da manutenção e atualização dos ativos relativos aos indicadores de faltas.

\subsubsection{Ensaio Para a Corrente de Trip}

O ensaio para a corrente de trip deverá ser realizado com o objetivo de verificar a sensibilidade do indicador para suas condições nominais , sobretudo, para as condições nas quais o indicador de falta operará. A metodologia para o ensaio de corrente de trip é descrita na Seção 4. 


\subsubsection{Ensaios Para as Formas de Rearme}

O objetivo dos ensaios para as formas de rearme é de verificar se o indicador de falta retorna ao modo de operação normal depois de satisfeitas as condições de rearme especificadas pelo fabricante. Nesse plano de ensaio as seguintes formas de rearme são consideradas:

Rearme por corrente: Para os indicadores de falta que requerem uma corrente fluindo pelo cabo no qual o indicador está instalado, para alterarem a indicação de condição de falta para operação normal, o seguinte critério se aplica: uma vez que a corrente circulante for tal como a especificada pelo fabricante, o indicador deverá alterar sua indicação em um tempo não superior a 10 minutos;

* Rearme por tensão: Para os indicadores de falta que requerem uma tensão no cabo no qual o indicador está instalado, para alterarem a indicação de condição de falta para operação normal, o seguinte critério se aplica: uma vez que a tensão no condutor for tal como a especificada pelo fabricante, o indicador deverá alterar sua indicação em um tempo não superior a 10 minutos;

Rearme por tempo: Para indicadores de falta que se rearmam por tempo, o mesmo deverá apresentar a modificação da condição de falta para a condição de operação normal no tempo especificado pelo fabricante, aceitando a tolerância de $\pm 20 \%$. Como a tolerância aceita é alta e os tempos de rearme também o podem ser, a realização desse tipo de ensaio pode ser dispensada caso o fabricante garanta, por meio do projeto do indicador, que os tempos de rearme e a tolerância citada são observados.

Rearme manual: Para indicadores de falta que se rearmam por meio de ferramentas ou equipamentos especificados pelo fabricante, o mesmo deverá apresentar a modificação da condição de falta para a condição de operação normal logo após a realização do procedimento de rearme manual especificado pelo fabricante. Por exemplo, o indicador Linetroll 
$110 \mathrm{E} \mu$ de cabo tem rearme manual por meio da desconexão e conexão da bateria ou por meio de um imã externo.

\subsubsection{Teste de Suportabilidade de Corrente}

O teste de suportabilidade de corrente tem por meta verificar se o indicador de falta não altera suas características após ser submetido a uma das duas possíveis formas de ensaio destacadas na Tabela 3.1.

TABELA 3.1 - Parâmetros para o ensaio de suportabilidade de corrente.

\begin{tabular}{|c|c|c|c|}
\hline Corrente de Falta & $\begin{array}{c}\text { Corrente de Falta } \\
\text { Simétrica }\end{array}$ & Duração do ensaio & $\begin{array}{c}\text { Mínimo Fator de } \\
\text { Assimetria }\end{array}$ \\
\hline 10.000 & 10.000 & 10 ciclos & $1,3(X / R=6)$ \\
\hline 20.000 & 20.000 & 10 ciclos & $1,6(X / R=20)$ \\
\hline
\end{tabular}

O valor eficaz do primeiro ciclo de onda aplicado ao indicador deverá ser igual ou maior ao valor da corrente simétrica multiplicada pelo fator de assimetria correspondente. A realização de ensaio deverá ser feita no mínimo duas vezes em cada indicador de falta.

\subsubsection{Efeito da Corrente de Condutores Adjacentes}

Esse ensaio tem por objetivo verificar a influência da corrente de condutores adjacentes na indicação provida pelos indicadores de falta. Assim, esse tipo de ensaio é particular para os indicadores de falta do tipo cabo.

Esse ensaio deve ser conduzido observando-se os seguintes passos:

* O indicador de falta deve ser instalado em um condutor desprovido de corrente durante a realização do ensaio.

* Observando-se a mínima distância de condutores fase no sistema de distribuição, deve-se então ter outro condutor no qual, durante a realização do ensaio será feito circular uma corrente com magnitude e tempo igual aos apresentados na Tabela 3.1. 
* Nesse ensaio deve-se observar se o indicador sinalizará ou não. Em caso de sinalização o indicador é rejeitado.

Esse ensaio deverá ser realizado duas vezes no mínimo.

* As condições de tensão necessárias ao correto funcionamento do indicador deverão ser obedecidas durante o ensaio.

\subsection{Preparativos do Indicador de Faltas}

Tendo em vista que muitos dos indicadores de falta possuem ajustes para a parametrização da corrente de trip, esse passo metodológico tem por objetivo conferir ao ensaio em questão a habilidade de se verificar a sensibilidade para cada um dos patamares de ajuste. Assim sendo, deve-se conduzir os ensaios de corrente de trip para cada um dos patamares de corrente passíveis de ajuste. Portanto, o primeiro ensaio deverá ser conduzido no menor ajuste de corrente possível para o indicador de falta.

Tome-se, como por exemplo, um indicador de falta com corrente de trip ajustável em 6, 12, 25, 60 e 120A. Assim, o primeiro conjunto de ensaios deverá ser realizado para o ajuste de $4 \mathrm{~A}$. O segundo conjunto será, então, feito para uma corrente de trip de 6A. Procedendo dessa forma até o ajuste mais alto, para o exemplo em questão, o último conjunto de ensaios será para uma corrente de trip de $120 \mathrm{~A}$.

Uma vez ajustado, o indicador de falta deverá ser instalado no laboratório de ensaios observando-se seu princípio de operação, se de cabo ou de poste, bem como as instruções providas pelo fabricante. 


\subsection{Determinando as Condições Elétricas do Ensaio}

Nesse passo metodológico duas quantidades serão determinadas. A primeira delas é a corrente de pré-falta e a segunda é a corrente de falta propriamente dita.

A corrente de pré-falta tem por objetivo fornecer ao indicador de falta características eletromagnéticas semelhantes àquelas observadas quando de uma operação normal do sistema de distribuição sob carga. Dessa forma, diferentes correntes de pré-falta deverão ser aplicadas ao indicador de maneira a possibilitar uma verificação da sensibilidade do indicador sob diferentes condições de carga. Sugere-se que a primeira corrente de pré-falta seja de $0 \%$ da corrente de carga. Essa corrente de carga pode ser incrementada a passos de $10 \%$ a cada novo ensaio.

Uma observação importante é a determinação da corrente de carga. Para indicadores de falta já instalados essa corrente de carga deverá ser igual ou maior do que a máxima corrente de carga, observando a taxa de crescimento da carga no local de instalação, bem como o horizonte de crescimento considerado. O horizonte a ser considerado para o cálculo da corrente de carga deverá estar consoante com a vida útil do indicador, principalmente no que se refere sua bateria.

Para se determinar a corrente de carga de indicadores de falta novos podese considerar a ampacidade dos cabos empregados no sistema de distribuição.

Assim como inicialmente citado, a determinação da corrente de pré-falta é o primeiro passo nos preparativos das condições elétricas do ensaio. O segundo passo é a determinação da corrente de pós-falta no sistema. Assim, como o objetivo é ensaiar a sensibilidade do indicador de falta, a corrente de pós-falta deverá ser 
ajustada de maneira a fornecer um valor eficaz igual à soma algébrica da corrente de carga e da corrente de falta. A corrente de falta, por sua vez, deverá ser inicialmente ajustada em um patamar imediatamente abaixo da corrente de trip especificada na Seção 3.3.

As condições de pré-falta e de pós-falta deverão ser aplicadas ao indicador de falta. Assim, uma vez aplicada as condições citadas, verifica-se então se houve ou não atuação do indicador de falta. Em caso positivo, o valor da corrente de falta aplicada deverá ser anotado. Em caso negativo, a mesma deve ser incrementada até se verificar a atuação do indicador. Para auxiliar na tabulação dos resultados apresenta-se a Tabela 3.2 como padrão a ser adotado ao longo dos ensaios.

Uma vez determinada a corrente de trip para cada patamar de corrente de carga, deve-se então parametrizar o indicador de falta para um novo patamar de corrente de trip e repetir os passos descritos nesse item.

Os ensaios descritos nessa seção podem ser executados com o auxílio de rotinas descritas posteriormente no Capítulo 4. 
TABELA 3.2 - Tabela padrão para registro dos ensaios de corrente de trip.

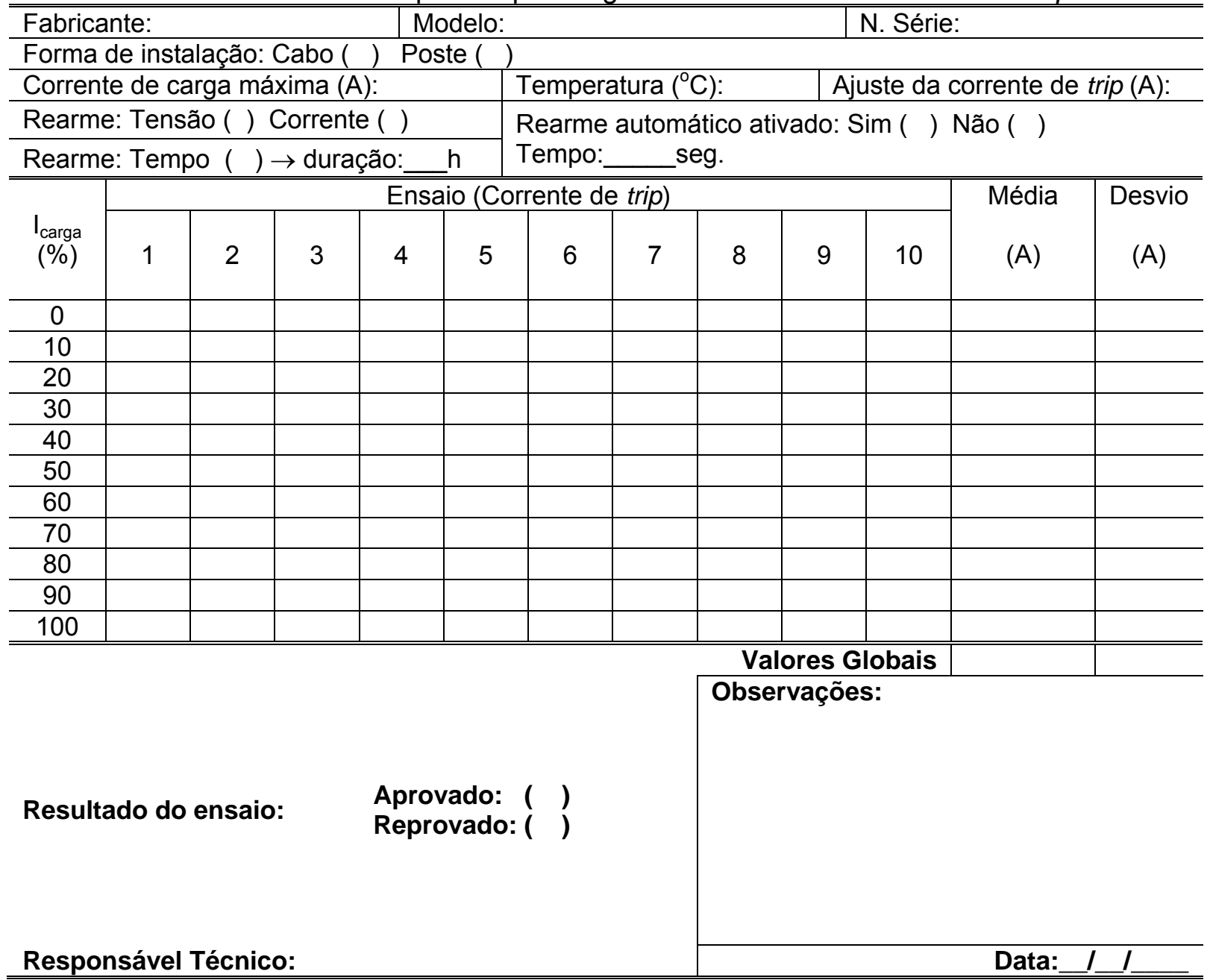

\subsection{Análise dos Resultados Para a Corrente de Trip}

Uma vez conduzidos os ensaios, segundo o especificado na Seção 3.4, os dados obtidos deverão ser analisados com o objetivo de se determinar:

- Variação da corrente de trip real em função da corrente de carga;

- Máximos e mínimos valores da corrente de trip em função da corrente de trip;

- Verificar se as tolerâncias especificadas pelo fabricante são válidas para toda a faixa de corrente de carga e para cada um dos ajustes de corrente de trip possíveis de serem parametrizadas no indicador de falta. 


\subsection{Considerações Acerca dos Indicadores de Faltas do Tipo Poste}

Os indicadores de falta do tipo poste são específicos para indicarem faltas desbalanceadas, ou seja, faltas fase-terra ou faltas fase-fase-terra. Nessas condições a corrente de carga equilibrada não influencia nos resultados. Assim sendo, a corrente de carga especificada na Seção 3.4 deverá ser interpretada como a corrente de carga de desbalanço, ou seja, há de se considerar a máxima corrente de desbalanço observável no sistema.

\subsection{Estrutura Básica de Ensaio}

Os elementos utilizados na construção da estrutura laboratorial são fundamentados nos mesmos empregados em sistemas de distribuição real. A montagem e configuração são similares aos encontrados em campo.

Basicamente foi montado um esquema simulando um sistema monofásico de distribuição, conforme apresentado nas figuras a seguir. 


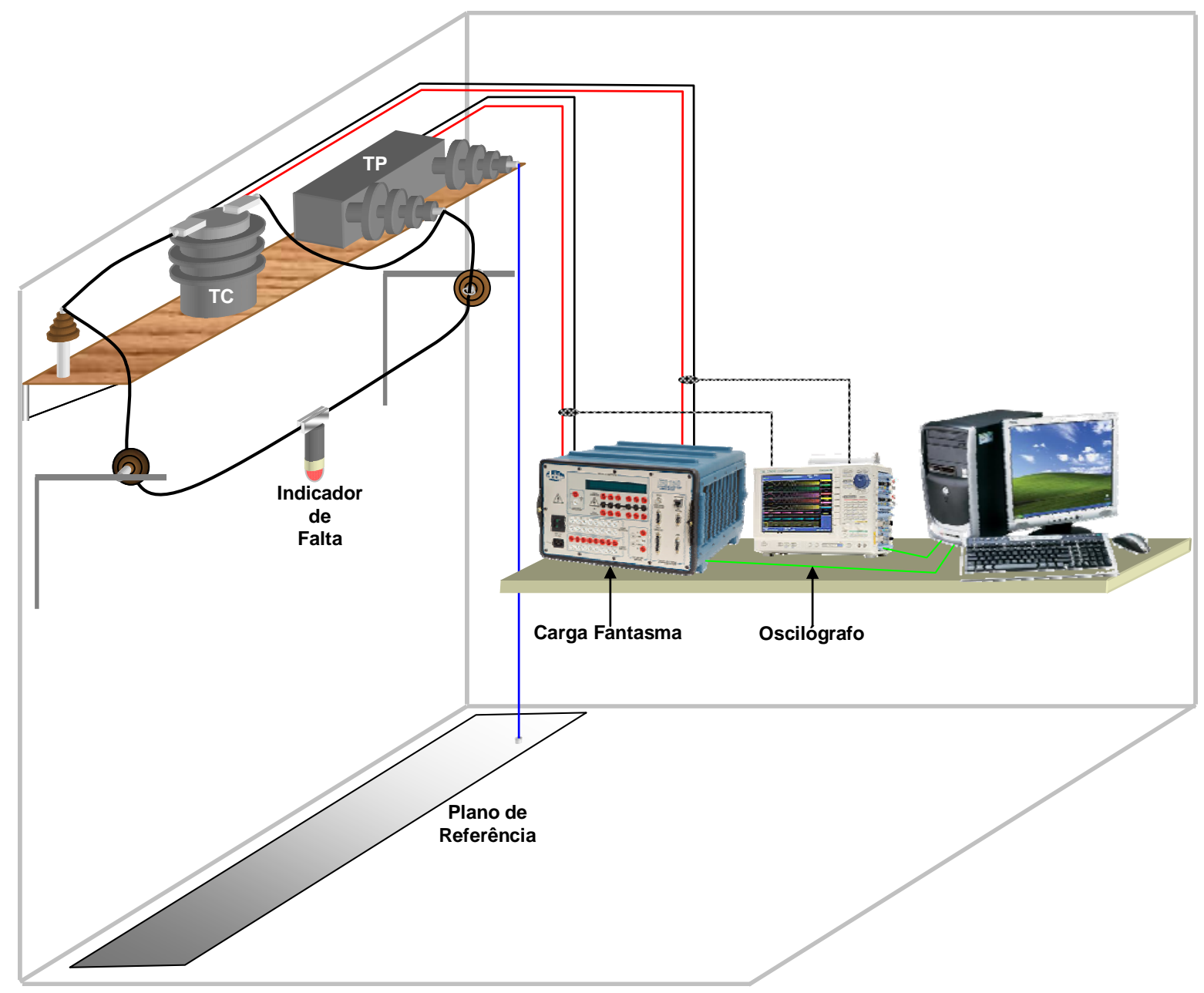

FIGURA 3.1 - Estrutura laboratorial de ensaios.
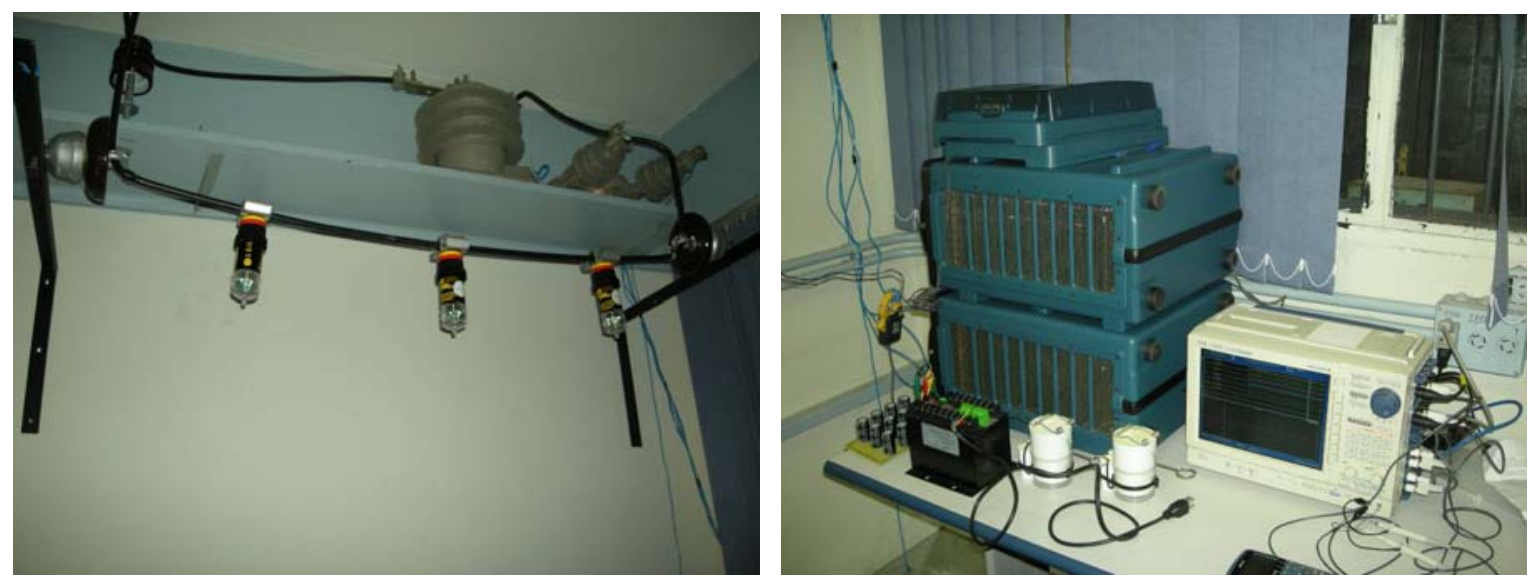

FIGURA 3.2 - Montagem física da estrutura laboratorial de ensaios.

Os equipamentos e materiais necessários para compor a estrutura laboratorial são apresentados no que segue. 


\subsubsection{Transformador de Corrente (TC)}

Equipamento com a função de ajustar a corrente. Foi empregado o TC, da fabricante ALSTOM, com relação de 30:5. Porém, tal equipamento foi montado com finalidade de elevar a corrente para um nível empregado nas redes de distribuição de média tensão.

\subsubsection{Transformador de Potencial (TP)}

Equipamento com função de reduzir a tensão. Foi utilizado o TP, da fabricante ALSTOM, com relação 120:1. Tal equipamento também foi montado para elevar a tensão para valores utilizados nos sistemas de distribuição.

\subsubsection{Carga Fantasma}

É uma caixa de teste com função de simular o sistema elétrico de potência para gerar eventos, como por exemplo, subtensão, interrupção, curtos-circuitos e outros. A caixa utilizada foi o modelo F6150 fabricado pela Double.

\subsubsection{Softwares}

Aplicativos computacionais utilizados na configuração e controle do simulador de eventos de sistema de potência, como por exemplo, ProTest e F6 Test.

\subsubsection{Microcomputador}

Foram utilizados para executar os aplicativos de comunicação, configuração, monitoramento, análise e geração de eventos para os equipamentos integrantes da estrutura laboratorial. 


\subsubsection{Oscilógrafo}

Tal equipamento tem a função de registrar e oscilografar as formas de ondas durante os testes. O equipamento aplicado nessa tarefa foi o Yokogawa DL750.

\subsubsection{Materiais}

Diversos materiais foram utilizados para compor a estrutura laboratorial, tais como:

- Chapa de aço galvanizada

- 1 Isolador tipo Pino 15 kV

- 2 Isoladores tipo Disco 15 kV

- Cabo alumínio $1 / 0$

Portanto, todo o aparato experimental para se realizar testes experimentais em indicadores de faltas, assim como a exposição dos procedimentos envolvidos com o planejamento dos referidos ensaios, foi abordado neste capítulo, tendo-se aqui o intuito de complementar aqueles testes padronizados executados pelos fabricantes. 


\section{Metodologia Experimental e Estudos de Caso}

\subsection{Introdução}

Para automatizar e padronizar o processo de ensaios dos dispositivos indicadores de falta, foram desenvolvidos planos de teste por meio de recursos disponíveis no software da caixa de teste de relés. Tal recurso é presente no software de controle da caixa chamado ProTest.

Foram elaboradas rotinas para avaliar as seguintes situações dos indicadores de falta:

Condições iniciais para o indicador de falta estar apto a funcionar.

- Trip por variação de corrente e/ou tensão.

- Rearmes por tensão, corrente e tempo.

- Rearme automático.

As rotinas foram elaboradas por meio de planos de testes disponíveis no ProTest denominadas de Macro e foram definidas como segue:

- Evolução de corrente.

- Correntes pulsadas com amplitude variável e crescente.

- Religamento sem sucesso e remoção do defeito.

- Religamento com sucesso.

Foram utilizadas as Macros do ProTest LRAMPI e PRAMPI. Vale lembrar que tais Macros possuem condições de pré-falta. 


\subsubsection{Macro LRAMPI}

Tal Macro consiste em aplicar uma corrente crescente ou decrescente semelhante a uma função degrau. A Figura 4.1 ilustra o comportamento dessa Macro.

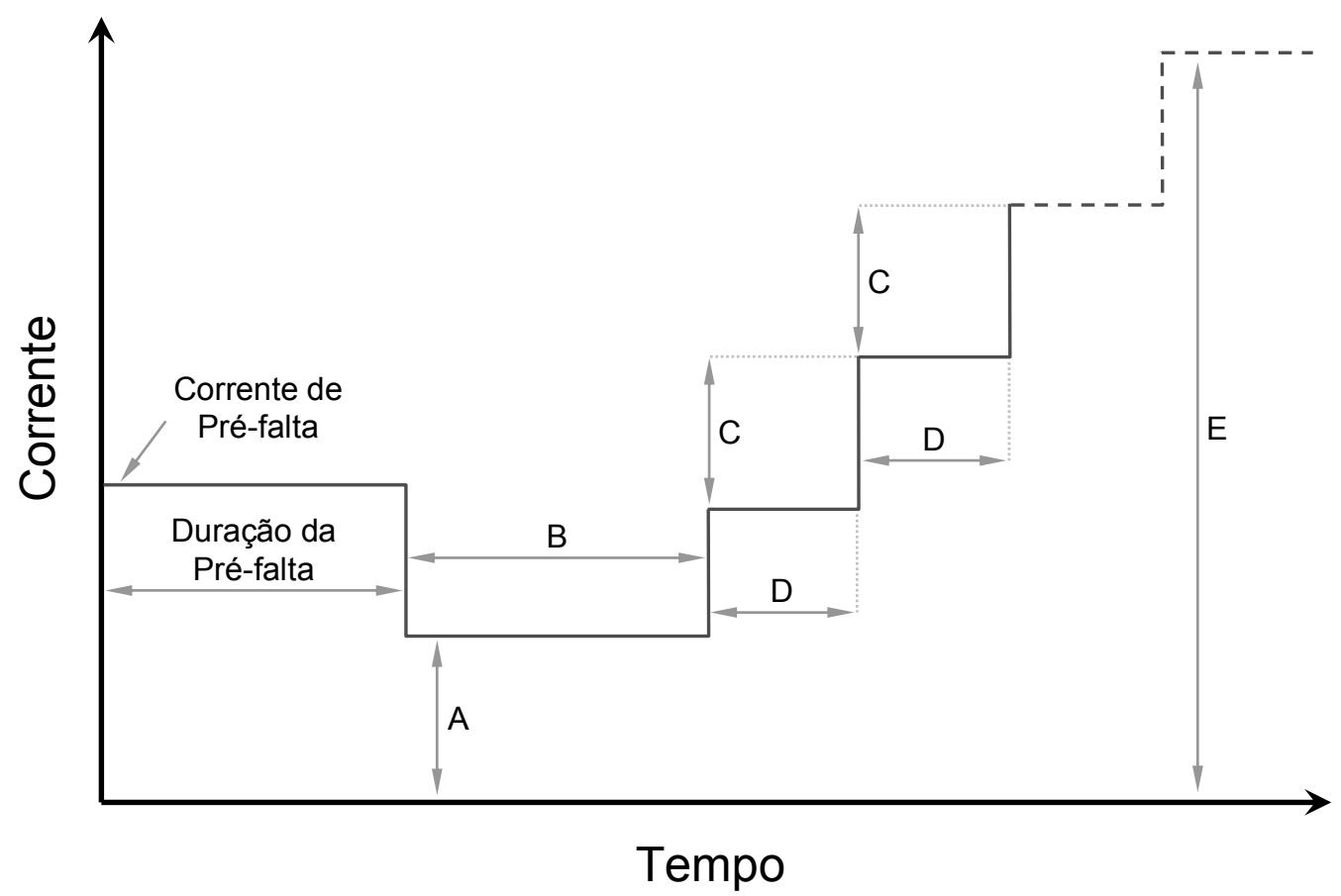

FIGURA 4.1 - Macro LRAMPI.

Conforme ilustrado na Figura 4.1, é necessário definir alguns parâmetros de pré-falta e da função rampa. Os parâmetros a serem ajustados pelo usuário são apresentados a seguir:

- Canais de Tensão e Corrente.

- Tensão de Pré-Falta.

- Corrente de Pré Falta.

- Duração da Pré-Falta em ciclos.

- A - Corrente inicial.

- B - Tempo de duração da corrente inicial.

- C - Incremento/Decremento de corrente considerando o valor da corrente antecedente.

- D - Tempo de duração do "degrau" de corrente.

- E - Limite máximo do valor de corrente. 


\subsubsection{Macro PRAMPI}

Tal Macro consiste em aplicar uma corrente pulsante de forma crescente ou decrescente, conforme pode ser visualizado na Figura 4.2.

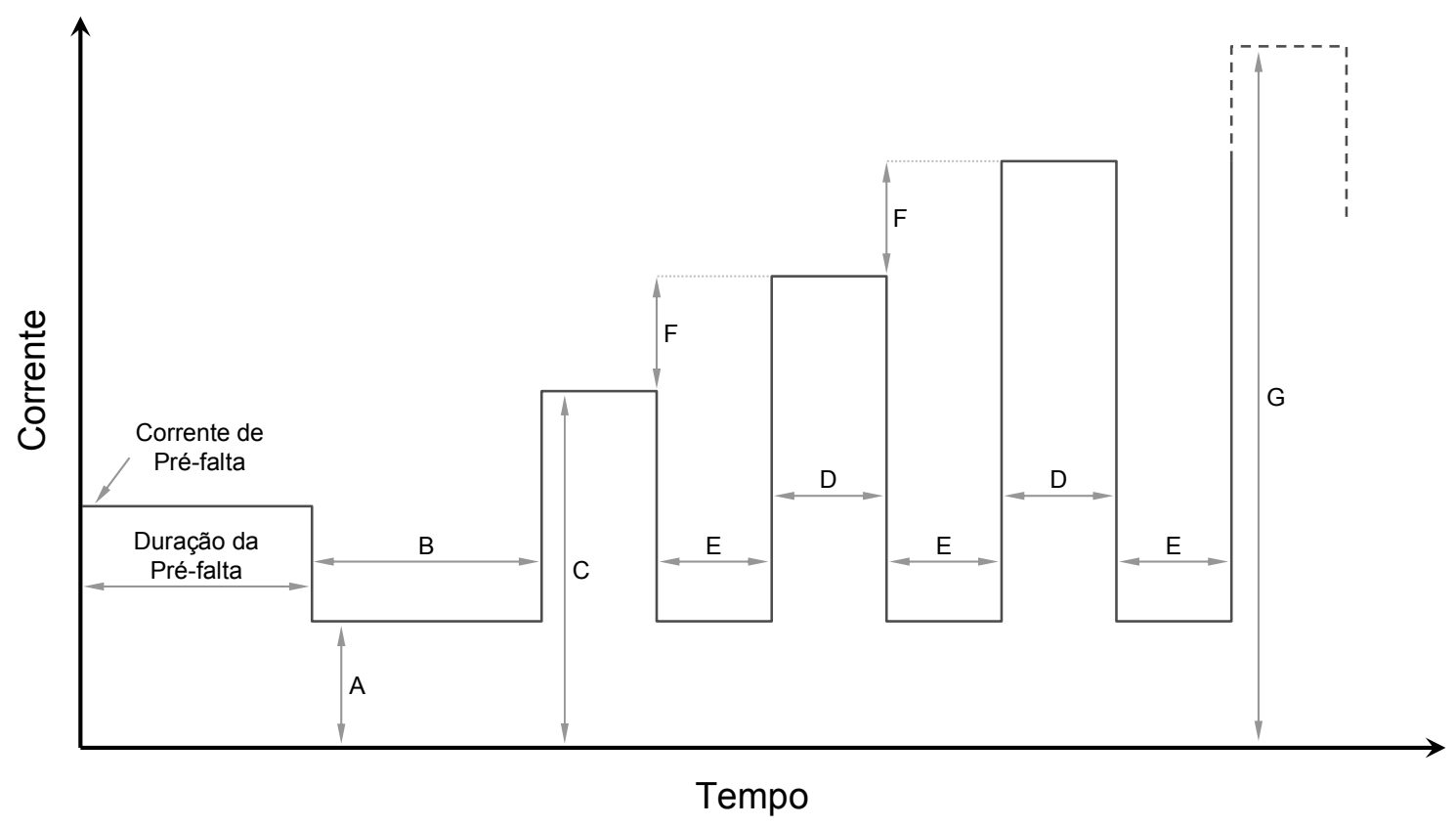

FIGURA 4.2 - Macro PRAMPI.

A - Corrente inicial

B - Tempo de duração da corrente inicial

C - Amplitude do primeiro "pulso" de corrente

D - Tempo de duração do "pulso" de corrente

E - Intervalo de tempo entre os "pulsos"

$\mathrm{F}$ - Incremento/Decremento de corrente considerando o valor da amplitude do "pulso" de corrente antecedente

G - Limite máximo do valor de corrente

\subsection{Teste de Evolução de Corrente}

Para verificar o comportamento dos indicadores de falta frente a um crescimento de carga no sistema de distribuição, foi elaborado um ensaio utilizando o plano de teste denominado LRAMPI, que consiste de uma fonte de corrente com comportamento de subida em "degraus", conforme ilustrado na Figura 4.3. A subida de corrente não pode ser elevada e rápida a ponto de representar uma variação de di/dt que sensibilize os dispositivos indicadores de falta, pois o intuito desse teste é 
apenas verificar se há atuação indevida desses dispositivos em condições normais de elevação de carga.
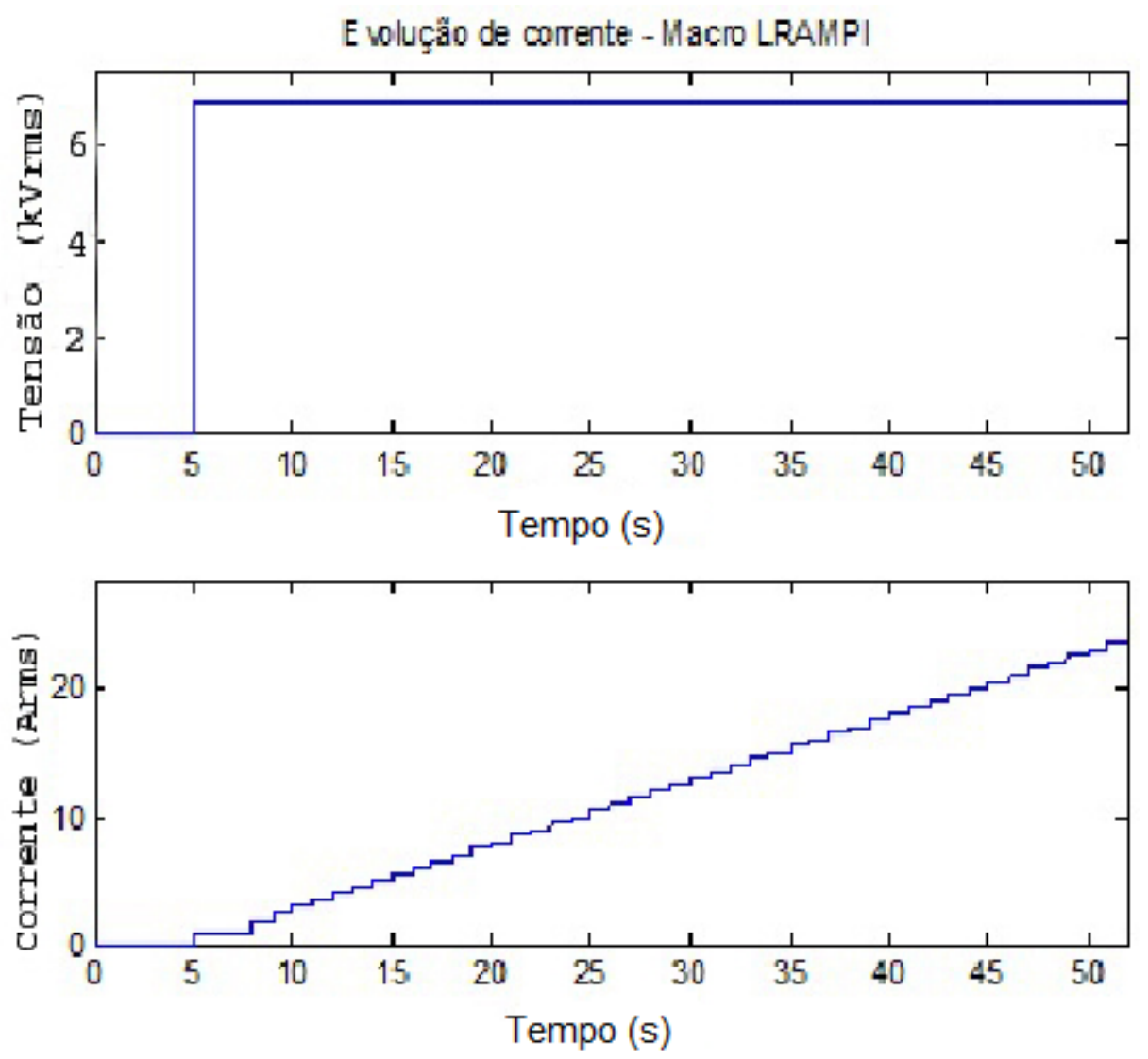

FIGURA 4.3 - Teste de evolução de corrente.

\subsection{Teste de Correntes Pulsadas com Amplitude Variável e Crescente}

A segunda rotina de teste contempla a aplicação de correntes pulsadas com variação crescente da amplitude, para cada intervalo de tempo, como mostra a Figura 4.4 . 

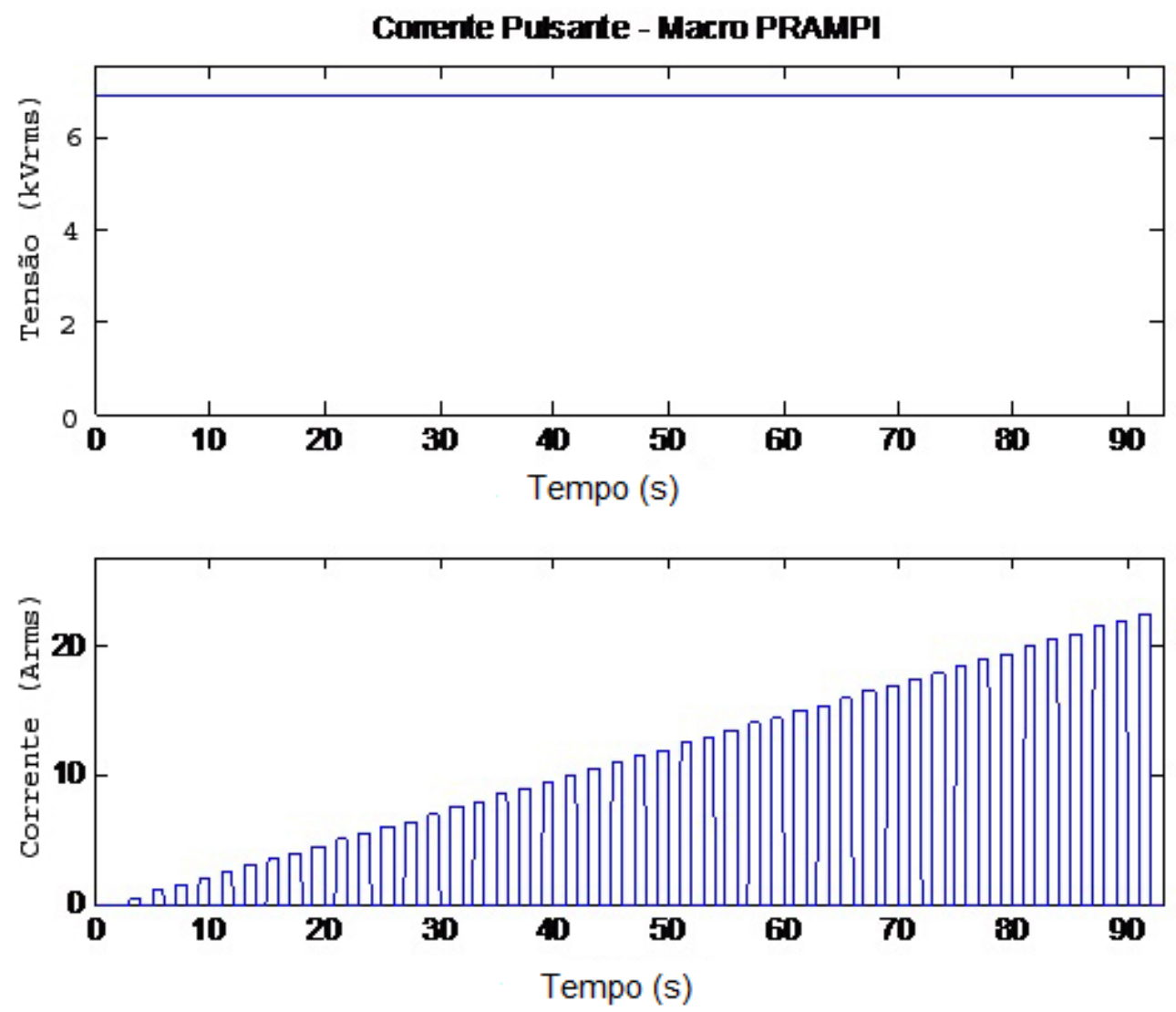

FIGURA 4.4 - Correntes pulsadas com amplitude variável e crescente.

A finalidade desse teste é verificar se correntes pulsadas sensibilizam o indicador de falta. Com isso é possível determinar se o nível de trip é compatível com o ajustado previamente.

Tal Macro é importante também para a utilização dos ensaios descritos na Seção 4.2, como por exemplo, uma simulação que inicia com uma condição de préfalta de 7 A, ou seja, uma corrente de carga. Após um período de tempo de 300 ciclos (5 segundos) ocorre uma falta de forma a sensibilizar o dispositivo indicador de falta, sendo que a corrente vai a $15 \mathrm{~A}$. Vale lembrar que os valores de corrente são elevados na relação 1:6 pelo TC, portanto, uma corrente de carga de 7 A na saída da caixa de teste é elevada na linha a 42 A. A Macro PRAMPI irá apenas dar um pulso de $8 \mathrm{~A}$, ou seja, irá de $7 \mathrm{~A}$ para $15 \mathrm{~A}$ e como esse último valor é o limite 
máximo de corrente ajustado, a simulação é finalizada, conforme pode ser visualizado na Figura 4.5.

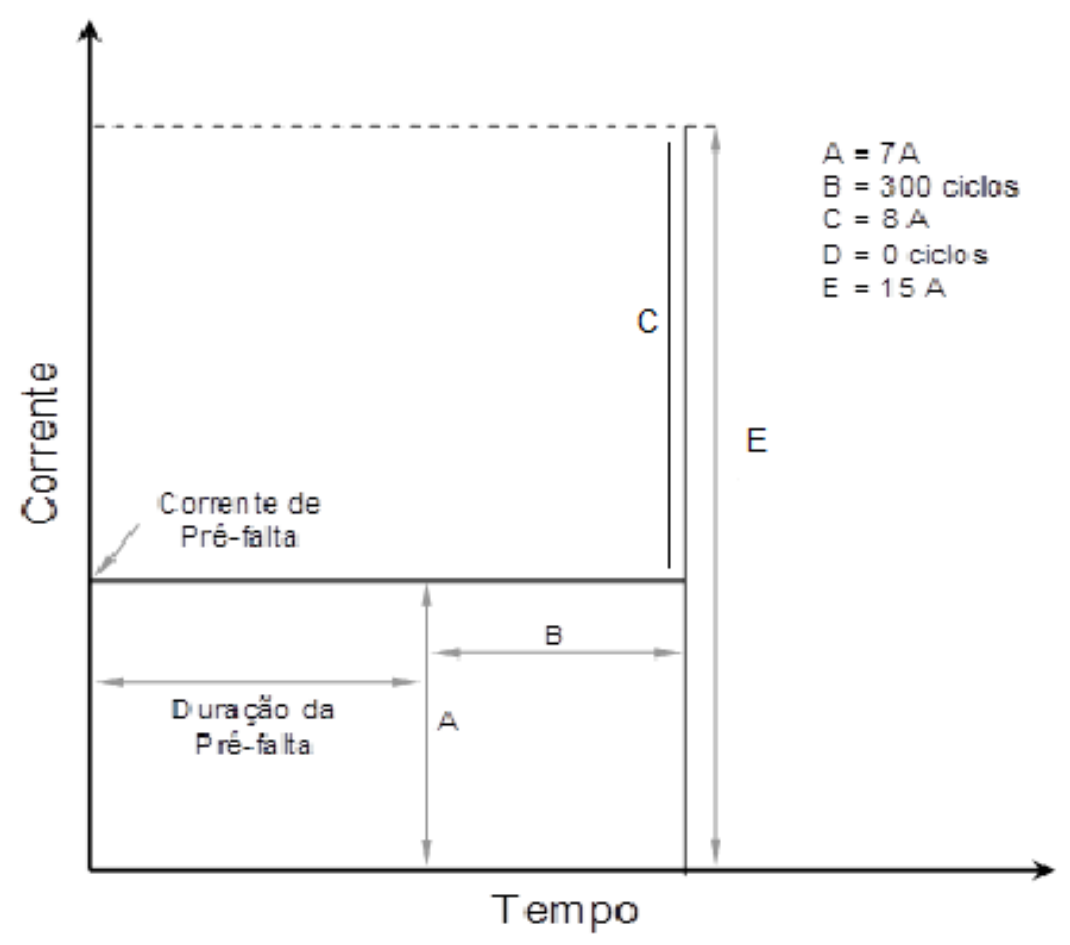

FIGURA 4.5 - Exemplo de condição de trip com condição de carga na pré-falta.

\subsection{Teste de Religamento sem Sucesso}

Nesse teste é simulada uma situação de falta permanente na rede de distribuição. Foram consideradas três tentativas para religamento do sistema, porém, sem a obtenção de sucesso. Após um período é removido o defeito da linha e restabelecido o fornecimento de energia. Para esse teste foram utilizados cinco planos de teste em seqüência. A rotina seqüencial é apresentada na Figura 4.6.

O objetivo desse teste é verificar se os dispositivos indicadores de falta atuam corretamente na ocorrência de falta transitória e permanente. Outra verificação importante refere-se ao seu rearme após restabelecimento normal do sistema. 
Religamento sem sucesso
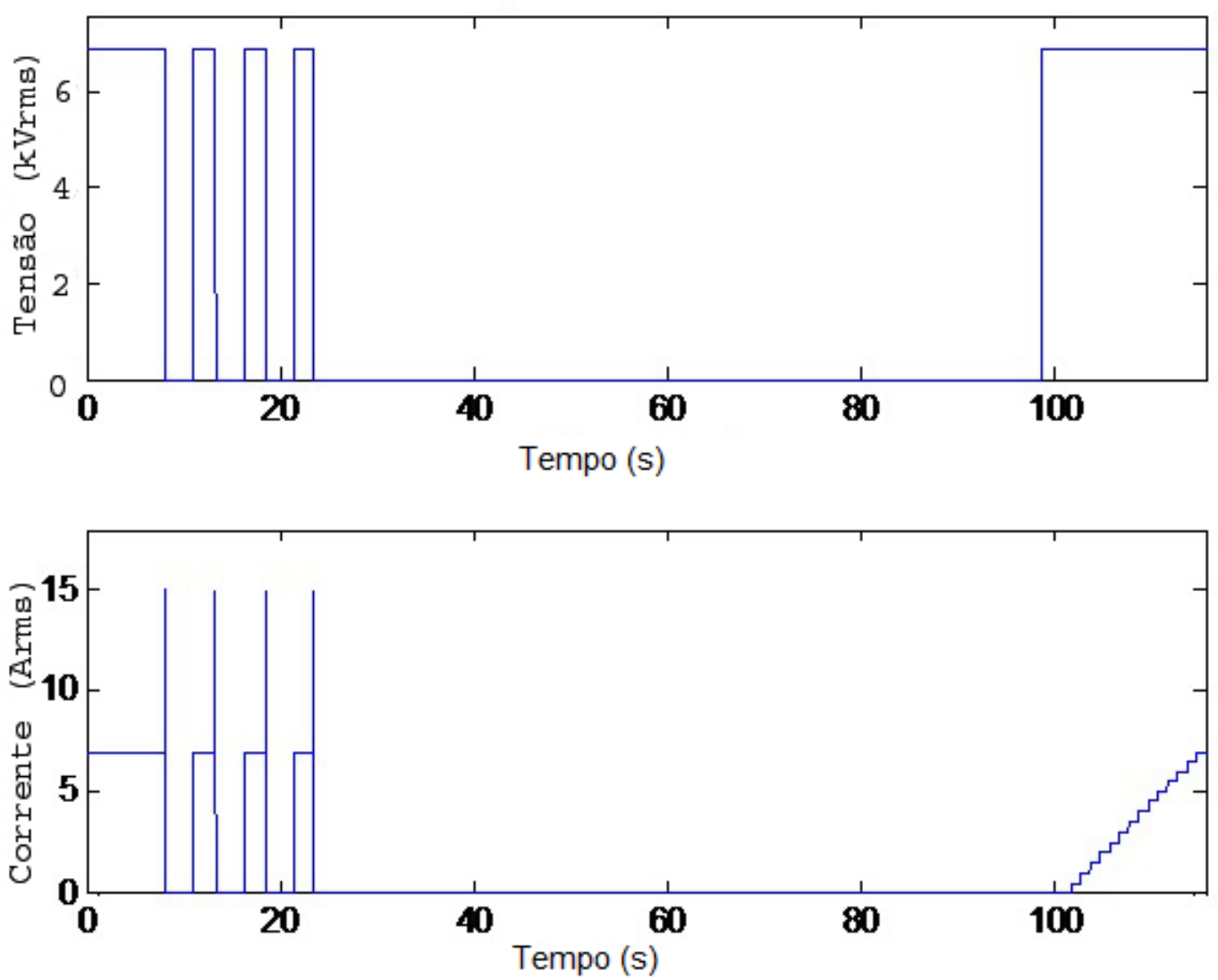

FIGURA 4.6 - Simulação de uma condição de falta e tentativas de religamento.

\subsection{Teste de Religamento com Sucesso}

Nesse teste são simuladas situações de falta com religamento do sistema de distribuição e sucesso na segunda tentativa. Os planos de testes utilizados foram quatro em seqüência. A rotina seqüencial é apresentada na Figura 4.7.

Tal teste refere-se à verificação com relação à atuação do indicador de falta sob uma condição de falta e religamento bem sucedido do sistema de proteção. $\mathrm{O}$ indicador de falta deve sensibilizar na ocorrência da primeira falta e, após o religamento do sistema de distribuição, o mesmo deve sinalizar a ocorrência de uma falta transitória e, para alguns casos, rearmar. 
Religamento com sucesso
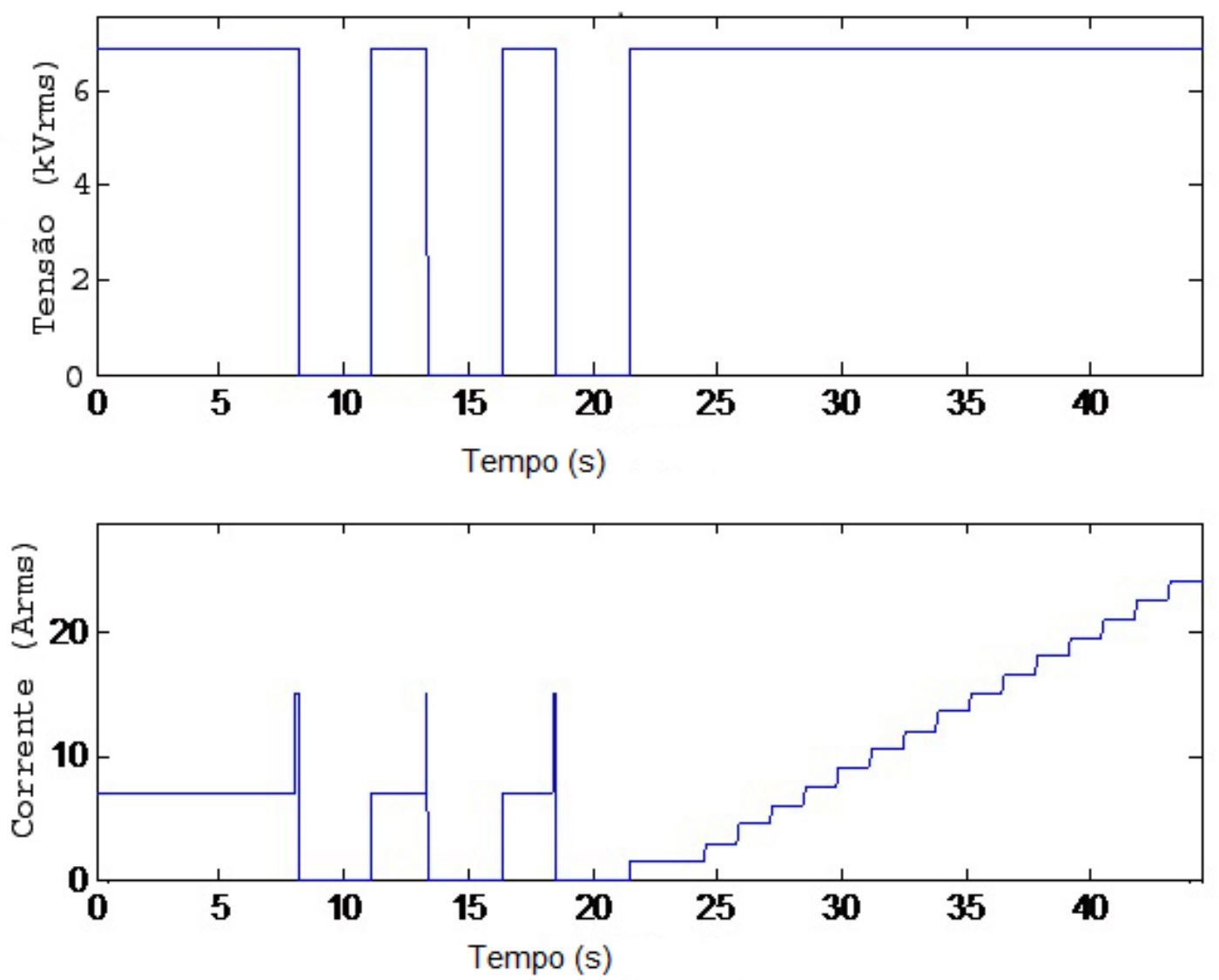

FIGURA 4.7 - Situação de falta com religamento bem sucedido.

\subsection{Arranjo Considerando Apenas Um Indicador de Faltas}

Em todas as situações de testes descritas nas seções anteriores foi preciso realizar variações nos arranjos dos indicadores de faltas posicionados na linha a fim de verificar o comportamento dos dispositivos, considerando-se ainda o mesmo ajuste ou ajustes diferenciados, visando determinar características construtivas capazes de contribuir para o funcionamento correto dos equipamentos.

O primeiro arranjo é o mais simples, sendo que há apenas um indicador na linha. Nesse arranjo devem ser verificados todos os testes de trip sob carga, evolução de carga e religamentos para todos os ajustes possíveis com a estrutura laboratorial disponível. Uma ilustração do ensaio desse arranjo pode ser conferida na Figura 4.8. 


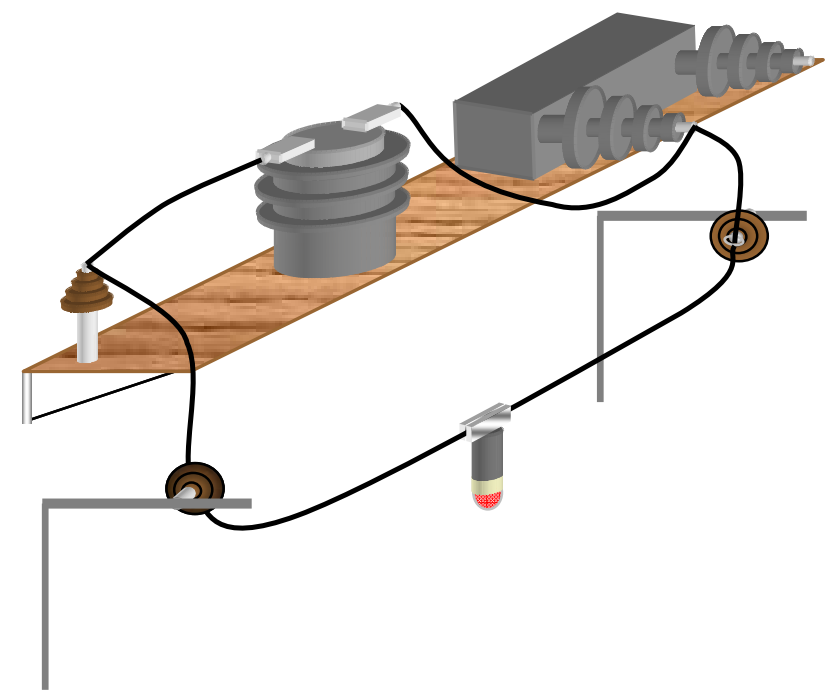

FIGURA 4.8 - Arranjo contendo apenas um indicador de faltas.

Os mesmos testes podem ser estendidos para arranjos envolvendo mais de um indicador de falta.

\subsection{Variação da Quantidade de Indicadores de Faltas}

Outra configuração refere-se à quantidade de indicadores de falta instalados. Esse teste serve para verificar se há influência no funcionamento entre os indicadores próximos. Duas variações desse arranjo podem ser investigadas. A primeira refere-se à instalação dos indicadores considerando uma distância entre os dispositivos e a outra variação coloca-se todos os indicadores juntos. Esses arranjos estão ilustrados na Figura 4.9.

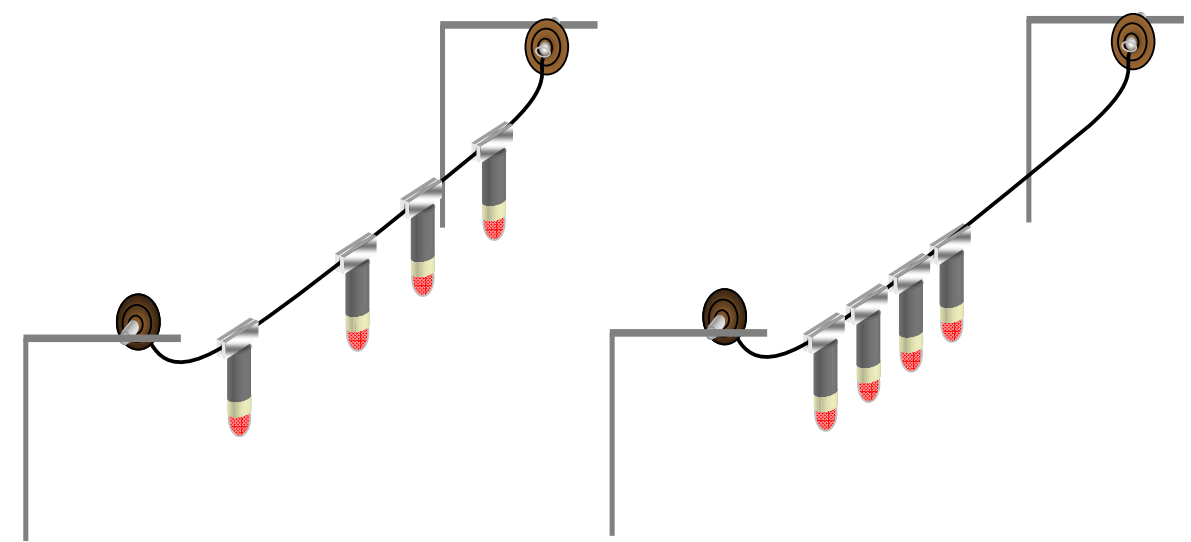

FIGURA 4.9 - Arranjo considerando vários indicadores de falta. 


\subsection{Variação do Ângulo de Instalação}

Outro arranjo interessante refere-se à posição angular de instalação dos indicadores de falta conforme ilustrado na Figura 4.10. Tal arranjo pode ser complementado considerando também os arranjos da Seção 4.7.

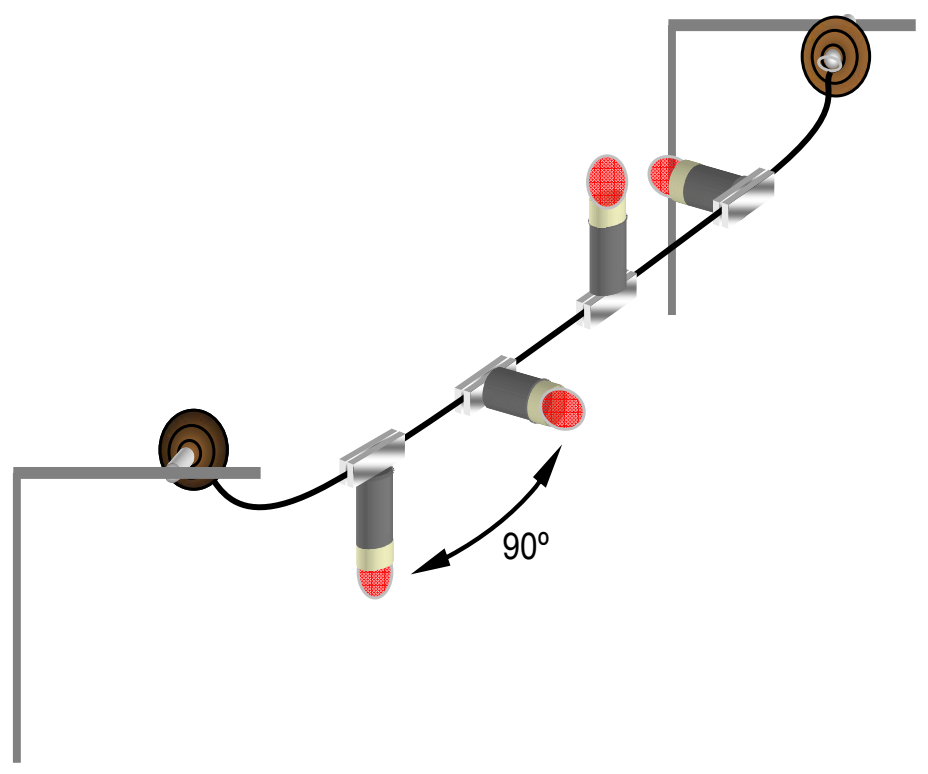

FIGURA 4.10 - Arranjo com variação no ângulo de instalação dos indicadores de falta.

\subsection{Indicador de Faltas do Tipo Poste}

Uma montagem que contempla os ensaios relativos aos indicadores de falta com instalação no poste pode ser observada na Figura 4.11. Para estes dispositivos deve-se considerar a distância de instalação em relação ao condutor da rede de distribuição. Diversos testes variando-se a distância de instalação devem ser realizados. Vale ressaltar também o estudo da influência de diversos indicadores de poste instalados juntos ao mesmo poste. 


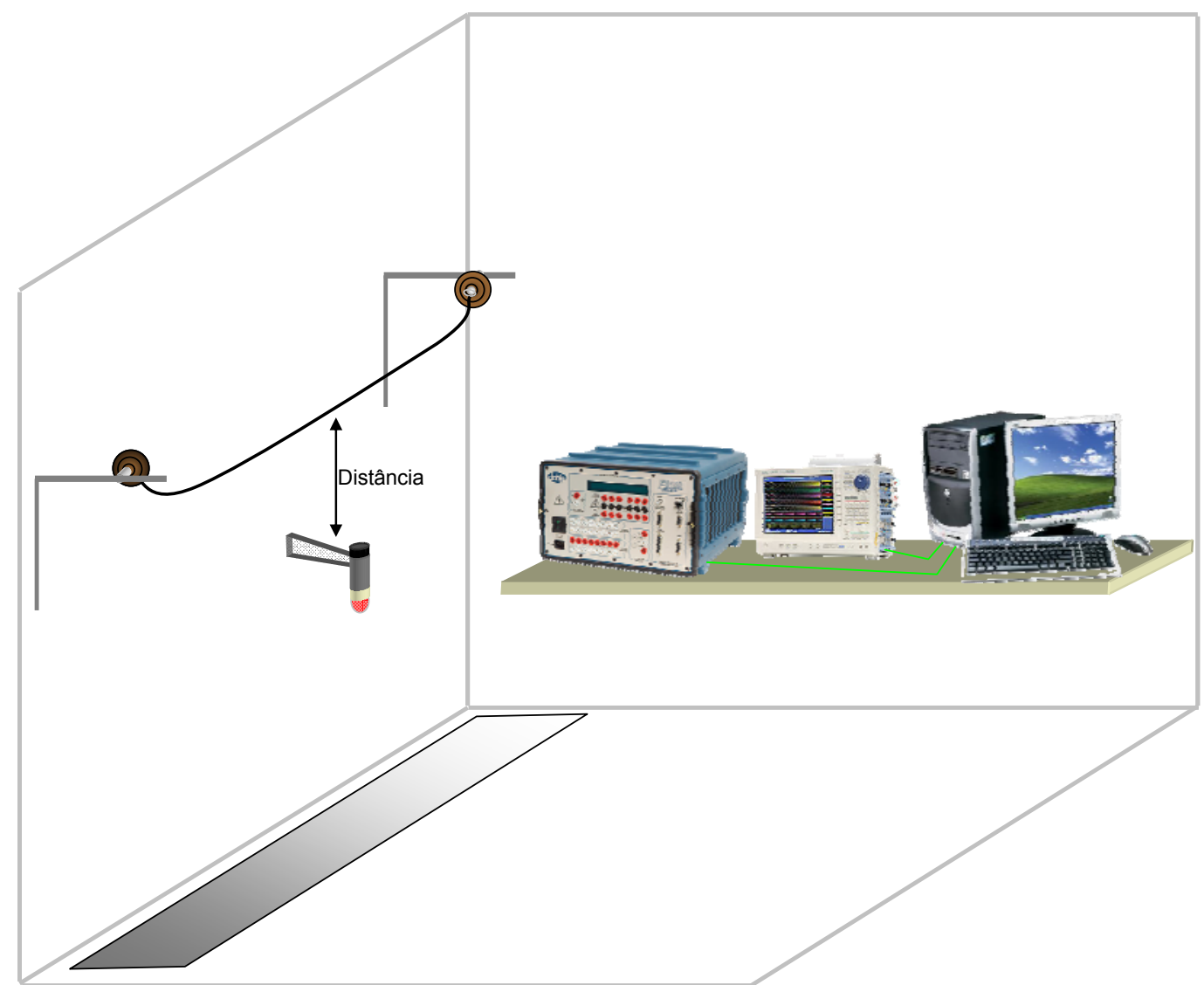

FIGURA 4.11 - Arranjo considerando o teste de indicadores de poste.

\subsection{Indicadores de Faltas Selecionados Para Teste Laboratorial}

Diversos indicadores de falta foram selecionados para os ensaios descritos nas seções anteriores. Tais dispositivos foram escolhidos contemplando fabricantes diferentes, modelos e aplicação. Cabe ressaltar que os indicadores de falta disponíveis para teste encontram-se distribuídos em quantidade proporcional aos instalados na rede de distribuição da Distribuidora. Há também modelos que a Distribuidora não utiliza, mas que serão avaliados frente às mesmas condições de testes dos modelos encontrados nos alimentadores da empresa.

A seguir serão apresentados os indicadores de faltas empregados nos ensaios em laboratório, juntamente com um breve descritivo. 


\subsubsection{Linetroll $110 \mathrm{E} \mu$}

Esse modelo é fabricado pela empresa Nortroll e consiste em um dispositivo de sinalização de curto-circuitos instalado diretamente no condutor de redes elétricas de distribuição com níveis de tensão entre 6 e 69kV.

O seu princípio de funcionamento consiste de sinalizar as condições de elevação rápida de corrente acima do valor configurado (di/dt) ou se exceder o valor do limiar de corrente ajustado pelo usuário. Na detecção de uma condição de falta, o dispositivo emite um sinal luminoso por meio de um conjunto de LED's. A sinalização de faltas transitórias é indicada por um LED verde. Três LED's vermelhos e um LED amarelo representam uma indicação de falta permanente. A Figura 4.12 apresenta uma foto do Linetroll 110E $\mu$.

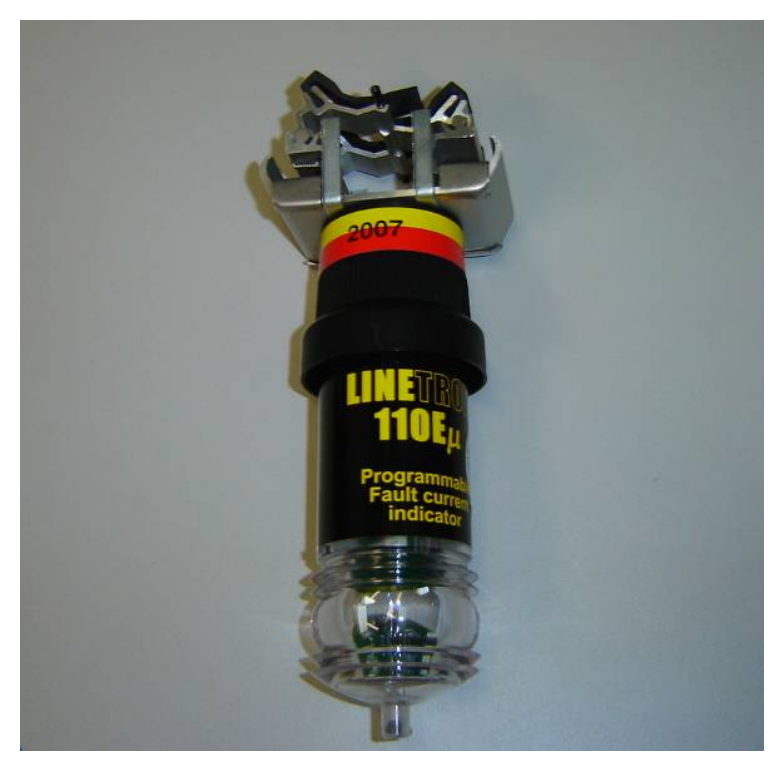

FIGURA 4.12 - Indicador de falta Linetroll 110E $\mu$.

Após a detecção de uma falta e a conseqüente desenergização da linha, a sinalização transitória será acionada. Se houver um religamento com sucesso, sustentando a tensão, o dispositivo continuará a sinalizar por um tempo programado (2, 6, 12 ou 24 horas). Por outro lado, se houver um religamento mal sucedido, ou 
sob falta, a sinalização transitória irá passar para permanente após 70 segundos em situação de falta permanente, e irá persistir até uma condição de rearme.

Outra possibilidade de rearme presente nesse modelo consiste no rearme manual por meio de um imã. Os parâmetros são programados através de um banco de 8 chaves, disponibilizados internamente no dispositivo, conforme pode ser observado na Figura 4.13, cujas características são descritas nas Tabelas 4.1 e 4.2. Para estar apto a reconhecer a passagem de correntes de falta o indicador $110 \mathrm{E} \mu$ necessita de um tempo mínimo de energização de 5 segundos.

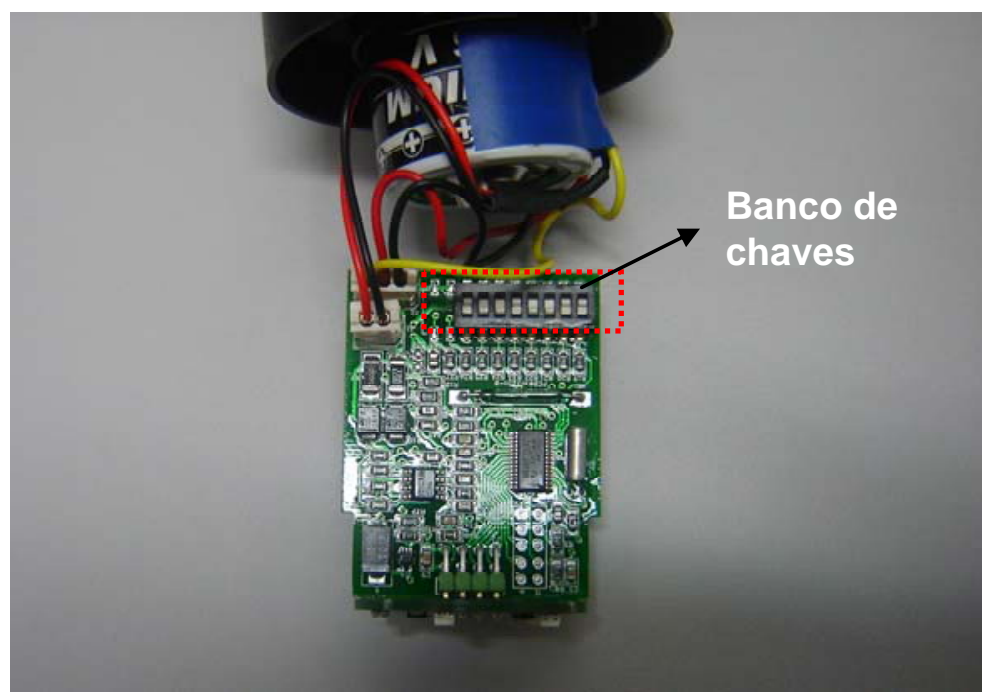

FIGURA 4.13 - Banco de chaves para programação do Linetroll $110 \mathrm{E} \mu$.

TABELA 4.1 - Resumo das características do Linetroll 110E $\mu$.

\begin{tabular}{|l|l|}
\hline \multicolumn{1}{|c|}{ Parâmetro } & \multicolumn{1}{c|}{ Especificação } \\
\hline Faixas de disparo de di/dt (A) & $6,12,25,60$ e 120 \\
\hline Limiar de corrente de falta (A) & $250,500,750$ e 1000 \\
\hline \multirow{2}{*}{ Tipo de Rearme } & $\begin{array}{l}\text { Manual (Imã) } \\
\text { Automático por Tensão } \\
\text { Automático por Tempo }\end{array}$ \\
\hline Sinalização & $\begin{array}{l}\text { Transitória (LED verde) } \\
\text { Permanente (LED verde e vermelho) }\end{array}$ \\
\hline Bateria & 2 Células de 3.6V 16,5Ah tipo kBB \\
\hline Tipo de Programação & 1 banco de 8 chaves \\
\hline & 1 - Linha energizada por pelo menos 5s \\
Condição de sinalização & 2- Variação extremamente rápida de corrente ou \\
& extrapolação do limiar de corrente \\
& $3-$ Linha desenergizada \\
\hline Bloqueio de InRush & Sim (5s) \\
\hline
\end{tabular}


TABELA 4.2 - Programação das chaves do Linetroll 110E $\mu$.

\begin{tabular}{|c|c|c|c|}
\hline Chaves & Descrição Funcional & \multicolumn{2}{|c|}{ Opções } \\
\hline \multirow{5}{*}{$\begin{array}{l}1 \\
2 \\
3 \\
8\end{array}$} & \multirow{5}{*}{ Faixas de di/dt } & $6 \mathrm{~A}$ & 0000 \\
\hline & & $12 \mathrm{~A}$ & 0010 \\
\hline & & $25 \mathrm{~A}$ & 0100 \\
\hline & & $60 \mathrm{~A}$ & 0110 \\
\hline & & $120 \mathrm{~A}$ & 0111 \\
\hline \multirow{4}{*}{$\begin{array}{l}1 \\
2 \\
3 \\
8\end{array}$} & \multirow{4}{*}{ Nível de limiar } & 250 & 1001 \\
\hline & & 500 & 1011 \\
\hline & & 750 & 1101 \\
\hline & & 1000 & 1111 \\
\hline \multirow{2}{*}{4} & \multirow{2}{*}{ Critério Inicialização / Parada } & Corrente & 0 \\
\hline & & Tensão & 1 \\
\hline \multirow{4}{*}{5} & \multirow{4}{*}{ Limiar de corrente de falta } & 2horas & 00 \\
\hline & & 6horas & 01 \\
\hline & & 12horas & 10 \\
\hline & & 24horas & 11 \\
\hline \multirow{2}{*}{7} & \multirow{2}{*}{ Rearme automático } & Desligado & 0 \\
\hline & & Ligado & 1 \\
\hline
\end{tabular}

Para os indicadores de cabo da Linetroll $110 \mathrm{E} \mu$ foram escolhidos 9 unidades para ensaios, conforme mostra a Tabela 4.3.

TABELA 4.3 - Indicadores de Falta Linetroll 110E $\mu$.

\begin{tabular}{|c|c|c|c|}
\hline Número & Fabricante & Modelo & $\mathbf{N}^{\mathbf{o}}$ de série \\
\hline 1 & Linetroll & $110 \mathrm{E} \mu$ & xxxxx69 \\
\hline 2 & Linetroll & $110 \mathrm{E} \mu$ & 5620801489 \\
\hline 3 & Linetroll & $110 \mathrm{E} \mu$ & 5620801473 \\
\hline 4 & Linetroll & $110 \mathrm{E} \mu$ & 5620801410 \\
\hline 5 & Linetroll & $110 \mathrm{E} \mu$ & 5620801443 \\
\hline 6 & Linetroll & $110 \mathrm{E} \mu$ & 5620801304 \\
\hline 7 & Linetroll & $110 \mathrm{E} \mu$ & 5620801466 \\
\hline 8 & Linetroll & $110 \mathrm{E} \mu$ & 5620801479 \\
\hline 9 & Linetroll & $110 \mathrm{E} \mu$ & 5620801405 \\
\hline
\end{tabular}

O primeiro teste a ser aplicado no Linetroll $110 \mathrm{E} \mu$ é o de evolução de carga, com os parâmetros mostrados na Tabela 4.4. Este teste é composto de apenas uma Macro, denominada Sec01, do tipo LRAMPI.

TABELA 4.4 - Parâmetros do Teste 1 - Evolução de Carga - Linetroll 110E $\mu$.

\begin{tabular}{|c|c|}
\hline Seqüência & Parâmetros \\
\hline Sec01 - LRAMPI & $\begin{array}{l}\text { Prefault: } V a=V b=V c=69 V, I=0 A \text {, Fase }=0 \text { e } t=600 \text { ciclos } \\
V a=V b=V c=69 V \text { e I }=A C T I O N \\
A=0 ; B=180 ; C=0.6 ; D=300 ; E=22.5 ;\end{array}$ \\
\hline Duração total & 3.3 minutos \\
\hline
\end{tabular}


Na Figura 4.14 encontram-se registrados os valores de tensão e corrente eficazes que serão apresentados ao Linetroll $110 \mathrm{E} \mu$.
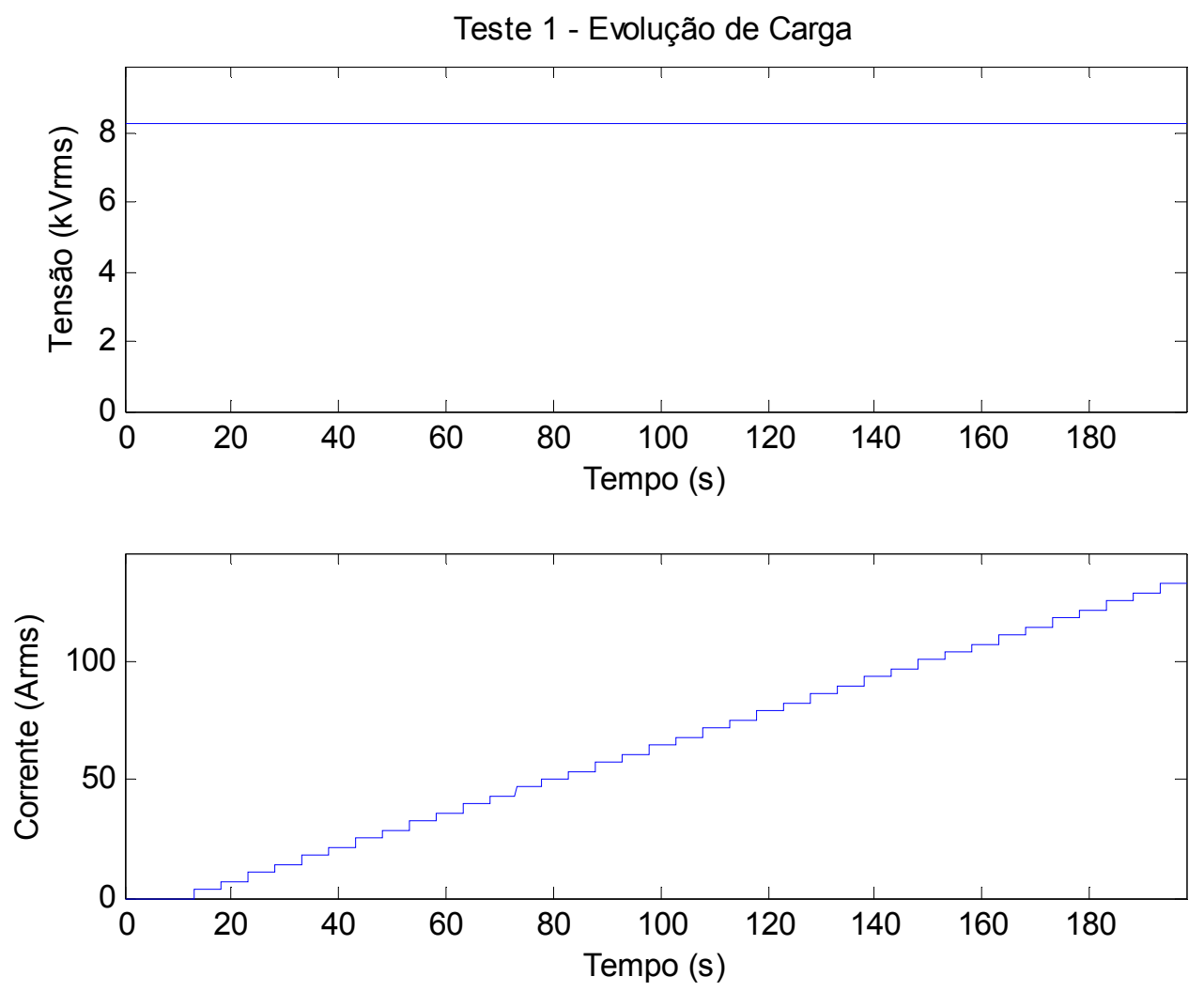

FIGURA 4.14 - Teste 1 - Evolução de Carga para o Linetroll 110E $\mu$.

$\mathrm{Na}$ Tabela 4.5 encontram-se os parâmetros para o teste de correntes pulsadas e, na Figura 4.15, os respectivos valores de tensão e corrente eficazes aplicados no Linetroll $110 \mathrm{E}_{\mu}$. Este teste também é formado por uma única Macro, do tipo PRAMPI.

TABELA 4.5 - Parâmetros do Teste 2 - Correntes Pulsadas - Linetroll 110E $\mu$.

\begin{tabular}{|c|c|}
\hline Seqüência & Parâmetros \\
\hline Sec01 - PRAMPI & $\begin{array}{l}\text { Prefault: } V a=V b=V c=69 V, I=0 A, \text { Fase }=0 \text { e } t=600 \text { ciclos } \\
V a=V b=V c=69 V \text { e I }=A C T I O N \\
A=0 ; B=360 ; C=1.2 ; D=3 ; E=120 ; F=1.2 ; G=22.5 ;\end{array}$ \\
\hline Duração total & 0.88 minutos \\
\hline
\end{tabular}



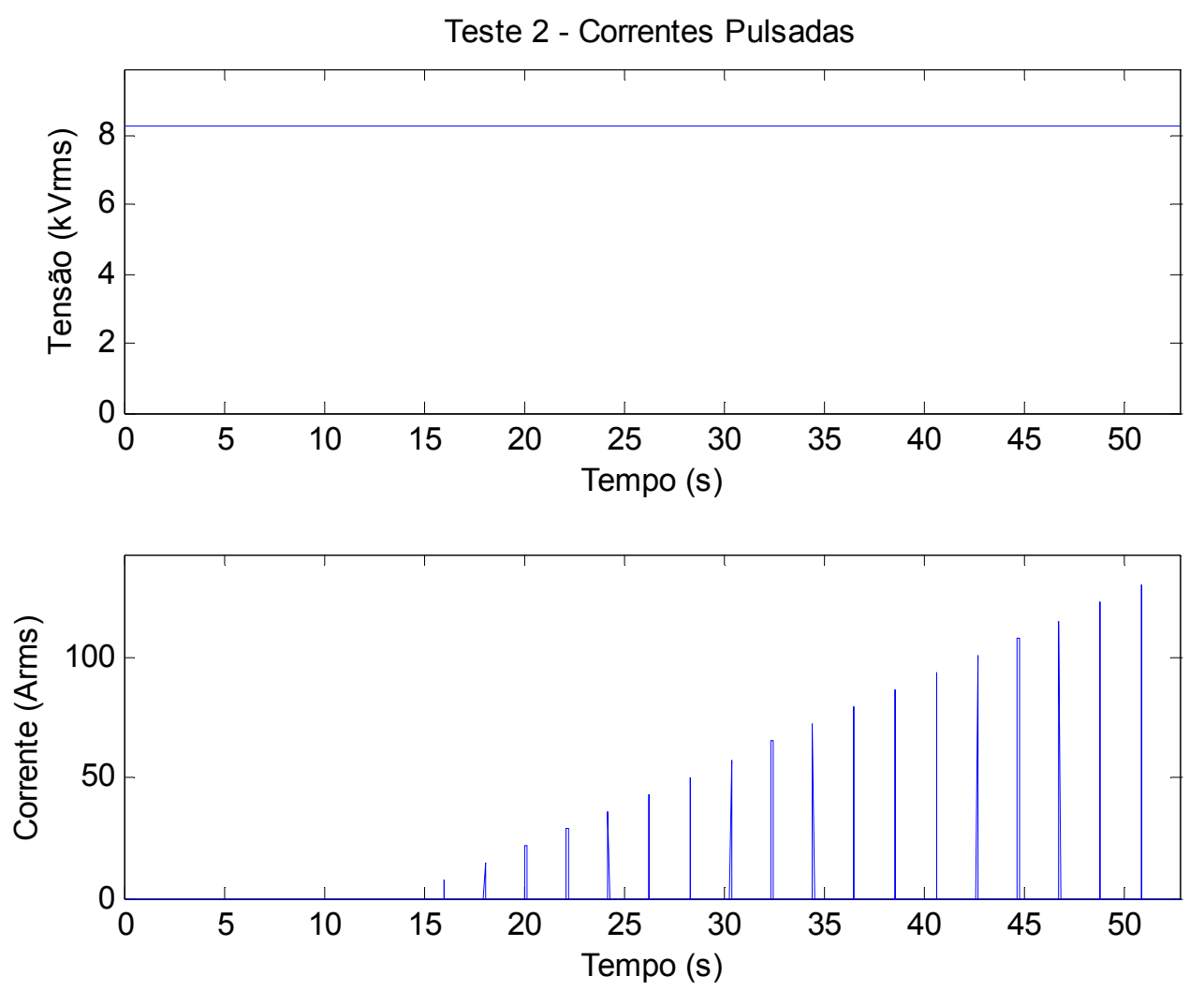

FIGURA 4.15 - Teste 2 - Correntes Pulsadas para o Linetroll $110 \mathrm{E} \mu$.

Os Testes 3 e 4, relacionados com a simulação de correntes de falta e desligamentos da linha, são mais elaborados e por isso utilizam mais de uma seqüência de Macros. O Teste 3 (Religamento Sem Sucesso) utiliza 5 seqüências, sendo as 4 primeiras PRAMPI e a última LRAMPI. Já o Teste 4 (Religamento Com Sucesso) utiliza 4 seqüências, sendo as 3 primeiras PRAMPI e a última LRAMPI. Na Tabela 4.6 e na Figura 4.16 encontram-se as informações a respeito do Teste 3 , sendo que na Tabela 4.7 e Figura 4.17 encontram-se as informações referentes ao Teste 4. 
TABELA 4.6 - Parâmetros do Teste 3 - Religamento Sem Sucesso - Linetroll 110E $\mu$.

\begin{tabular}{|c|c|}
\hline Seqüência & Parâmetros \\
\hline Sec01 - PRAMPI & $\begin{array}{l}\text { Prefault:Va=Vb=Vc=69V, I }=7 A \text {, Fase }=0 \text { e } t=360 \text { ciclos } \\
V a=V b=V c=69 V \text { e I = ACTION } \\
A=7 ; B=20 ; C=7 ; D=5 ; E=0 ; \quad F=8 ; G=15 ;\end{array}$ \\
\hline Sec02 - PRAMPI & $\begin{array}{l}\text { Prefault: } V a=V b=V c=0 V, I=0 A, \text { Fase }=0 \text { e } t=180 \text { ciclos } \\
V a=V b=V c=69 V \text { e } I=A C T I O N \\
A=7 ; B=120 ; C=7 ; D=5 ; E=0 ; F=8 ; G=15\end{array}$ \\
\hline Sec03 - PRAMPI & $\begin{array}{l}\text { Prefault:Va=Vb=Vc=0V, I =0A, Fase }=0 \text { e } t=180 \text { ciclos } \\
V a=V b=V c=69 V \text { e I }=A C T I O N \\
A=7 ; B=120 ; C=7 ; D=5 ; E=0 ; F=8 ; G=15 ;\end{array}$ \\
\hline Sec04 - PRAMPI & $\begin{array}{l}\text { Prefault: } V a=V b=V c=0 V, I=0 A, \text { Fase }=0 \text { e } t=180 \text { ciclos } \\
V a=V b=V c=69 V \text { e } I=A C T I O N \\
A=7 ; B=120 ; C=7 ; D=5 ; E=0 ; F=8 ; G=15\end{array}$ \\
\hline Sec05 - LRAMPI & $\begin{array}{l}\text { Prefault: } V a=V b=V c=0 V, I=0 A, \text { Fase }=0 \text { e } t=4500 \text { ciclos } \\
V a=V b=V c=69 V \text { e } I=A C T I O N \\
A=0 ; B=120 ; C=0.5 ; D=300 ; E=7 ;\end{array}$ \\
\hline Duração total & 2.82 minutos \\
\hline
\end{tabular}

Teste 3 - Religamento Sem Sucesso
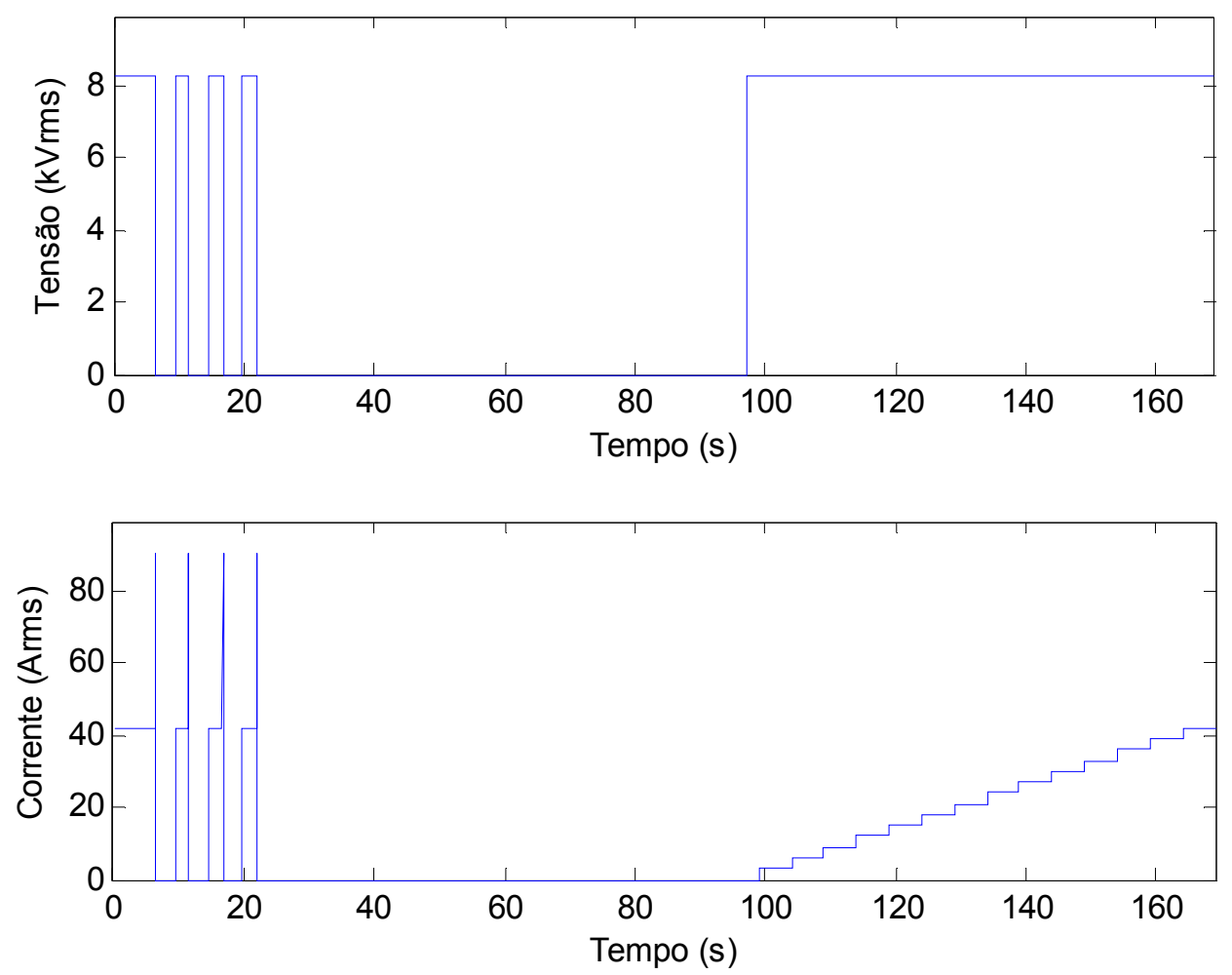

FIGURA 4.16 - Teste 3 - Religamento Sem Sucesso - Linetroll 110E $\mu$. 
TABELA 4.7 - Parâmetros do Teste 4 - Religamento Com Sucesso - Linetroll 110E $\mu$.

\begin{tabular}{|c|c|}
\hline Seqüência & Parâmetros \\
\hline Sec01 - PRAMPI & $\begin{array}{l}\text { Prefault: } V a=V b=V c=69 V, I=7 A \text {, Fase }=0 \text { e } t=1900 \text { ciclos } \\
V a=V b=V c=69 V \text { e } I=A C T I O N \\
A=7 ; B=120 ; C=7 ; D=5 ; E=0 ; F=8 ; G=15 ;\end{array}$ \\
\hline Sec02 - PRAMPI & $\begin{array}{l}\text { Prefault: } V a=V b=V c=0 V, I=0 A, \text { Fase }=0 \text { e } t=180 \text { ciclos } \\
V a=V b=V c=69 V \text { e } I=A C T I O N \\
A=7 ; B=120 ; C=7 ; D=5 ; E=0 ; F=8 ; G=15 ;\end{array}$ \\
\hline Sec03 - PRAMPI & $\begin{array}{l}\text { Prefault: } V a=V b=V c=0 V, I=0 A, \text { Fase }=0 \text { e } t=180 \text { ciclos } \\
V a=V b=V c=69 V \text { e I }=A C T I O N \\
A=7 ; B=120 ; C=7 ; D=5 ; E=0 ; F=8 ; G=15 ;\end{array}$ \\
\hline Sec04 - LRAMPI & $\begin{array}{l}\text { Prefault: } V a=V b=V c=0 V, I=0 A, \text { Fase }=0 \text { e } t=180 \text { ciclos } \\
V a=V b=V c=69 V \text { e } I=A C T I O N \\
A=1.5 ; B=180 ; C=0.5 ; D=80 ; E=22.5 ;\end{array}$ \\
\hline Duração total & 1.77 minutos \\
\hline
\end{tabular}

Teste 4 - Religamento Com Sucesso
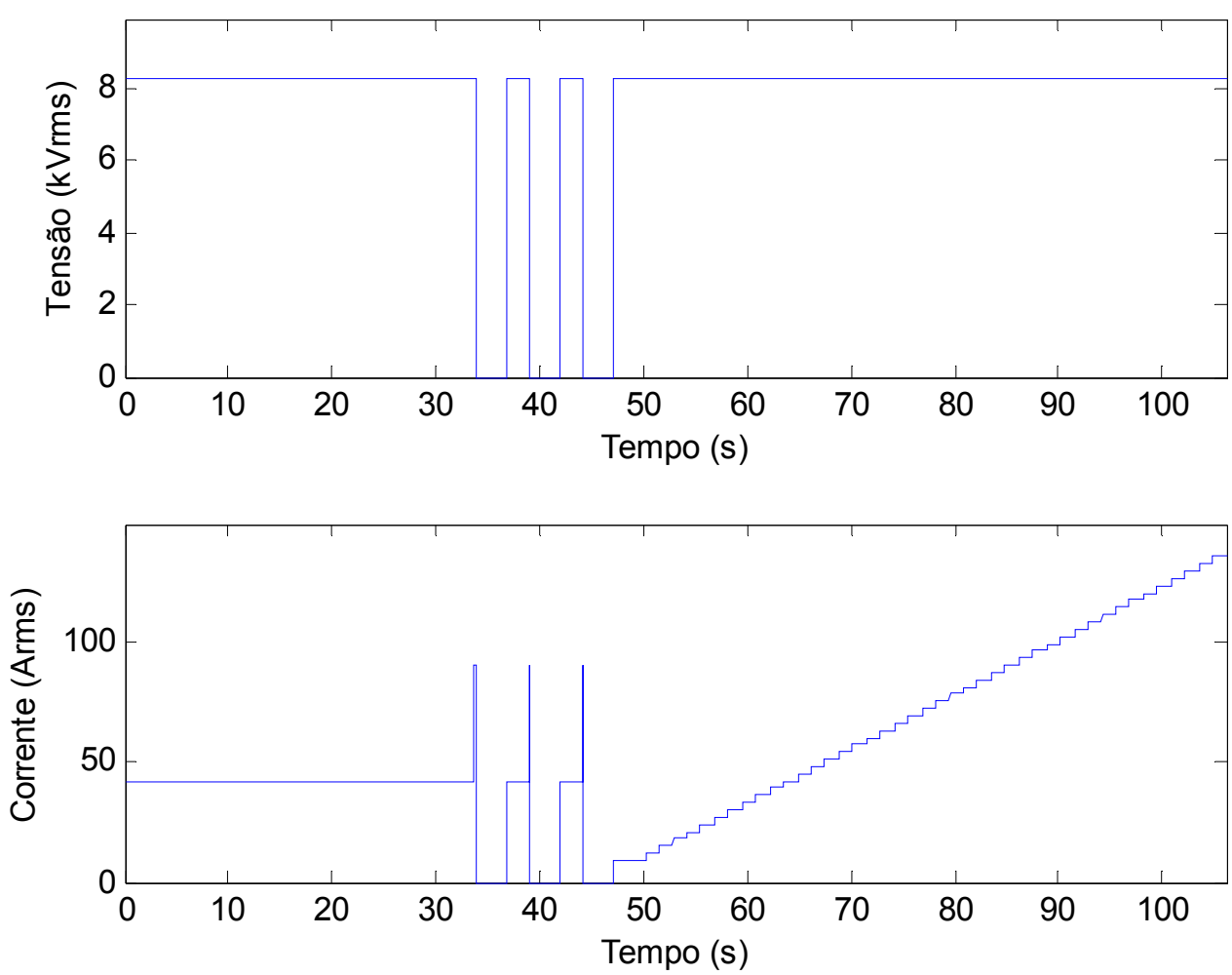

FIGURA 4.17 - Teste 4 - Religamento Com Sucesso - Linetroll 110E $\mu$.

\subsubsection{Linetroll $111 \mathrm{k}$}

O modelo $111 \mathrm{k}$ é instalado em postes e seu funcionamento consiste no monitoramento das três fases simultaneamente, por meio de sensores que acompanham a variação do campo magnético abaixo dos condutores. Este dispositivo também é capaz de atuar de acordo com o limiar de corrente de falta. A 
sinalização é feita por meio de LED’s de alta intensidade e também por uma lâmpada de gás Xenon. A sinalização de faltas é realizada por dois modos diferentes, programados pelo usuário, sendo que no primeiro o IF indica falta permanente por meio da lâmpada de gás-xenon e falta transitória através do LED. No segundo modo, o LED pisca até a linha ser reenergizada ou por um período de 24 horas. Esse último modo tem um baixíssimo consumo de energia. Na Figura 4.18 é possível visualizar o Linetroll 111k.

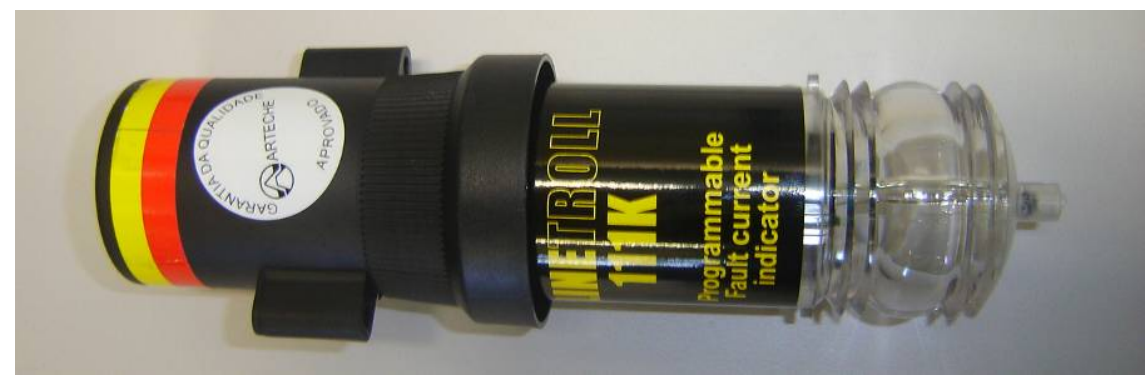

FIGURA 4.18 - Linetroll 111k.

Após a detecção de uma falta e a conseqüente desernegização da linha, a sinalização transitória será acionada instantaneamente ou após 5 segundos com a linha desligada.

Mediante um religamento com sucesso, sustentando a tensão por pelo pelos 15 ou 30 segundos, a sinalização de uma falta transitória será mantida de acordo com o tempo para sinalizar faltas permanentes, previamente programado. No caso de um religamento mal sucedido, ou sob falta, a sinalização transitória irá passar para permanente com o decorrer do tempo programado, e irá persistir até uma condição de rearme.

Por meio do mecanismo de sinalização é também disponibilizado uma das formas de rearme do Linetroll $111 \mathrm{k}$, sendo este o rearme manual, que é realizado aproximando-se um imã no ponto de reset. 
Este indicador conta ainda com rearme automático por tensão, após 15 ou 30 segundos de linha energizada e também por tempo, com as opções de $1 \mathrm{~h} 30,3 \mathrm{~h}$, $6 \mathrm{~h}$ e $12 \mathrm{~h}$. Os parâmetros de rearme e outros itens podem ser programados através de 1 banco de chaves, disponibilizados na extremidade oposta àquela de sinalização, conforme pode ser observado na Figura 4.19.

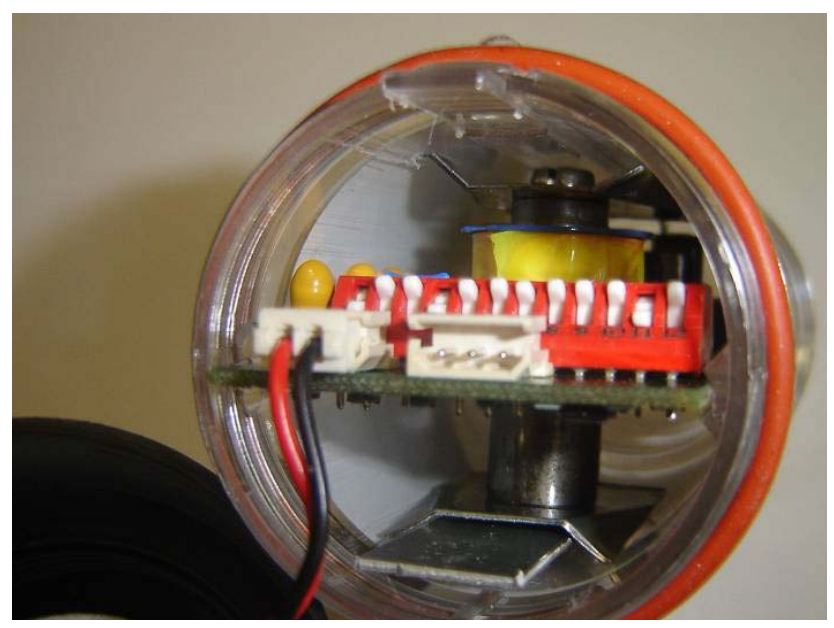

FIGURA 4.19 - Banco de chaves de programação do Linetroll 111k.

Para estar apto a reconhecer a passagem de correntes de falta, o Linetroll 111k necessita de um tempo mínimo de energização de 5 segundos. Durante esse tempo o mesmo permanece em bloqueio. O posicionamento deste modelo de indicador no poste deve ser realizado por centralizar as três fases, com uma distância que pode ser de 3, 4 ou 5 metros, dependendo da relação entre a corrente de carga e a corrente de disparo.

A Tabela 4.8 condensa as principais características do Linetroll $111 \mathrm{k}$. 
TABELA 4.8 - Principais características do Linetroll 111k.

\begin{tabular}{|l|l|}
\hline \multicolumn{1}{|c|}{ Parâmetro } & \multicolumn{1}{c|}{ Especificação } \\
\hline Faixas de disparo de di/dt (A) & $4,7,15$ e 50 \\
\hline Tipo de Rearme & $\begin{array}{l}\text { Manual (imã) } \\
\text { Automático por Tensão (15s / 30s) } \\
\text { Automático por Tempo (1h30, 3h, 6h, 12h) }\end{array}$ \\
\hline Sinalização & $\begin{array}{l}\text { Transitória (1 LED verde) } \\
\text { Permanente (Lâmpada Gás-Xenon e LED verde) }\end{array}$ \\
\hline Bateria & 1 Célula de 3.6V \\
\hline Tipo de Programação & 1 banco de 12 chaves \\
\hline Condição de sinalização & $\begin{array}{l}\text { 1- Linha energizada por pelo menos 3s } \\
\text { 2- Aumento da corrente de linha de no mínimo 100\% } \\
\text { por 20ms e chegando a um nível que excede o } \\
\text { nível de trip programado }\end{array}$ \\
& $\begin{array}{l}\text { 3- Tripping de disjuntor dentro de um período de } 5 \\
\text { segundos após a falta. }\end{array}$ \\
\hline Bloqueio de InRush & Sim (3s) \\
\hline
\end{tabular}

A programação das chaves procede de acordo com a tabela a seguir.

TABELA 4.9 - Programação do Linetrol 111k.

\begin{tabular}{|c|c|c|c|}
\hline Chaves & Descrição Funcional & \multicolumn{2}{|c|}{ Opções } \\
\hline \multirow{4}{*}{$\begin{array}{l}1 \\
2 \\
3\end{array}$} & \multirow{4}{*}{ Sensibilidade } & $4 \mathrm{~A}$ & 100 \\
\hline & & $7 \mathrm{~A}$ & 010 \\
\hline & & $15 \mathrm{~A}$ & 001 \\
\hline & & $50 \mathrm{~A}$ & 000 \\
\hline 4 & \multirow{4}{*}{ Rearme por tempo } & $1,5 \mathrm{~h}$ & 1000 \\
\hline 5 & & $3 \mathrm{~h}$ & 0100 \\
\hline 6 & & $6 \mathrm{~h}$ & 0010 \\
\hline 7 & & $12 \mathrm{~h}$ & 0001 \\
\hline \multirow{2}{*}{8} & \multirow{2}{*}{ Sinalização por trip do disjuntor } & Desabilitado & 0 \\
\hline & & Habilitado & 1 \\
\hline \multirow{3}{*}{$\begin{array}{c}9 \\
10\end{array}$} & \multirow{3}{*}{ Rearme por Tensão } & Desabilitado & 00 \\
\hline & & $15 \mathrm{~s}$ & 11 \\
\hline & & $30 \mathrm{~s}$ & 10 \\
\hline \multirow{2}{*}{$\begin{array}{l}11 \\
12\end{array}$} & \multirow{2}{*}{ Funções do led } & Modo 1 & 01 \\
\hline & & Modo 2 & 10 \\
\hline
\end{tabular}

Foram empregados os mesmos parâmetros adotados nas rotinas de teste do Linetroll $110 \mathrm{E} \mu$ para os testes do Linetroll $111 \mathrm{k}$.

\subsubsection{Linetroll 3100}

Este modelo é empregado em postes e monitora as três fases simultaneamente, por meio de sensores que acompanham a variação do campo 
magnético entre os condutores, em busca de desbalanços típicos provocados por situações de falta, principalmente com a rápida variação da corrente (di/dt). Este indicador também está apto a atuar de acordo com o limiar de corrente de falta. A sinalização é feita com 5 LED's de alto brilho de cor vermelha, sendo que na ocorrência de uma falta transitória, inicialmente 1 LED sinaliza, passando para 3 LED's posteriormente. A sinalização com os 5 LED's ocorre quando uma falta permanente é detectada. Na Figura 4.20 é possível visualizar o sistema de alimentação do Linetroll 3100, formado por duas baterias de $3.6 \mathrm{~V}$ e também o mecanismo de sinalização.

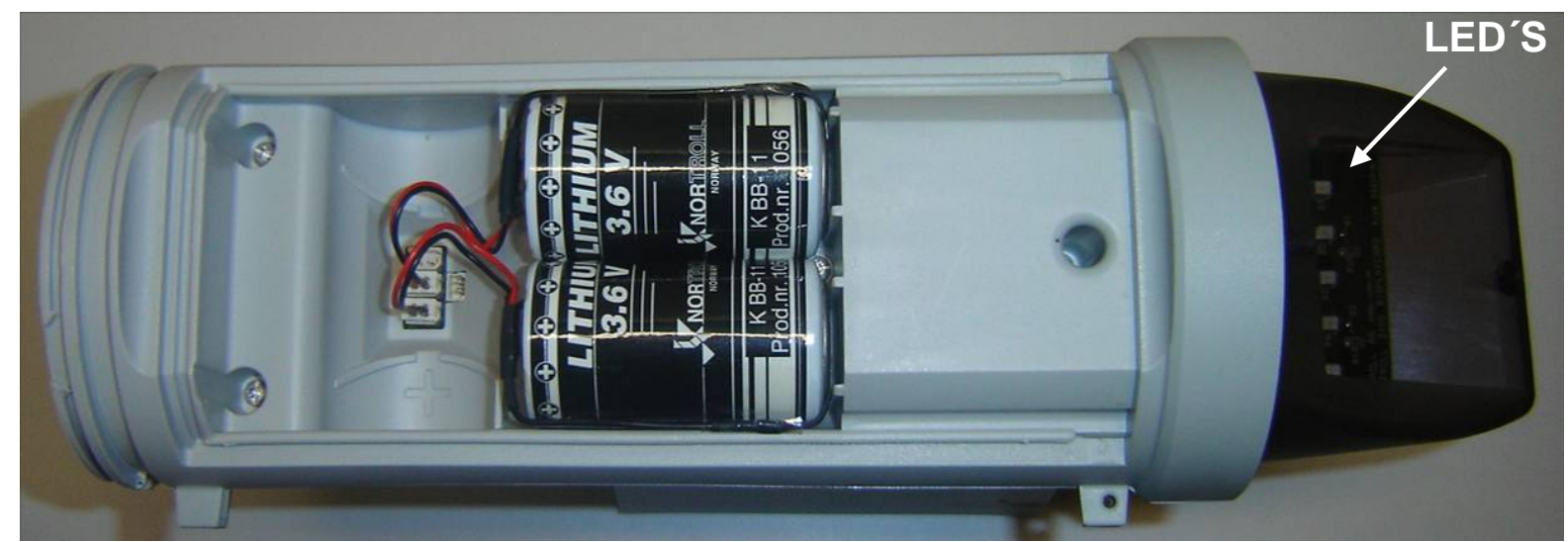

FIGURA 4.20 - Linetroll 3100.

A lente de sinalização pode ser rotacionada para melhorar a visibilidade, de acordo com as facilidades de acesso ao local de instalação.

Após a detecção de uma falta e a conseqüente desernegização da linha, a sinalização transitória será acionada. Mediante um religamento com sucesso, sustentando a tensão por pelo pelos 15 ou 30 segundos, a sinalização de uma falta transitória será mantida de acordo com o tempo para sinalizar faltas permanentes, reviamente programado. Esta medida visa auxiliar a equipe de inspeção na identificação de eventos geradores de faltas na rede. No caso de um religamento 
mal sucedido, ou sob falta, a sinalização transitória irá passar para permanente com o decorrer do tempo programado, e irá persistir até uma condição de RESET.

Por meio do mecanismo de sinalização é também disponibilizado uma das formas de rearme do Linetroll 3100, sendo este o RESET manual, que é realizado girando-se a base de sinalização no sentido horário. Girando-se esta base no sentido oposto é possível realizar o autoteste do sistema de sinalização.

Este indicador conta ainda com rearme automático por tensão, após 15 ou 30 segundos de linha energizada e também por tempo, com as opções de $1 \mathrm{~h} 30$, 3h, $6 \mathrm{~h}$ e $12 \mathrm{~h}$. Os parâmetros de rearme e outros itens podem ser programados por meio de 3 bancos de chaves, disponibilizados na extremidade oposta a de sinalização, conforme pode ser observado na Figura 4.21.

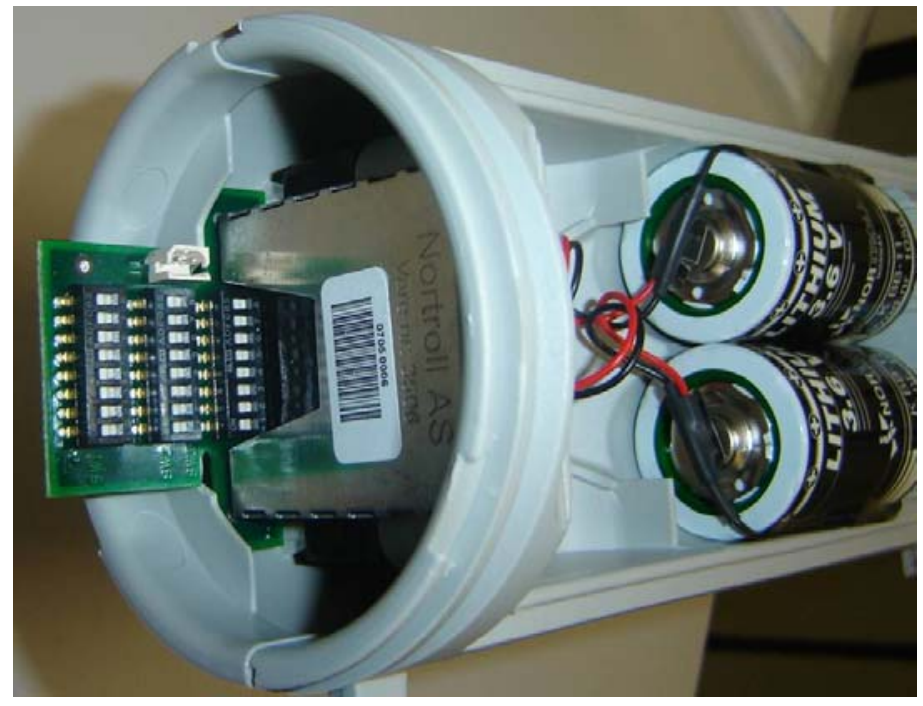

FIGURA 4.21- Banco de chaves de programação do Linetroll 3100.

Para estar apto a reconhecer a passagem de correntes de falta, o 3100 necessita de um tempo mínimo de energização de 5 segundos. O posicionamento deste modelo de indicador no poste deve ser realizado por centralizar as três fases, com uma distância que pode ser de 3, 4 ou 5 metros, dependendo da relação entre a corrente de carga e a corrente de disparo. 
A Tabela 4.10 condensa as principais características do Linetroll 3100.

TABELA 4.10 - Principais características do Linetroll 3100.

\begin{tabular}{|l|l|}
\hline \multicolumn{1}{|c|}{ Parâmetro } & \multicolumn{1}{c|}{ Especificação } \\
\hline Faixas de disparo de di/dt (A) & $4,7,15$ e 50 \\
\hline Limiar de corrente de falta (A) & $100,200,500$ e 1000 \\
\hline \multirow{2}{*}{ Tipo de Rearme } & $\begin{array}{l}\text { Manual (Giro da base no sentido horário) } \\
\text { Automático por Tensão (15s / 30s) } \\
\text { Automático por Tempo (1h30, 3h, 6h, 12h) }\end{array}$ \\
\hline Sinalização & $\begin{array}{l}\text { Transitória (3 LED's vermelhos) } \\
\text { Permanente (5 LED's vermelhos) }\end{array}$ \\
\hline Bateria & 2 Células de 3.6V \\
\hline Tipo de Programação & 3 bancos de chaves \\
\hline \multirow{3}{*}{ Condição de sinalização } & 1 - Linha energizada por pelo menos 5s \\
& 2-Variação extremamente rápida de corrente \\
& 3- Linha desenergizada \\
\hline Bloqueio de InRush & Sim (5s) \\
\hline
\end{tabular}

A programação dos três bancos de chaves procede de acordo com as tabelas a seguir.

TABELA 4.11 - Programação do Linetrol 3100 (banco de chaves SW1).

\begin{tabular}{|c|c|c|c|}
\hline Chaves & Descrição Funcional & \multicolumn{2}{|c|}{ Opções } \\
\hline \multirow{2}{*}{1} & \multirow{2}{*}{ Tempo de religamento } & $1 \mathrm{~s}$ & 0 \\
\hline & & $3 \mathrm{~s}$ & 1 \\
\hline \multirow{4}{*}{2} & \multirow{4}{*}{ Faixas de di/dt } & $4 \mathrm{~A}$ & 00 \\
\hline & & $7 A$ & 01 \\
\hline & & $15 \mathrm{~A}$ & 10 \\
\hline & & $50 \mathrm{~A}$ & 11 \\
\hline \multirow{2}{*}{4} & \multirow{2}{*}{$\begin{array}{l}\text { Incremento relativo de corrente } \\
\text { de falta }\end{array}$} & $100 \%$ & 0 \\
\hline & & $200 \%$ & 1 \\
\hline \multirow{4}{*}{5} & \multirow{4}{*}{ Limiar de corrente de falta } & $100 \mathrm{~A}$ & 00 \\
\hline & & $200 \mathrm{~A}$ & 01 \\
\hline & & $500 \mathrm{~A}$ & 10 \\
\hline & & $1000 \mathrm{~A}$ & 11 \\
\hline \multirow{2}{*}{7} & \multirow{2}{*}{$\begin{array}{l}\text { Janela de tempo para } \\
\text { sensibilizar faltas fase-terra }\end{array}$} & $60 \mathrm{~ms}$ & 0 \\
\hline & & $120 \mathrm{~ms}$ & 1 \\
\hline \multirow{2}{*}{8} & \multirow{2}{*}{$\begin{array}{l}\text { Janela de tempo para } \\
\text { sensibilizar faltas trifásicas }\end{array}$} & $60 \mathrm{~ms}$ & 0 \\
\hline & & $120 \mathrm{~ms}$ & 1 \\
\hline
\end{tabular}


Previamente programado na fábrica, o RTA-A espera 6h para interromper com a sinalização de faltas, realizada através de dois LED's de alto brilho na cor vermelha, quando a linha não é energizada. O tempo de rearme pode ser de 1 hora a 12 horas, de acordo com o lote solicitado ao fabricante.

Para a realização do disparo da sinalização, o RTA-A precisa ser sensibilizado por uma variação de 30 A sustentada por 10 ciclos (167 ms), seguido de uma desnergização do sistema. Caso seja detectada uma variação desta magnitude e a linha não seja desenergizada, a sinalização irá funcionar por um tempo, mas logo o indicador irá se rearmar de forma automática devido a presença de tensão na linha.

Uma característica muito peculiar deste modelo é que mesmo sendo o encapsulamento do circuito totalmente fechado, as baterias ficam expostas ao ambiente, como pode ser observado na Figura 4.22.
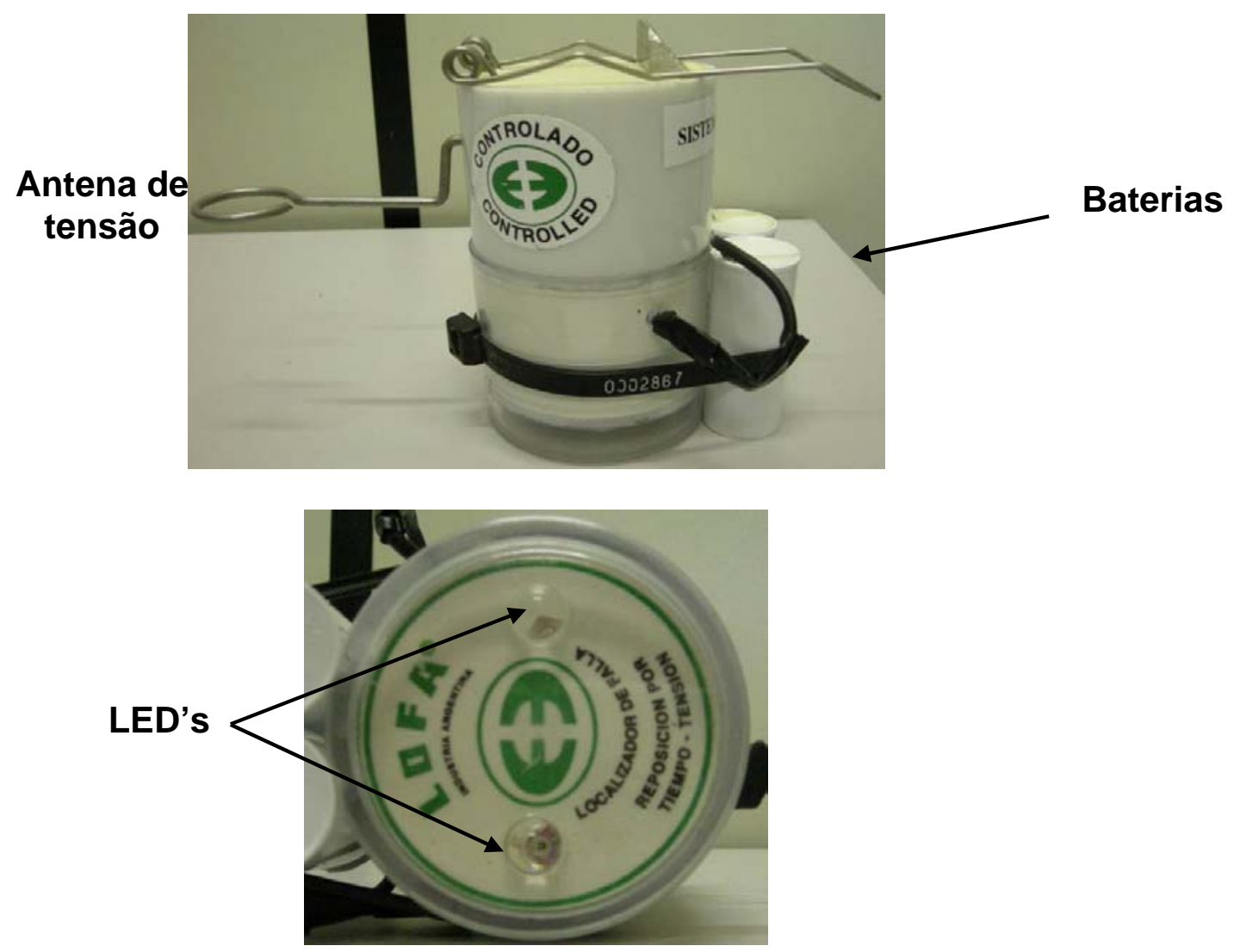

FIGURA 4.22 - LOFA RTA-A. 
O fabricante faz uma observação bastante importante quanto à tensão fornecida pelas duas células de baterias de $3.6 \mathrm{~V}$. Tal menção refere-se ao fato de que o equipamento pode não funcionar corretamente quando a tensão de qualquer uma das duas baterias chegarem a $2.8 \mathrm{~V}$. A fim de verificar o status das baterias foi então feita uma leve descoberta dos condutores de alimentação e a tensão entre os terminais da bateria foi checada, estando de acordo com o especificado.

A Tabela 4.14 condensa as principais características do RTA-A.

TABELA 4.14 - Principais características do RTA-A.

\begin{tabular}{|l|l|}
\hline \multicolumn{1}{|c|}{ Parâmetro } & \multicolumn{1}{c|}{ Especificação } \\
\hline Nível de disparo (A) & 30 (por 167ms) \\
\hline Tipo de Rearme & $\begin{array}{l}\text { Automático por Tensão (5 minutos) } \\
\text { Automático por Tempo (6h) }\end{array}$ \\
\hline Sinalização & Permanente (2 LED's vermelhos, 40 pulsos por minuto) \\
\hline Bateria & 2 Células de 3.6V \\
\hline Tipo de Programação & Fixa \\
\hline & $\begin{array}{l}1-\text { Linha energizada por 5 minutos e corrente de carga } \\
\text { superior a 25A }\end{array}$ \\
Condição de sinalização & $2-$ Variação de corrente de 30A sustentada por 167ms \\
& $3-$ Linha desenergizada \\
\hline Bloqueio de InRush & Sim \\
\hline
\end{tabular}

Para os indicadores de cabo da LOFA RTA-A foram escolhidos 6 unidades para ensaios conforme mostra a Tabela 4.15.

TABELA 4.15 - Ajuste dos indicadores da LOFA.

\begin{tabular}{|c|c|c|c|}
\hline Número & Marca & Modelo & $\mathbf{N}^{\mathbf{0}}$ de série \\
\hline 1 & LOFA & RTA-A & xxxx377 \\
\hline 2 & LOFA & RTA-A & 0002867 \\
\hline 3 & LOFA & RTA-A & 0002916 \\
\hline 4 & LOFA & RTA-A & 0002888 \\
\hline 5 & LOFA & RTA-A & 0002550 \\
\hline 6 & LOFA & RTA-A & 0002878 \\
\hline
\end{tabular}

Na Tabela 4.16 encontram-se os parâmetros de configuração para o Teste 1 (Evolução de Carga) realizado para o RTA-A. Na Figura 4.23 encontram-se os valores de tensão e corrente aplicados ao RTA-A, referentes ao Teste 1. 
TABELA 4.16 - Parâmetros do Teste 1 - Evolução de Carga - LOFA RTA-A.

\begin{tabular}{|c|c|}
\hline Seqüência & Parâmetros \\
\hline Sec01 - LRAMPI & $\begin{array}{l}\text { Prefault: } V a=V b=V c=69 V, I=4.2 A, \text { Fase }=0 \text { e } t=18720 \text { ciclos } \\
\text { Va }=V b=V c=69 V \text { e } I=A C T I O N \\
A=4.2 ; B=180 ; C=0.6 ; D=300 ; E=22.5 ;\end{array}$ \\
\hline Duração total & 7.8 minutos \\
\hline
\end{tabular}
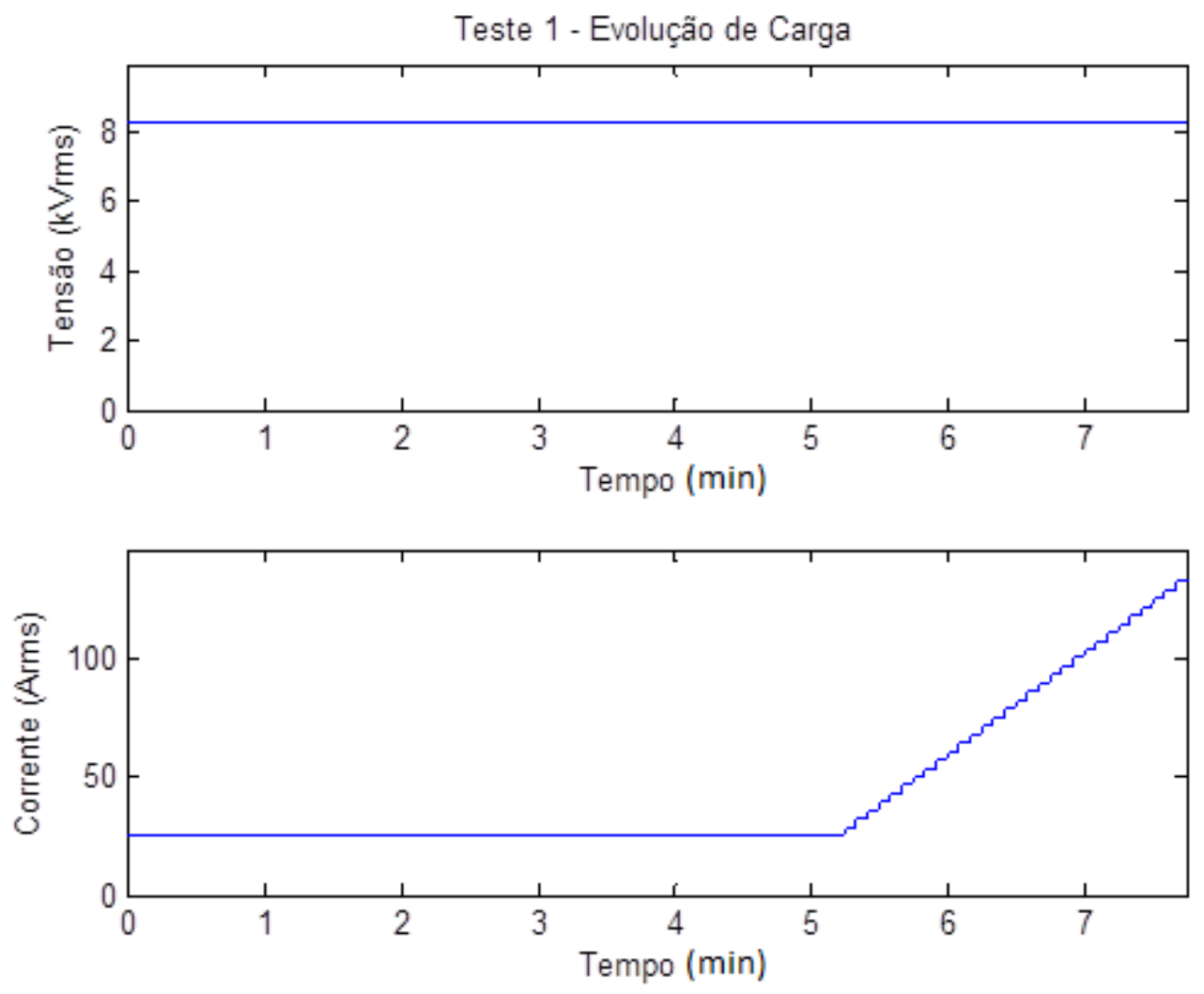

FIGURA 4.23 - Teste 1 - Evolução de Carga para o LOFA RTA-A.

Os Testes 2, 3 e 4, sendo "Correntes Pulsadas", "Religamento Sem Sucesso" e "Religamento Com Sucesso", respectivamente, tem seus parâmetros de configurações relatados nas Tabelas $4.17,4.18$ e 4.19. Os valores de tensão e corrente aplicados no RTA-A para tais testes encontram-se registrados nas Figuras $4.24,4.25$ e 4.26 .

TABELA 4.17 - Parâmetros do Teste 2 - Correntes Pulsadas - LOFA RTA-A.

\begin{tabular}{|c|l|}
\hline Seqüência & \multicolumn{1}{|c|}{ Parâmetros } \\
\hline \multirow{2}{*}{ Sec01 - PRAMPI } & $\begin{array}{l}\text { Prefault: } \mathrm{Va}=\mathrm{V} b=\mathrm{V}=69 \mathrm{~V}, \mathrm{I}=4.2 \mathrm{~A}, \text { Fase=0 e } \mathrm{t}=18720 \text { ciclos } \\
\mathrm{Va}=\mathrm{V} b=\mathrm{Vc}=69 \mathrm{~V} \text { e I }=\mathrm{ACTION}\end{array}$ \\
\hline Duração total & \multicolumn{1}{c|}{7.17 minutos } \\
\hline
\end{tabular}


Teste 2 - Correntes Pulsadas
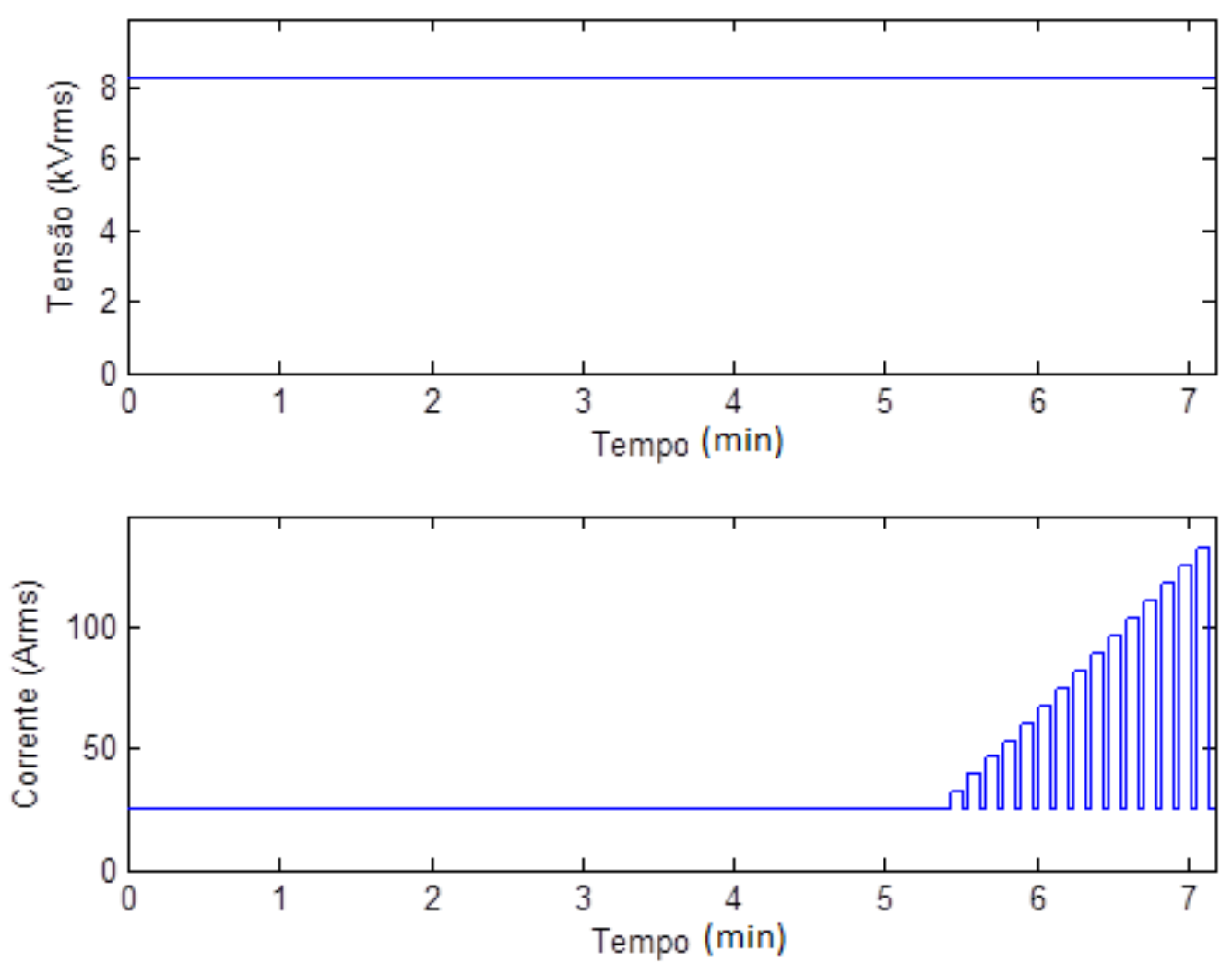

FIGURA 4.24 - Teste 2 - Correntes Pulsadas - LOFA RTA-A.

TABELA 4.18 - Parâmetros do Teste 3 - Religamento Sem Sucesso - LOFA RTA-A.

\begin{tabular}{|c|c|}
\hline Seqüência & Parâmetros \\
\hline Sec01 - PRAMPI & $\begin{array}{l}\text { Prefault:Va=Vb=Vc=69V, I=4.2A, Fase }=0 \text { e } \mathrm{t}=18720 \text { ciclos } \\
V a=V b=V c=69 V \text { e } I=A C T I O N \\
A=4.2 ; B=20 ; C=4.2 ; D=5 ; E=0 ; F=8 ; G=15 ;\end{array}$ \\
\hline Sec02 - PRAMPI & $\begin{array}{l}\text { Prefault:Va }=V b=V c=0 V, I=0 A, \text { Fase }=0 \text { e } t=180 \text { ciclos } \\
V a=V b=V c=69 V \text { e } I=A C T I O N \\
A=7 ; B=120 ; C=3 ; D=12 ; E=0 ; F=5.1 ; G=15\end{array}$ \\
\hline Sec03 - PRAMPI & $\begin{array}{l}\text { Prefault: } V a=V b=V c=0 V, I=0 A, \text { Fase }=0 \text { e } t=180 \text { ciclos } \\
V a=V b=V c=69 V \text { e I }=A C T I O N \\
A=7 ; B=120 ; C=3 ; D=12 ; E=0 ; F=5.1 ; G=15\end{array}$ \\
\hline Sec04 - PRAMPI & $\begin{array}{l}\text { Prefault: } V a=V b=V c=0 V, I=0 A, \text { Fase }=0 \text { e } t=180 \text { ciclos } \\
V a=V b=V c=69 V \text { e } I=A C T I O N \\
A=7 ; B=120 ; C=3 ; D=12 ; E=0 ; F=5.1 ; G=15 ;\end{array}$ \\
\hline Sec05 - LRAMPI & $\begin{array}{l}\text { Prefault: } V a=V b=V c=0 V, I=0 A, \text { Fase }=0 \text { e } t=7900 \text { ciclos } \\
V a=V b=V c=69 V \text { e } I=A C T I O N \\
A=2.5 ; B=18720 ; C=1 ; D=300 ; E=15 ;\end{array}$ \\
\hline
\end{tabular}


Teste 3 - Religamento Sem Sucesso
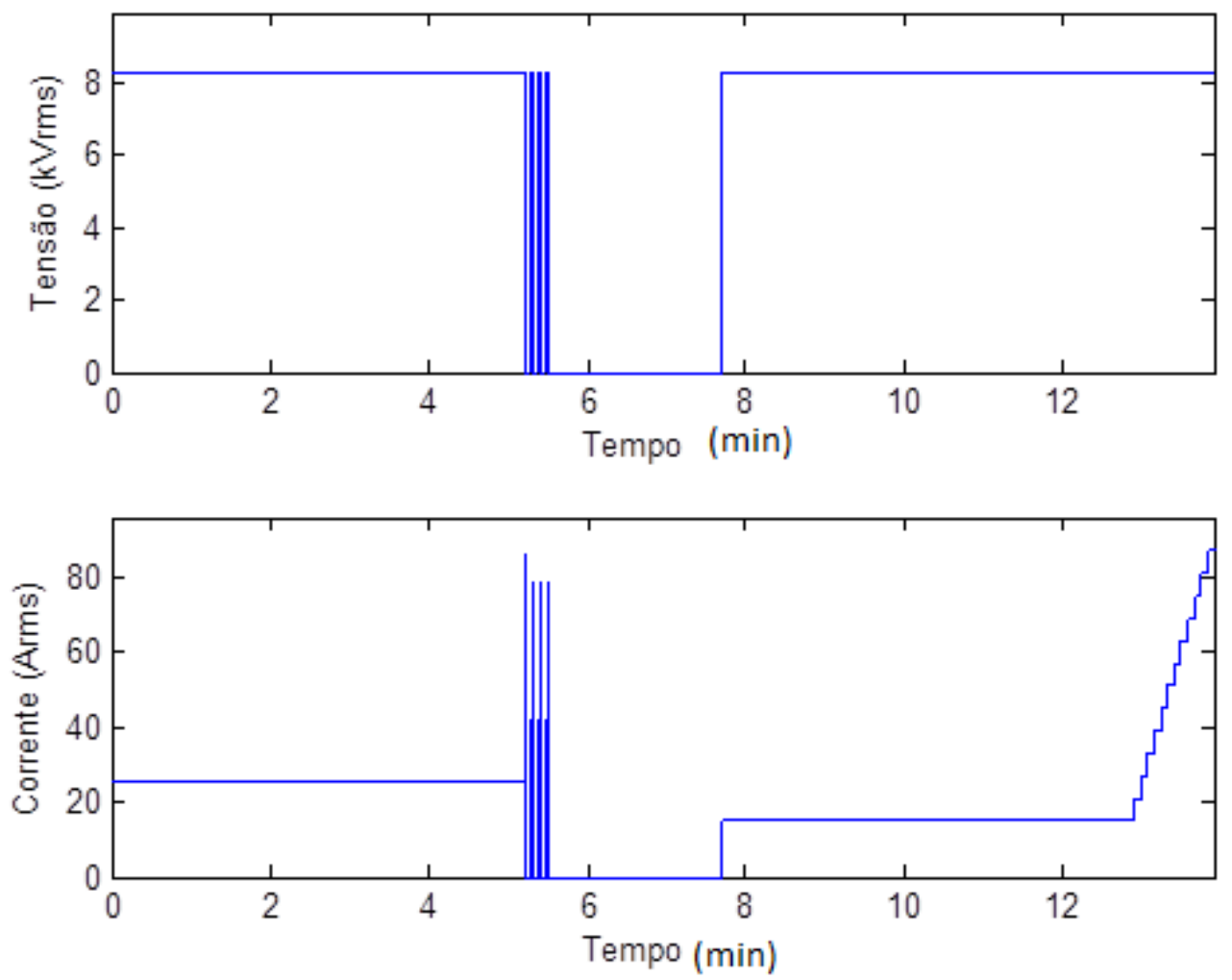

FIGURA 4.25 - Teste 3 - Religamento Sem Sucesso - LOFA RTA-A.

TABELA 4.19 - Parâmetros do Teste 4 - Religamento Com Sucesso - LOFA RTA-A.

\begin{tabular}{|c|c|}
\hline Seqüência & Parâmetros \\
\hline Sec01 - PRAMPI & $\begin{array}{l}\text { Prefault: } V a=V b=V c=69 V, I=4.2 A, \text { Fase }=0 \text { e } t=18720 \text { ciclos } \\
V a=V b=V c=69 V \text { e } I=A C T I O N \\
A=4.2 ; B=20 ; C=4.2 ; D=12 ; E=0 ; F=5.1 ; G=15 ;\end{array}$ \\
\hline Sec02 - PRAMPI & $\begin{array}{l}\text { Prefault: } V a=V b=V c=0 V, I=0 A, \text { Fase }=0 \text { e } t=180 \text { ciclos } \\
V a=V b=V c=69 V \text { e } I=A C T I O N \\
A=7 ; B=120 ; C=3 ; D=12 ; E=0 ; F=5.1 ; G=15 ;\end{array}$ \\
\hline Sec03 - PRAMPI & $\begin{array}{l}\text { Prefault: } V a=V b=V c=0 V, I=0 A, \text { Fase }=0 \text { e } t=180 \text { ciclos } \\
V a=V b=V c=69 V \text { e } I=A C T I O N \\
A=7 ; B=120 ; C=3 ; D=12 ; E=0 ; F=5.1 ; G=15 ;\end{array}$ \\
\hline Sec04 - LRAMPI & $\begin{array}{l}\text { Prefault: } V a=V b=V c=0 V, I=0 A, \text { Fase }=0 \text { e } t=7900 \text { ciclos } \\
V a=V b=V c=69 \vee \text { e } I=A C T I O N \\
A=2.5 ; B=18720 ; C=1 ; D=300 ; E=15 ;\end{array}$ \\
\hline Duração total & 13.8 minutos \\
\hline
\end{tabular}


Teste 4 - Religamento Com Sucesso
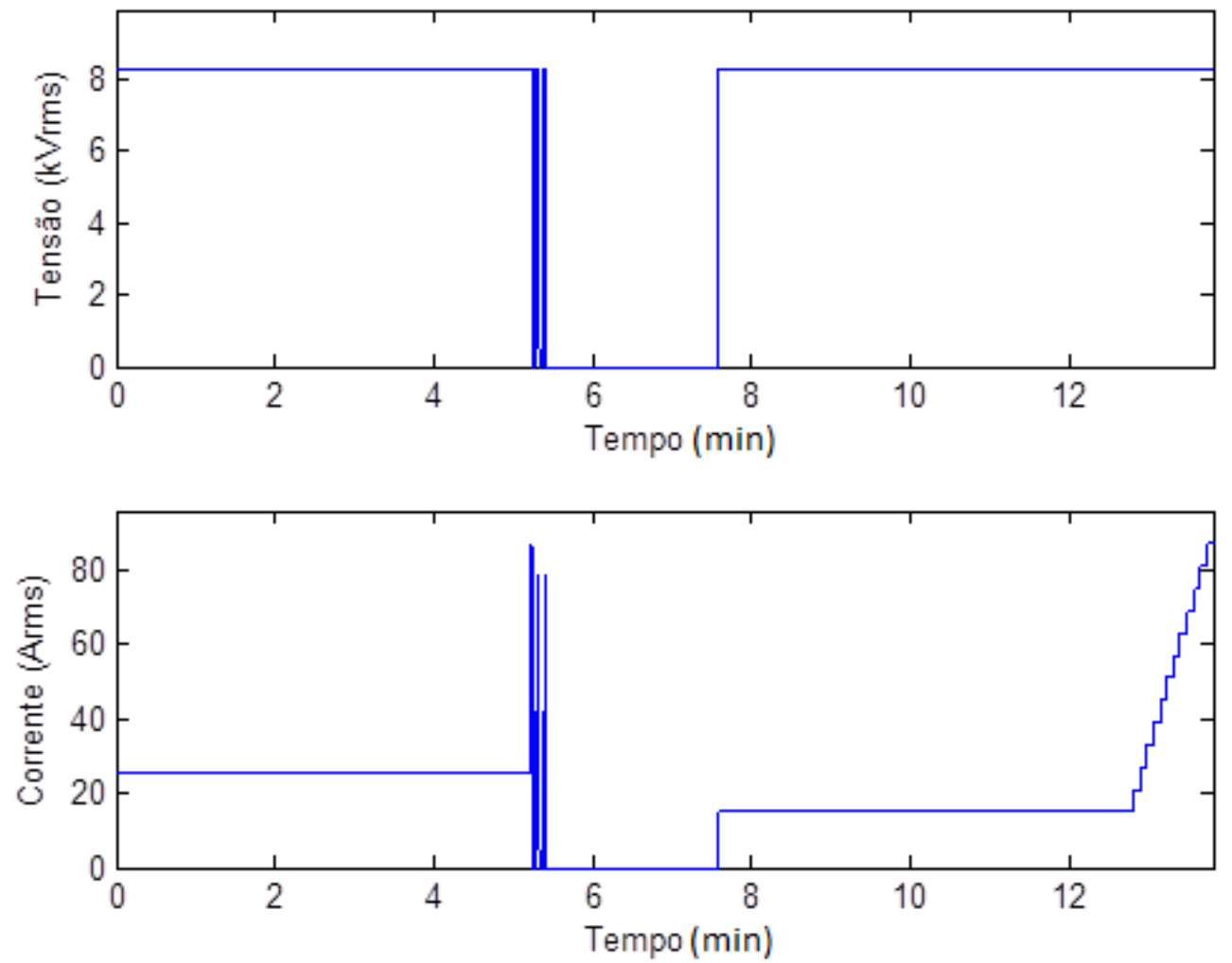

FIGURA 4.26 - Teste 4 - Religamento Com Sucesso - LOFA RTA-A.

\subsubsection{LOFA ICO}

O modelo ICO da empresa LOFA é um indicador de faltas programável, instalado no condutor fase. Sua programação/parametrização é feita por meio de dois bancos de chaves. O princípio de funcionamento é o acompanhamento da variação da corrente no tempo (di/dt) e também por limiar de corrente.

Para a realização do disparo da sinalização, o ICO precisa ser sensibilizado por uma variação de corrente sustentada por 30ms, seguido de uma desenergização do sistema. Este modelo de indicador de faltas possui alimentação de baterias de lítio com 3.6V e 5.2Ah.

Na Figura 4. 27, a seguir, têm-se uma visualização da estrutura do ICO. 


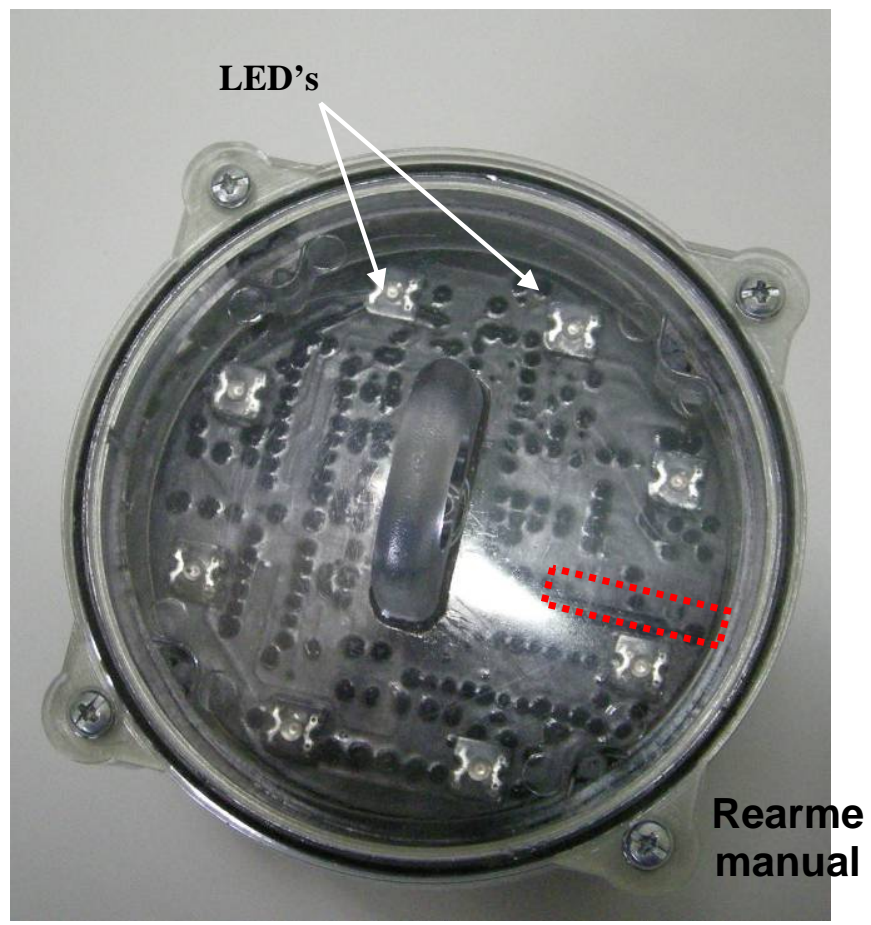

FIGURA 4.27 - LOFA ICO.

O sistema de sinalização é formado por 8 LED's vermelhos de alto brilho.

Removendo-se os parafusos do sistema de sinalização tem-se acesso aos bancos de chave de programação, conforme pode ser observado na Figura 4.28.

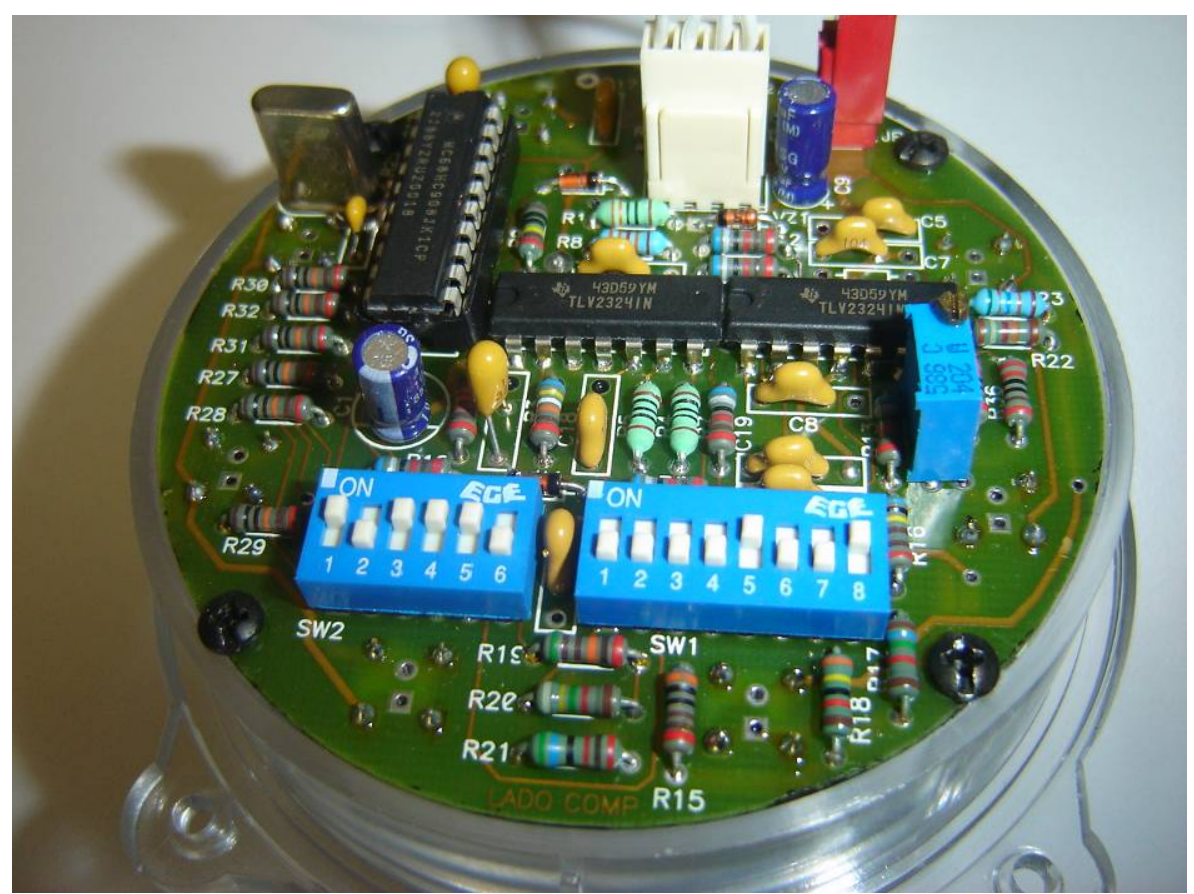

FIGURA 4.28 - Bancos de chaves do LOFA ICO. 
A placa de circuito principal do ICO fica localizada acima do sistema de sinalização, protegida pelo encapsulamento de plástico do dispositivo e é conectada à bateria e ao sensor de tensão, que ficam localizados na parte superior do dispositivo, próxima as garras que o fixam no condutor, conforme observado na Figura 4.29.

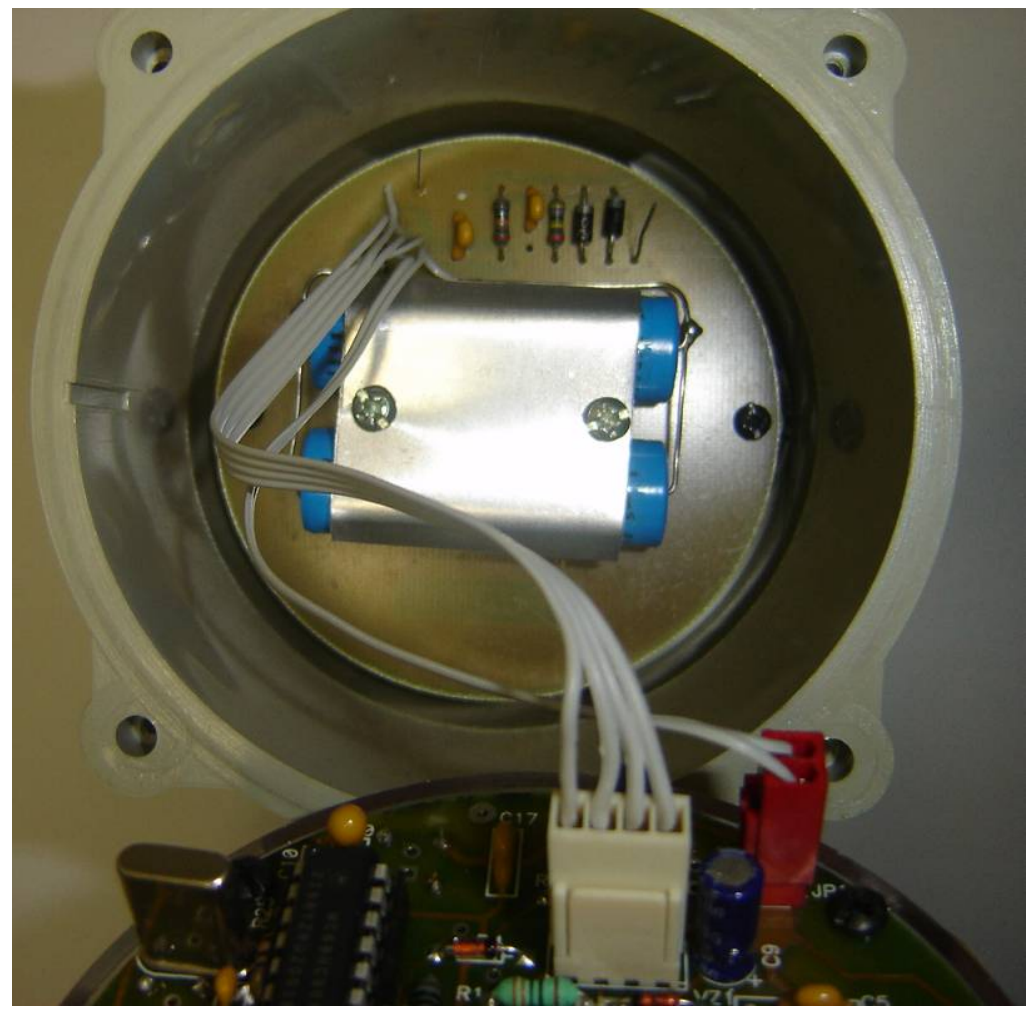

FIGURA 4.29 - Bateria e sensor de tensão do LOFA ICO.

Este modelo conta com rearme automático por tempo e tensão e também rearme manual, posicionando-se um ímã próximo do sensor magnético, situado na parte superior do dispositivo. O dispositivo fica apto a funcionar após o tempo de proteção de InRush, que pode ser programado em 0, 3, 30 ou 60 segundos.

O fabricante faz uma observação bem importante quanto ao modo de disparo retardado, pois uma variação de corrente muito alta pode ocasionar um disparo prematuro da sinalização. Com este modo ativado o fabricante garante que somente será dado o disparo de sinalização caso o a tensão na linha seja retirada 
antes do tempo de retardo de 5s. Neste mesmo item o fabricante afirma que o dispositivo não possui sinalização de faltas transitórias e, por isso, o sistema de retardo deve ser implementado para apenas sinalizarem faltas permanentes, ou seja, quando da atuação da proteção trifásica e desligamento da linha. Para uma sinalização prolongada após a remoção do defeito e para facilitar o trabalho da equipe de inspeção o fabricante recomenda o rearme automático por tempo.

A Tabela 4.20 condensa as principais características do ICO.

TABELA 4.20 - Principais características do ICO.

\begin{tabular}{|l|l|}
\hline \multicolumn{1}{|c|}{ Parâmetro } & \multicolumn{1}{c|}{ Especificação } \\
\hline Faixas de disparo de di/dt (A) & $6,12,25$ e 60 (por 30ms) \\
\hline Limiar de corrente de falta (A) & 200 e 500 \\
\hline Tipo de Rearme & $\begin{array}{l}\text { Manual (Utilização de um ímã) } \\
\text { Automático por Tensão (3s, 30s e 60s) } \\
\text { Automático por Tempo (2h, 4h, 8h e 16h) }\end{array}$ \\
\hline Sinalização & Permanente (8 LED's vermelhos) \\
\hline Bateria & 2 Células de 3.6V \\
\hline Tipo de Programação & 2 bancos de chaves \\
\hline Condição de sinalização & $\begin{array}{l}\text { 1 - Linha energizada pelo tempo mínimo de InRush } \\
\text { 2- Elevada variação de corrente sustentada por 30ms } \\
\text { 3 - Linha desenergizada }\end{array}$ \\
\hline Bloqueio de InRush & Sim (0, 3s, 30s e 60s) \\
\hline
\end{tabular}

A programação dos dois bancos de chaves procede de acordo com as tabelas a seguir.

TABELA 4.21 - Programação do LOFA ICO (banco de chaves DIP Switch 1).

\begin{tabular}{|c|c|c|c|}
\hline Chaves & Descrição Funcional & \multicolumn{2}{|c|}{ Opções } \\
\hline \multirow{4}{*}{1} & \multirow{4}{*}{$\begin{array}{l}\text { Tempo de rearme automático } \\
\text { por tempo }\end{array}$} & $2 \mathrm{~h}$ & 00 \\
\hline & & $4 \mathrm{~h}$ & 10 \\
\hline & & $8 \mathrm{~h}$ & 01 \\
\hline & & $16 \mathrm{~h}$ & 11 \\
\hline \multirow{4}{*}{4} & \multirow{4}{*}{ Proteção de InRush } & 0 & 00 \\
\hline & & $3 s$ & 10 \\
\hline & & $30 s$ & 01 \\
\hline & & $60 s$ & 11 \\
\hline \multirow{4}{*}{6} & \multirow{4}{*}{ Rearme automático por tensão } & $3 s$ & 00 \\
\hline & & $30 s$ & 10 \\
\hline & & $60 s$ & 01 \\
\hline & & Desativado & 11 \\
\hline
\end{tabular}


TABELA 4.22 - Programação do LOFA ICO (banco de chaves DIP Switch 2).

\begin{tabular}{|c|c|c|c|}
\hline Chaves & Descrição Funcional & \multicolumn{2}{|c|}{ Opções } \\
\hline 1 & \multirow{2}{*}{ Limiar de corrente } & $200 \mathrm{~A}$ & 10 \\
\hline 2 & & $500 \mathrm{~A}$ & 01 \\
\hline \multirow{2}{*}{$\begin{array}{l}3 \\
8\end{array}$} & \multirow{2}{*}{ Ativa limiar de corrente ou di/dt } & Limiar & 10 \\
\hline & & $\mathrm{d} i / \mathrm{d} t$ & 01 \\
\hline \multirow{4}{*}{$\begin{array}{l}4 \\
5 \\
6 \\
7\end{array}$} & \multirow{4}{*}{ Níveis de di/dt (A) } & $6 \mathrm{~A}$ & 1000 \\
\hline & & $12 \mathrm{~A}$ & 0100 \\
\hline & & $25 \mathrm{~A}$ & 0010 \\
\hline & & $60 \mathrm{~A}$ & 0001 \\
\hline
\end{tabular}

Os testes realizados com o LOFA ICO consistem em determinar as características de sensibilidade do aparelho e também averiguar seu comportamento mediante ao ajuste de variação de corrente praticado pela Distribuidora. Este modelo, apesar de ainda não estar em uso pela Distribuidora aqui estudada, possui níveis de ajuste bem similares a outros modelos que a empresa possui.

Na Tabela 4.23 encontram-se os parâmetros de configuração para o Teste 1 (Evolução de Carga), realizado para o ICO. Na Figura 4.30 encontram-se os valores de tensão e corrente aplicados ao ICO, referentes ao Teste 1.

TABELA 4.23 - Parâmetros do Teste 1 - Evolução de Carga - LOFA ICO.

\begin{tabular}{|c|l|}
\hline Seqüência & \multicolumn{1}{|c|}{ Parâmetros } \\
\hline \multirow{3}{*}{ Sec01 - LRAMPI } & $\begin{array}{l}\text { Prefault: } \mathrm{Va}=\mathrm{Vb}=\mathrm{V} c=69 \mathrm{~V}, \mathrm{I}=0, \text { Fase=0 e } \mathrm{t}=1900 \text { ciclos } \\
\mathrm{Va}=\mathrm{V} b=\mathrm{Vc}=69 \mathrm{~V} \text { e I }=\mathrm{ACT} \text { (ION } \\
\mathrm{A}=0.5 ; \mathrm{B}=180 ; \mathrm{C}=0.6 ; \mathrm{D}=300 ; \mathrm{E}=22.5 ;\end{array}$ \\
\hline Duração total & \multicolumn{1}{|c|}{3.6 minutos } \\
\hline
\end{tabular}


Teste 1 - Evolução de Carga
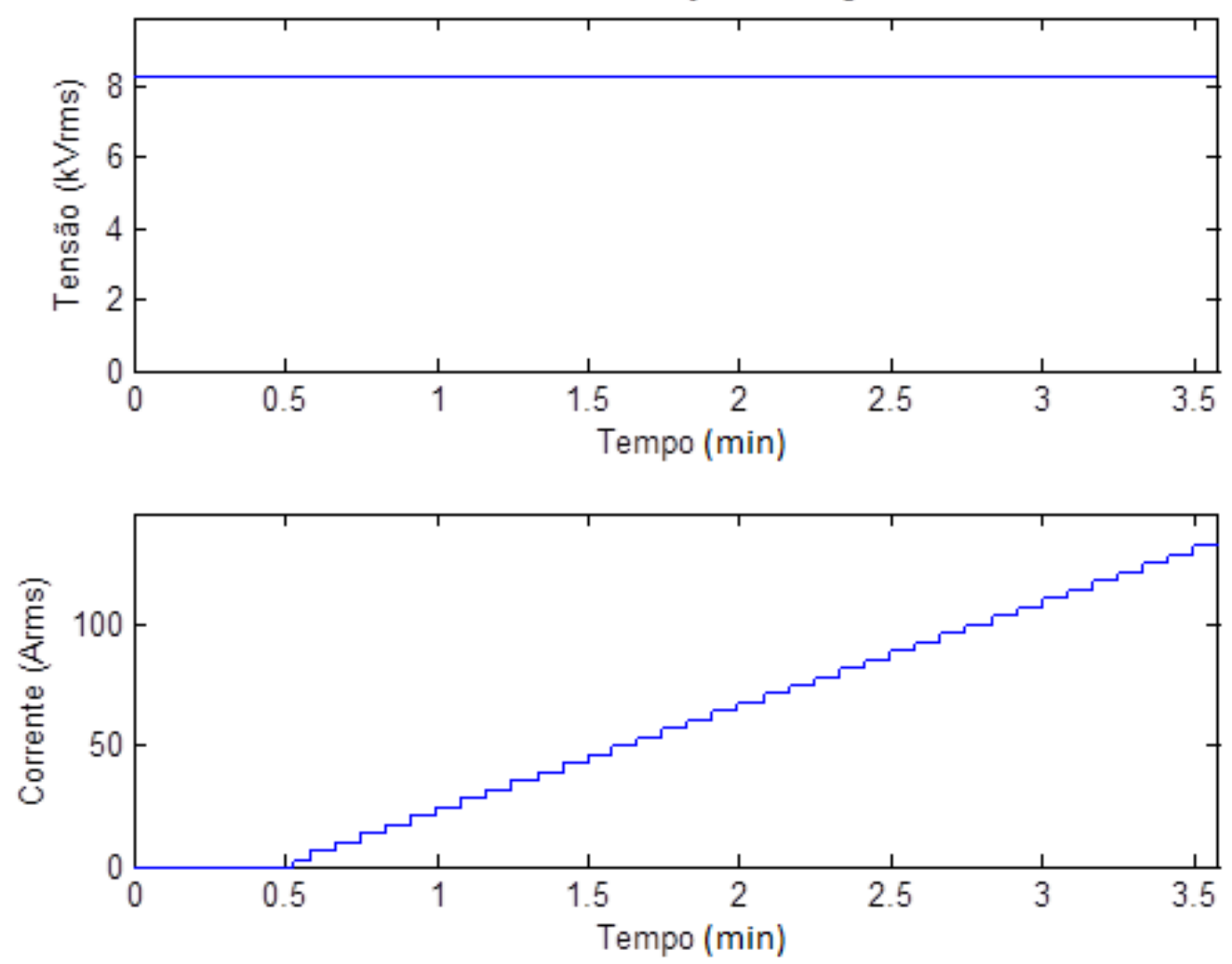

FIGURA 4.30 - Teste 1 - Evolução de Carga para o LOFA ICO.

Os Testes 2, 3 e 4, sendo "Correntes Pulsadas", "Religamento Sem Sucesso" e "Religamento Com Sucesso", respectivamente, tem seus parâmetros de configurações relatados na Tabelas $4.24,4.25$ e 4.26. Os valores de tensão e corrente aplicados no ICO para tais testes encontram-se registrados na Figuras 4.31, 4.32 e 4.33 .

TABELA 4.24 - Parâmetros do Teste 2 - Correntes Pulsadas - LOFA ICO.

\begin{tabular}{|c|c|}
\hline Seqüência & \multicolumn{1}{|c|}{ Parâmetros } \\
\hline \multirow{3}{*}{ Sec01 - PRAMPI } & $\begin{array}{l}\text { Prefault: } \mathrm{Va}=\mathrm{Vb}=\mathrm{Vc}=69 \mathrm{~V}, \mathrm{I}=0, \text { Fase }=0 \text { e } \mathrm{t}=1900 \text { ciclos } \\
\mathrm{Va}=\mathrm{Vb}=\mathrm{Vc}=69 \mathrm{~V} \text { e I }=\mathrm{ACTION} \\
\mathrm{A}=0.5 ; \mathrm{B}=360 ; \mathrm{C}=0.5 ; \mathrm{D}=3 ; \mathrm{E}=120 ; \mathrm{F}=1.2 ; \mathrm{G}=22.5 ;\end{array}$ \\
\hline Duração total & 77 segundos \\
\hline
\end{tabular}


Teste 2 - Correntes Pulsadas
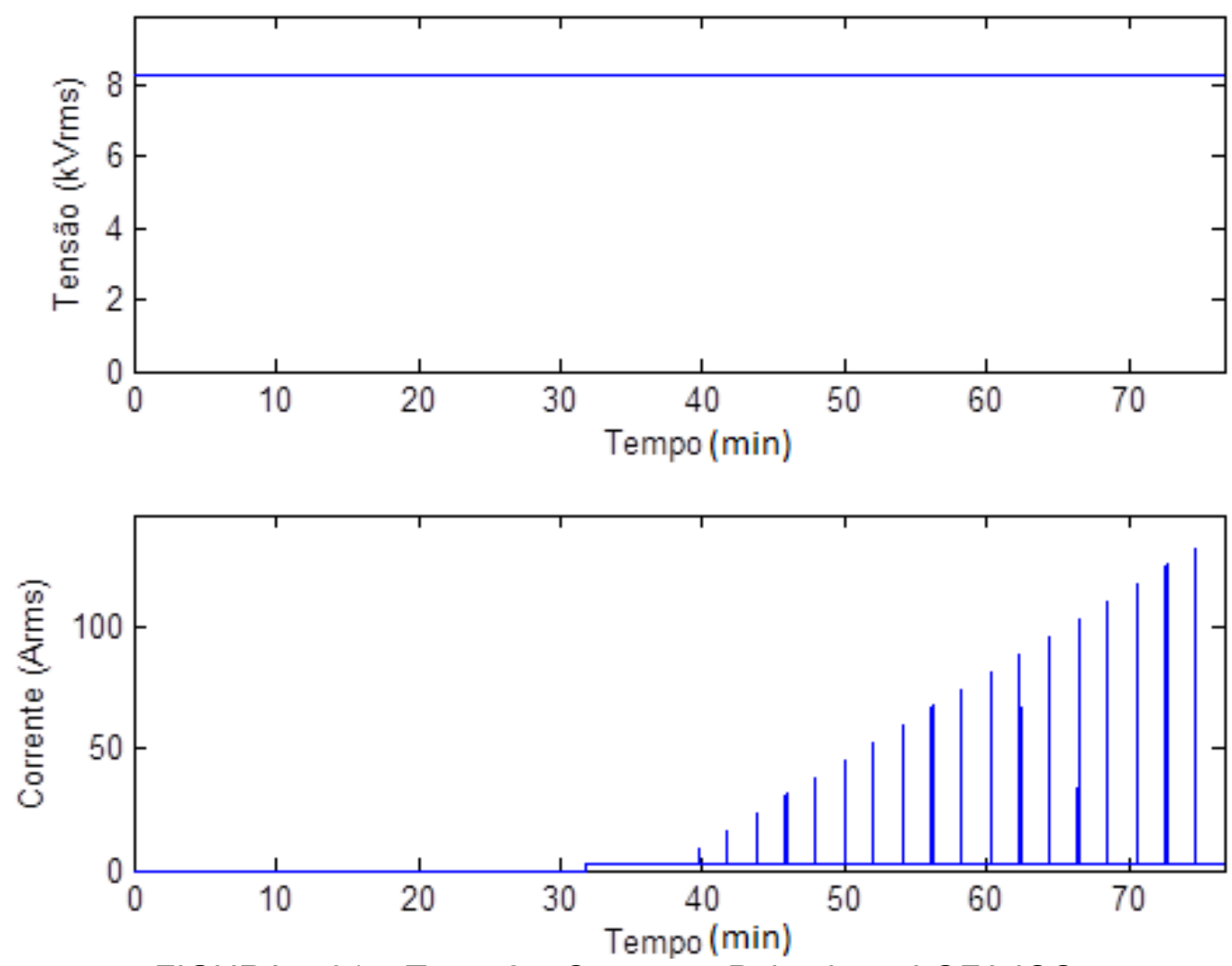

FIGURA 4.31 - Teste 2 - Correntes Pulsadas - LOFA ICO.

TABELA 4.25 - Parâmetros do Teste 3 - Religamento Sem Sucesso - LOFA ICO.

\begin{tabular}{|c|c|}
\hline Seqüência & Parâmetros \\
\hline Sec01 - PRAMPI & $\begin{array}{l}\text { Prefault: } V a=V b=V c=69 V, I=4 A \text {, Fase }=0 \text { e } t=1900 \text { ciclos } \\
V a=V b=V c=69 V \text { e I }=A C T I O N \\
A=4 ; B=20 ; C=4 ; D=4 ; E=0 ; F=2.2 ; G=15 ;\end{array}$ \\
\hline Sec02 - PRAMPI & $\begin{array}{l}\text { Prefault:Va=Vb=Vc=0V, I=0A, Fase }=0 \text { e } t=180 \text { ciclos } \\
V a=V b=V c=69 V \text { e I }=A C T I O N \\
A=4 ; B=120 ; C=4 ; D=4 ; E=0 ; F=2.2 ; G=15\end{array}$ \\
\hline Sec03 - PRAMPI & $\begin{array}{l}\text { Prefault:Va=Vb=Vc=0V, I=0A, Fase=0 e } t=180 \text { ciclos } \\
V a=V b=V c=69 V \text { e } I=A C T I O N \\
A=4 ; B=120 ; C=4 ; D=4 ; E=0 ; F=2.2 ; G=15 ;\end{array}$ \\
\hline Sec04 - PRAMPI & $\begin{array}{l}\text { Prefault:Va=Vb=Vc=0V, I=0A, Fase }=0 \text { e } t=180 \text { ciclos } \\
V a=V b=V c=69 V \text { e I }=A C T I O N \\
A=4 ; B=120 ; C=4 ; D=4 ; E=0 ; F=2.2 ; G=15 ;\end{array}$ \\
\hline Sec05 - LRAMPI & $\begin{array}{l}\text { Prefault: } V a=V b=V c=0 V, I=0 A, \text { Fase }=0 \text { e } t=1900 \text { ciclos } \\
V a=V b=V c=69 V \text { e } I=A C T I O N \\
A=0 ; B=1900 ; C=0.5 ; D=300 ; E=15 ;\end{array}$ \\
\hline Duração total & 4.4 minutos \\
\hline
\end{tabular}


Teste 3 - Religamento Sem Sucesso
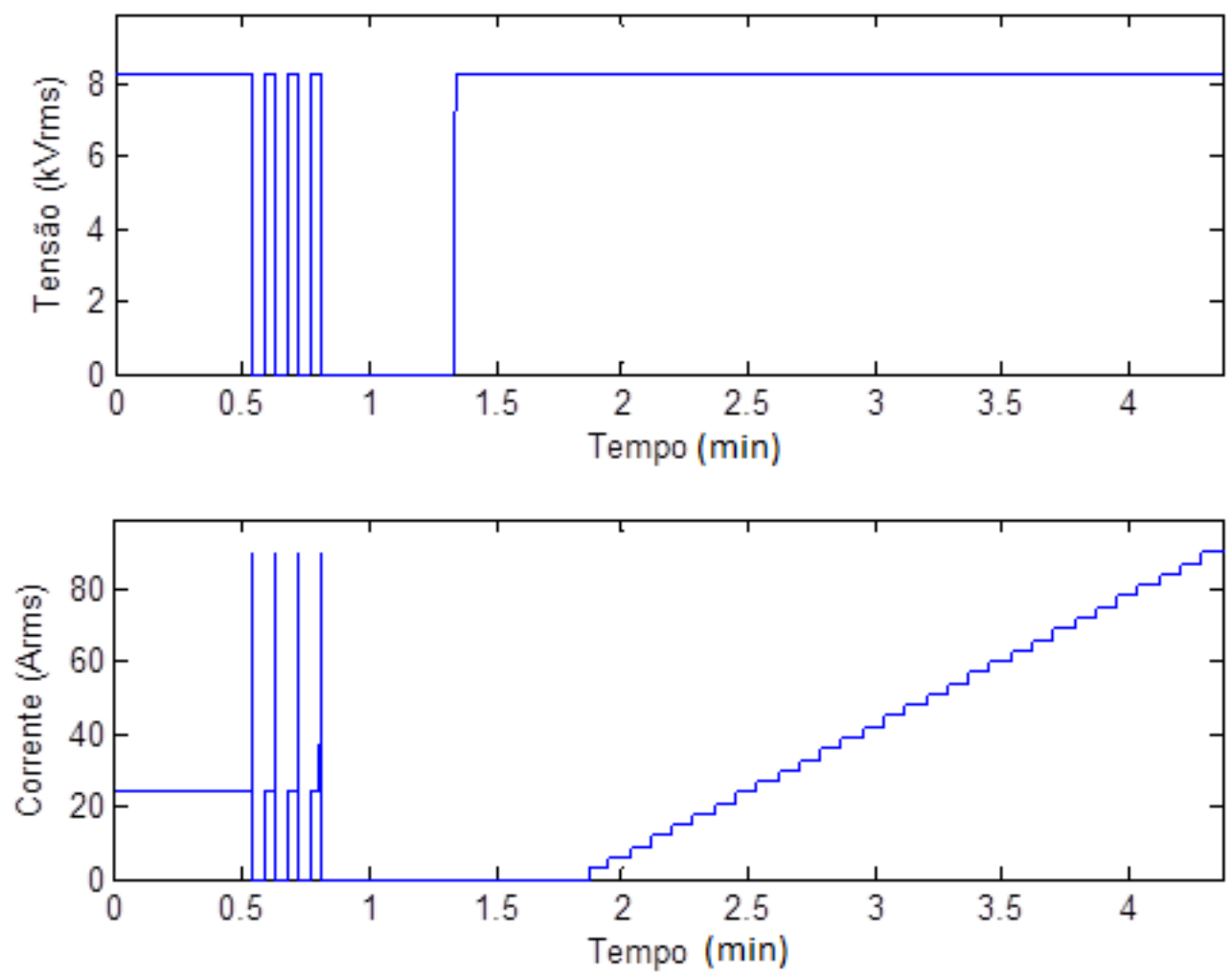

FIGURA 4.32 - Teste 3 - Religamento Sem Sucesso - LOFA ICO.

TABELA 4.26 - Parâmetros do Teste 4 - Religamento Com Sucesso - LOFA ICO.

\begin{tabular}{|c|c|}
\hline Seqüência & Parâmetros \\
\hline Sec01 - PRAMPI & $\begin{array}{l}\text { Prefault: } V a=V b=V c=69 V, I=4 A, \text { Fase }=0 \text { e } t=1900 \text { ciclos } \\
V a=V b=V c=69 V \text { e I }=A C T I O N \\
A=4 ; B=20 ; C=4 ; D=4 ; E=0 ; F=2.2 ; G=15 ;\end{array}$ \\
\hline Sec02 - PRAMPI & $\begin{array}{l}\text { Prefault: } V a=V b=V c=0 V, I=0 A, \text { Fase }=0 \text { e } t=180 \text { ciclos } \\
V a=V b=V c=69 V \text { e } I=A C T I O N \\
A=4 ; B=120 ; C=4 ; D=4 ; E=0 ; F=2.2 ; G=15\end{array}$ \\
\hline Sec03 - PRAMPI & $\begin{array}{l}\text { Prefault:Va }=V b=V c=0 V, I=0 A, \text { Fase }=0 \text { e } t=180 \text { ciclos } \\
V a=V b=V c=69 V \text { e } I=A C T I O N \\
A=4 ; B=120 ; C=4 ; D=4 ; E=0 ; F=2.2 ; G=15\end{array}$ \\
\hline Sec04 - LRAMPI & $\begin{array}{l}\text { Prefault: } V a=V b=V c=0 V, I=0 A, \text { Fase }=0 \text { e } t=1900 \text { ciclos } \\
V a=V b=V c=69 V \text { e } I=A C T I O N \\
A=0 ; B=1900 ; C=0.5 ; D=300 ; E=15 ;\end{array}$ \\
\hline Duração total & 4.3 minutos \\
\hline
\end{tabular}



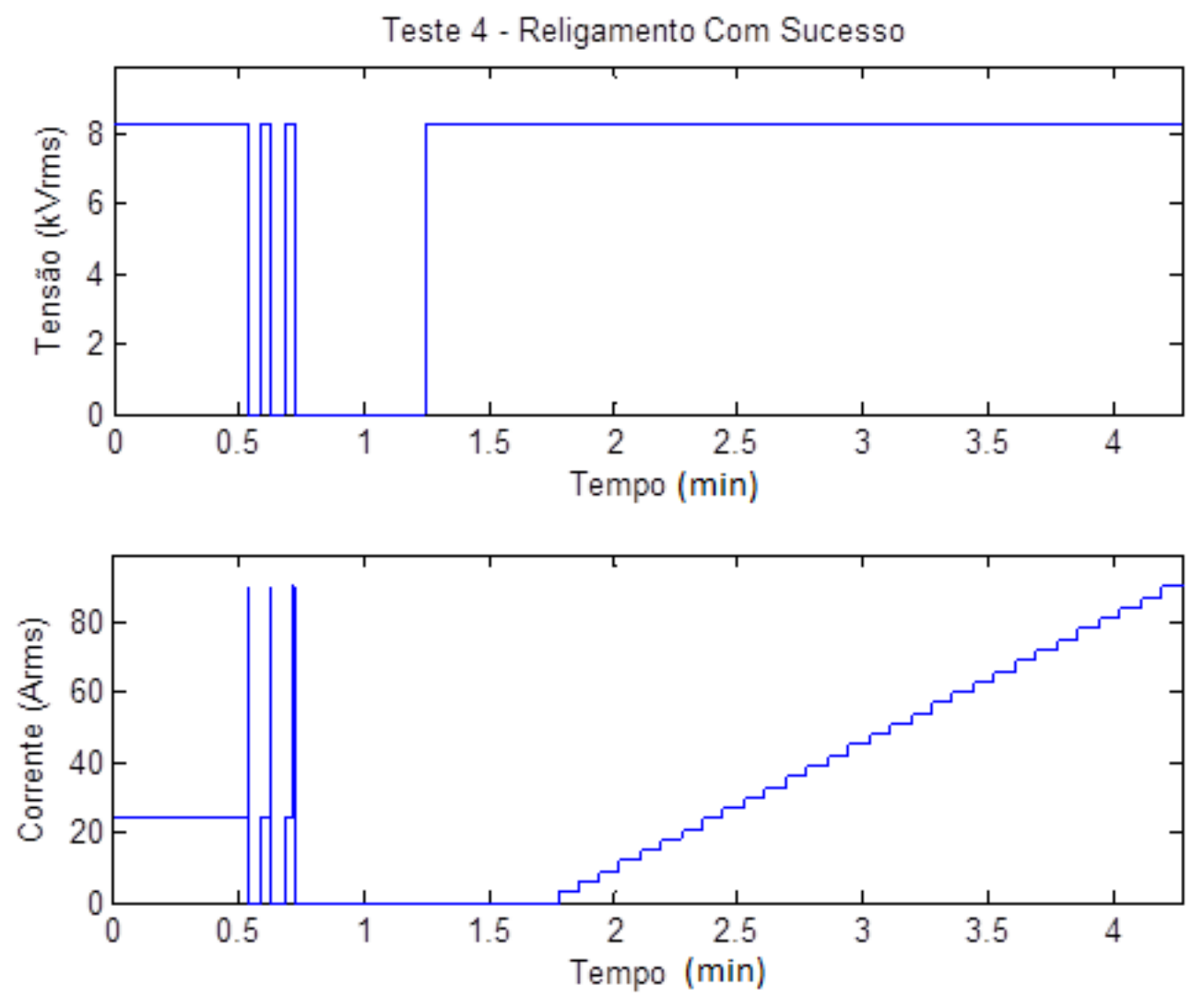

FIGURA 4.33 - Teste 4 - Religamento Com Sucesso - LOFA ICO.

\subsubsection{SEL Auto Ranger}

A principal característica do indicador Auto Ranger da SEL é se adaptar automaticamente às condições de carga/falta. É um IF empregado em cabos e cada dispositivo monitora uma única fase, tendo como princípio de funcionamento a detecção de um limiar de corrente, não estando apto a atuar por di/dt. A sinalização de falta transitória é realizada por 1 LED amarelo e a permanente por 2 LED's de alto brilho de cor vermelha. Este modelo conta também com um sensor de luminosidade que ativa uma sinalização auxiliar, de acordo com a intensidade de luz do ambiente onde o indicador está instalado, quando da indicação de uma falta permanente. Quanto mais escuro o ambiente, mais módulos de iluminação serão ativados, na cor vermelha, e permanecerão piscando de acordo com o nível de 
corrente de carga antes da falta. Na Figura 4.34 é possível visualizar o sistema de sinalização do Auto Ranger.

Pode-se observar que ele é totalmente lacrado, uma vez que não necessita de nenhuma programação.

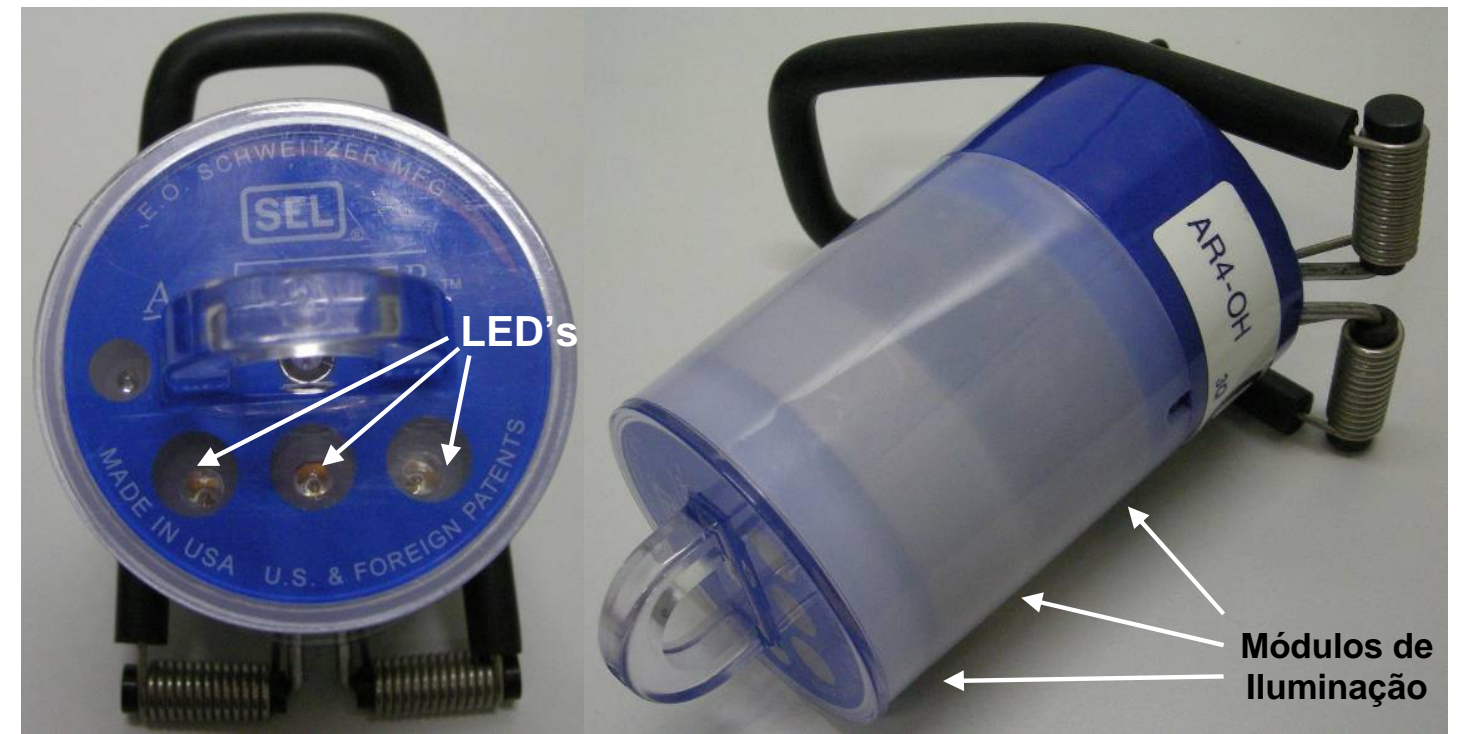

FIGURA 4.34 - SEL Auto Ranger.

Qualquer variação sustentada de corrente por mais de $24 \mathrm{~ms}$, dentro dos limiares auto-ajustáveis do Auto Ranger, causa uma imediata sinalização de falta permanente, com dois LED's vermelhos. Dois minutos após esta oscilação de corrente, o dispositivo analisa a tensão e a corrente para tomar uma das seguintes decisões:

- Novo Nível de Carga: Se o novo nível de corrente se mantém, o dispositivo então pára de sinalizar uma falta permanente e se autoajusta a um novo nível de carga / trip.

- Falta Transitória: Se a tensão e a corrente de carga são as nominais, o indicador então compreende que houve uma tentativa bem sucedida de religar a linha após a falta e inicia o modo de sinalização temporária com o LED amarelo, por 8h. 
- Falta Permanente: Caso o circuito esteja desenergizado, o Auto Ranger continuará então com a indicação de falta permanente com os 2 LED's vermelhos por $4 \mathrm{~h}$ ou $8 \mathrm{~h}$ de acordo com a corrente de pré falta. Neste caso o dispositivo faz uma checagem da iluminação do ambiente para ativar os módulos auxiliares de indicação.

O rearme do Auto Ranger é realizado por tempo, 4h ou 8h, de acordo com o nível de corrente de pré-falta e, também manual, por meio de um acessório que contém um imã. Tal acessório deve ser posicionado na lente do Auto Ranger por 5s para o rearme e também para checagem das normais condições da bateria. Com carga operacional da bateria, a seqüência de flashes é formada por 5 repetições de 3 flashes com os LED's vermelhos e 3 repetições de dois flashes com o LED amarelo.

A Tabela 4.27 condensa as principais características do SEL Auto Ranger.

TABELA 4.27 - Principais características do SEL Auto Ranger.

\begin{tabular}{|c|c|c|}
\hline Parâmetro & \multicolumn{2}{|c|}{ Especificação } \\
\hline \multirow{9}{*}{$\begin{array}{l}\text { Corrente de carga e nível de trip } \\
\text { por limiar de corrente (A) }\end{array}$} & Faixa de corrente & Valor de trip \\
\hline & $10<1<25$ & 50 \\
\hline & $25<1<50$ & 100 \\
\hline & $50<1<100$ & 200 \\
\hline & $100<1<200$ & 400 \\
\hline & $200<1<300$ & 600 \\
\hline & $300<1<400$ & 800 \\
\hline & $400<1<500$ & 1000 \\
\hline & $I>500$ & 1200 \\
\hline Tipo de Rearme & \multicolumn{2}{|c|}{$\begin{array}{l}\text { Manual (Ferramenta com imã) } \\
\text { Automático por Tempo ( } 4 \mathrm{~h} \text { ou } 8 \mathrm{~h})\end{array}$} \\
\hline & \multicolumn{2}{|l|}{$\begin{array}{l}\text { Transitória } \\
1 \text { LED amarelo por } 8 \mathrm{~h}\end{array}$} \\
\hline Sinalização & \multicolumn{2}{|c|}{$\begin{array}{l}\text { Permanente } \\
3 \text { LED's vermelhos por } 4 \mathrm{~h} \text { para I } \text { Iré-falta }^{\prime}>50 \mathrm{~A} \\
3 \text { LED's vermelhos por } 8 \mathrm{~h} \text { para } \mathrm{I}_{\text {pré-falta }}<50^{\mathrm{a}}\end{array}$} \\
\hline Bateria & \multicolumn{2}{|l|}{ Sem Informação } \\
\hline Tipo de Programação & \multicolumn{2}{|l|}{ Automática } \\
\hline Condição de sinalização & \multicolumn{2}{|c|}{$\begin{array}{l}1 \text { - Linha energizada por pelo menos } 5 \text { minutos } \\
2 \text { - Variação de corrente por pelo menos } 24 \mathrm{~ms} \\
3 \text { - Linha desenergizada } 2 \text { minutos após a falta }\end{array}$} \\
\hline Bloqueio de InRush & \multicolumn{2}{|l|}{ Sim (5 minutos) } \\
\hline
\end{tabular}


O primeiro teste a ser aplicado no Auto Ranger é o de evolução de carga, com os parâmetros mostrados na Tabela 4.28. Este teste é composto de apenas uma Macro, denominada Sec01, do tipo LRAMPI.

TABELA 4.28 - Parâmetros do Teste 1 - Evolução de Carga - SEL Auto Ranger.

\begin{tabular}{|c|c|}
\hline Seqüência & \multicolumn{1}{c|}{ Parâmetros } \\
\hline \multirow{3}{*}{ Sec01 - LRAMPI } & $\begin{array}{l}\text { Prefault: } \mathrm{Va}=\mathrm{Vb}=\mathrm{Vc}=69 \mathrm{~V}, \mathrm{I}=3.3 \mathrm{~A}, \text { Fase=0 e } \mathrm{t}=18720 \text { ciclos } \\
\mathrm{Va}=\mathrm{Vb}=\mathrm{Vc}=69 \mathrm{~V} \text { e } \mathrm{I}=\mathrm{ACTION} \\
\mathrm{A}=3.3 ; \mathrm{B}=180 ; \mathrm{C}=0.6 ; \mathrm{D}=300 ; \mathrm{E}=22.5 ;\end{array}$ \\
\hline Duração total & \multicolumn{1}{c|}{8.3 minutos } \\
\hline
\end{tabular}

Na Figura 4.35 encontram-se registrados os valores de tensão e corrente eficazes que serão apresentados ao Auto Ranger.

Teste 1 - Evolução de Carga
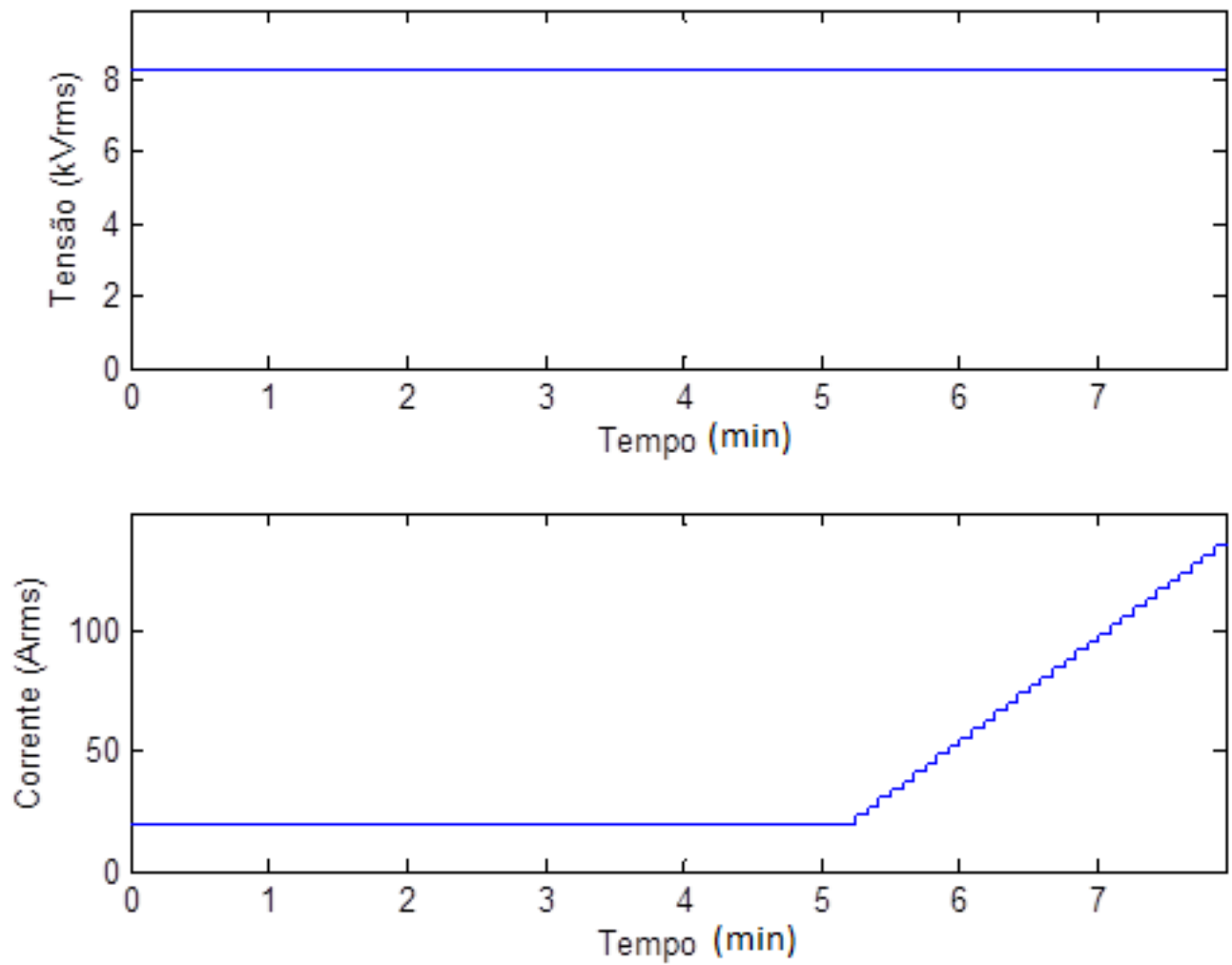

FIGURA 4.35 - Teste 1 - Evolução de Carga para o SEL AutoRanger.

Na Tabela 4.29 encontram-se os parâmetros para o teste de correntes pulsadas e na Figura 4.36 os respectivos valores de tensão e corrente eficazes 
aplicados no Auto Ranger. Este teste também é formado por uma única Macro, do tipo PRAMPI.

TABELA 4.29 - Parâmetros do Teste 2 - Correntes Pulsadas - SEL Auto Ranger.

\begin{tabular}{|c|c|}
\hline Seqüência & \multicolumn{1}{|c|}{ Parâmetros } \\
\hline \multirow{2}{*}{ Sec01 - PRAMPI } & $\begin{array}{l}\text { Prefault: } \mathrm{Va}=\mathrm{Vb}=\mathrm{Vc}=69 \mathrm{~V}, \mathrm{I}=3.3 \mathrm{~A}, \text { Fase=0 e } \mathrm{t}=18720 \text { ciclos } \\
\mathrm{Va}=\mathrm{V} \mathrm{b}=\mathrm{Vc}=69 \mathrm{~V} \text { e I }=\mathrm{ACTION} \\
\mathrm{A}=3.3 ; \mathrm{B}=360 ; \mathrm{C}=3.3 ; \mathrm{D}=3 ; \mathrm{E}=120 ; \mathrm{F}=1.2 ; \mathrm{G}=22.5 ;\end{array}$ \\
\hline Duração total & 5.9 minutos \\
\hline
\end{tabular}

Teste 2 - Correntes Pulsadas
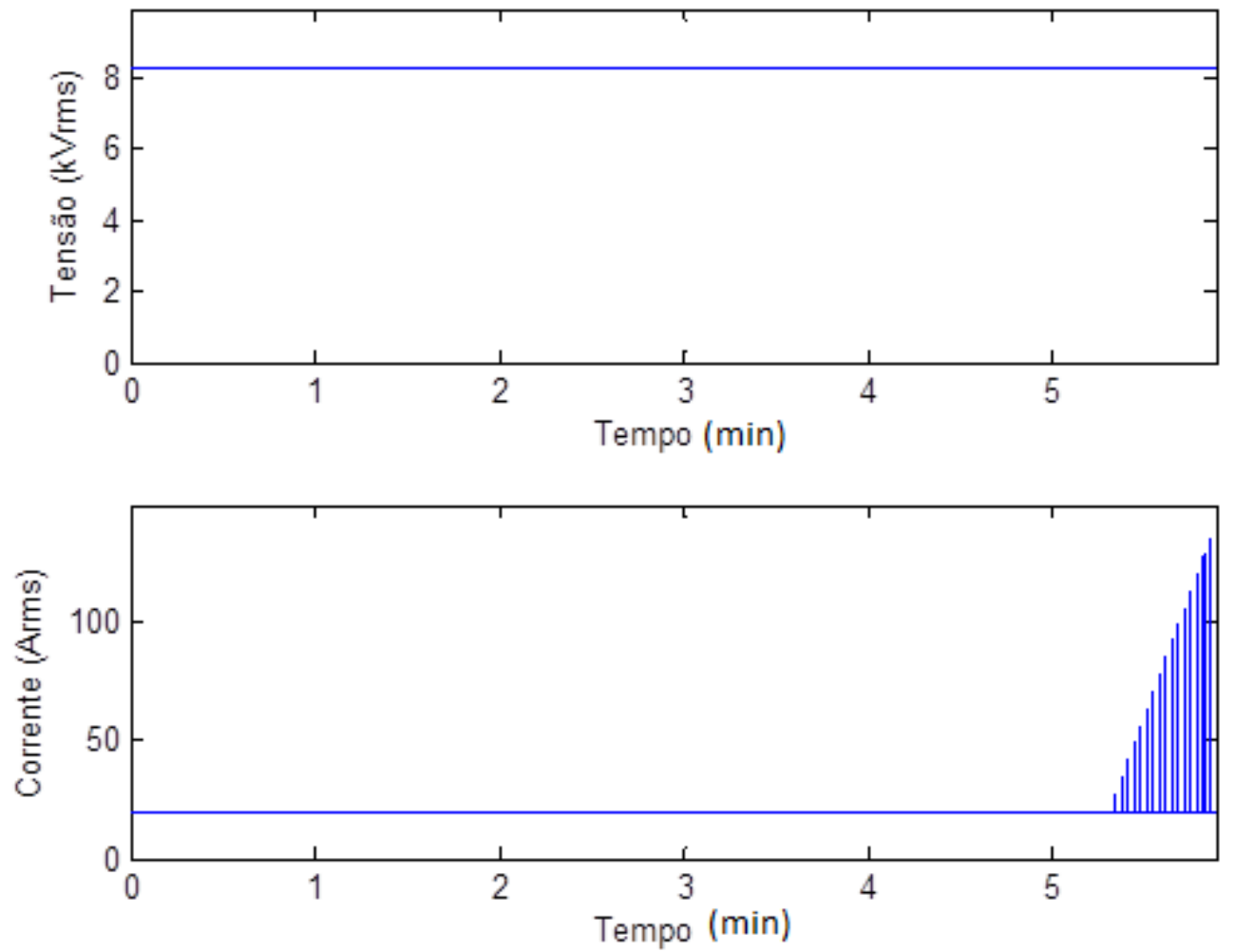

FIGURA 4.36 - Teste 2 - Correntes Pulsadas - SEL Auto Ranger.

Os Testes 3 e 4, relacionados com a simulação de correntes de falta e desligamentos da linha, são mais elaborados e por isso utilizam mais de uma seqüência de Macros. O Teste 3 (Religamento Sem Sucesso) utiliza 5 seqüências, sendo as 4 primeiras PRAMPI e a última LRAMPI. Já o Religamento Com Sucesso (Teste 4) utiliza 4 seqüências, sendo as 3 primeiras PRAMPI e a última LRAMPI. Na Tabela 4.30 e na Figura 4.37 encontram-se as informações a respeito do Teste 3, 
sendo que na Tabela 4.31 e Figura 4.38 encontram-se as informações referentes ao Teste 4.

TABELA 4.30 - Parâmetros do Teste 3 - Religamento Sem Sucesso - SEL Auto Ranger.

\begin{tabular}{|c|c|}
\hline Seqüência & Parâmetros \\
\hline Sec01 - PRAMPI & $\begin{array}{l}\text { Prefault: } V a=V b=V c=69 V, I=3 A, \text { Fase }=0 \text { e } t=18720 \text { ciclos } \\
V a=V b=V c=69 V \text { e I }=A C T I O N \\
A=3 ; B=20 ; C=3 ; D=5 ; E=0 ; F=8 ; G=15 ;\end{array}$ \\
\hline Sec02 - PRAMPI & $\begin{array}{l}\text { Prefault: } V a=V b=V c=0 V, I=0 A, \text { Fase }=0 \text { e } t=180 \text { ciclos } \\
V a=V b=V c=69 V \text { e I }=A C T I O N \\
A=7 ; B=120 ; C=3 ; D=5 ; E=0 ; F=8 ; G=15\end{array}$ \\
\hline Sec03 - PRAMPI & $\begin{array}{l}\text { Prefault:Va }=V b=V c=0 V, I=0 A, \text { Fase }=0 \text { e } t=180 \text { ciclos } \\
V a=V b=V c=69 V \text { e } I=A C T I O N \\
A=7 ; B=120 ; C=3 ; D=5 ; E=0 ; F=8 ; G=15 ;\end{array}$ \\
\hline Sec04 - PRAMPI & $\begin{array}{l}\text { Prefault:Va }=V b=V c=0 V, I=0 A, \text { Fase }=0 \text { e } t=180 \text { ciclos } \\
V a=V b=V c=69 V \text { e } I=A C T I O N \\
A=7 ; B=120 ; C=3 ; D=5 ; E=0 ; F=8 ; G=15 ;\end{array}$ \\
\hline Sec05 - LRAMPI & $\begin{array}{l}\text { Prefault: } V a=V b=V c=0 V, I=0 A, \text { Fase }=0 \text { e } t=10800 \text { ciclos } \\
V a=V b=V c=69 V \text { e I }=A C T I O N \\
A=0 ; B=180 ; C=0.3 ; D=300 ; E=3 ;\end{array}$ \\
\hline Duração total & 9.35 minutos \\
\hline
\end{tabular}

Teste 3 - Religamento Sem Sucesso
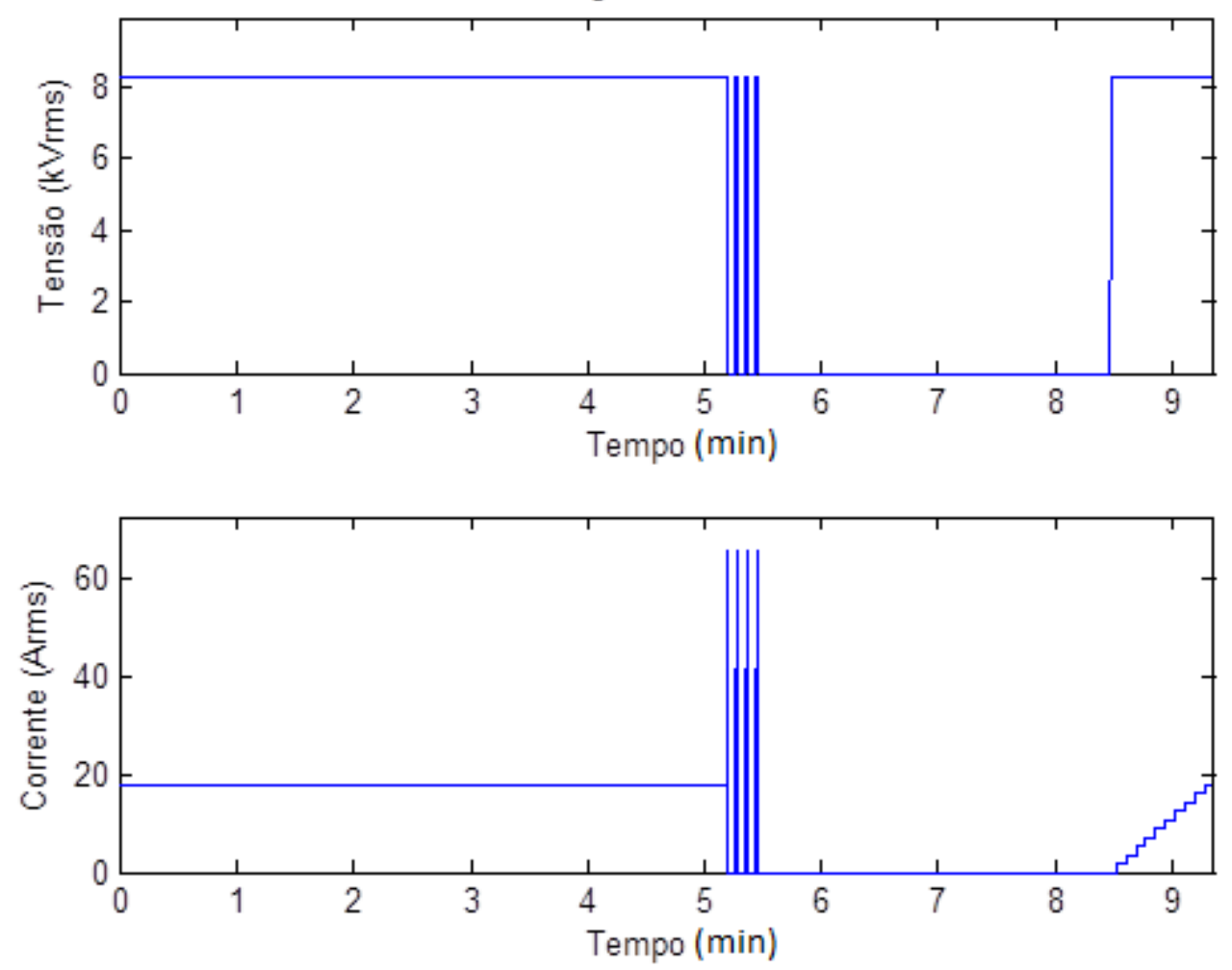

FIGURA 4.37 - Teste 3 - Religamento Sem Sucesso - SEL Auto Ranger. 
TABELA 4.31 - Parâmetros do Teste 4 - Religamento Com Sucesso - SEL Auto Ranger.

\begin{tabular}{|c|c|}
\hline Seqüência & Parâmetros \\
\hline Sec01 - PRAMPI & $\begin{array}{l}\text { Prefault: } V a=V b=V c=69 V, I=3.3 A, \text { Fase }=0 \text { e } t=18720 \text { ciclos } \\
V a=V b=V c=69 V \text { e I }=A C T I O N \\
A=3 ; B=20 ; C=3 ; D=5 ; E=0 ; F=5.45 ; G=15 ;\end{array}$ \\
\hline Sec02 - PRAMPI & $\begin{array}{l}\text { Prefault:Va=Vb=Vc=0V, I=0A, Fase }=0 \text { e } t=180 \text { ciclos } \\
V a=V b=V c=69 V \text { e } I=A C T I O N \\
A=7 ; B=120 ; C=3 ; D=5 ; E=0 ; F=8 ; G=15 ;\end{array}$ \\
\hline Sec03 - PRAMPI & $\begin{array}{l}\text { Prefault:Va }=V b=V c=0 V, I=0 A, \text { Fase }=0 \text { e } t=180 \text { ciclos } \\
V a=V b=V c=69 V \text { e } I=A C T I O N \\
A=7 ; B=120 ; C=3 ; D=5 ; E=0 ; F=8 ; G=15\end{array}$ \\
\hline Sec04 - LRAMPI & $\begin{array}{l}\text { Prefault: } V a=V b=V c=69 V, I=3.3 A, \text { Fase }=0 \text { e } t=10000 \text { ciclos } \\
V a=V b=V c=69 V \text { e } I=A C T I O N \\
A=2 ; B=180 ; C=0.3 ; D=300 ; E=3.3 ;\end{array}$ \\
\hline Duração total & $8.54 \mathrm{minc}$ \\
\hline
\end{tabular}

Teste 4 - Religamento Com Sucesso
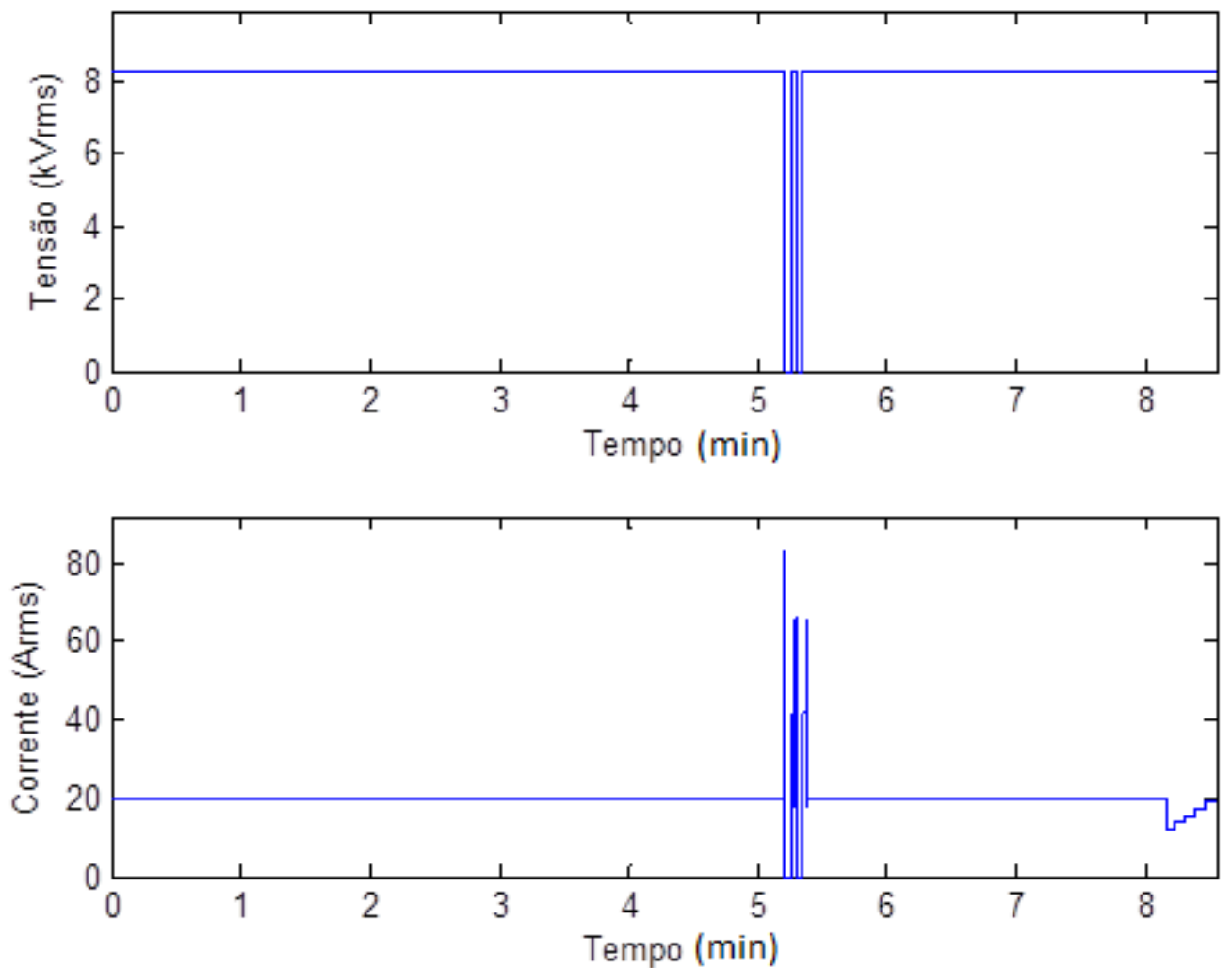

FIGURA 4.38 - Teste 4 - Religamento Com Sucesso - SEL AutoRanger.

A seqüência SEC04 representa o religamento do sistema elétrico com presença de tensão $(\mathrm{V}=8280 \mathrm{~V})$ e corrente de carga $(\mathrm{I}=19,8 \mathrm{~A})$ por um período de tempo de 10000 ciclos (2,78 minutos). Após esse tempo há uma pequena evolução de carga. Vale ressaltar que o SEL Auto Ranger precisa de condições de tensão e 
corrente de carga durante 2 minutos para rearmar após a ocorrência de uma situação faltosa.

Os testes descritos anteriormente para o SEL Auto Ranger foram elaborados considerando-se uma corrente de carga de 19,8 A ( I = 3.3 A). Conforme a Tabela 4.31, o valor de corrente de carga adotado indica que o dispositivo deve atuar para uma corrente que extrapole $50 \mathrm{~A}$. Se a corrente permanecer em $50 \mathrm{~A}$ e houver presença de tensão na linha por mais de 2 minutos, o sistema rearma de forma automática. Tal teste é contemplado no Teste 4 (Religamento Com Sucesso).

\subsection{Resultados Referentes aos Ensaios dos Indicadores de Faltas de Cabo}

Nessa etapa dos ensaios, a caixa de teste (Double F6150) foi comandada pelo software F6 Control Panel para a execução dos procedimentos descritos na Seção 3.2. Tal metodologia consistia do usuário inserir manualmente os valores de tensão e corrente a serem gerados pela caixa de teste. Esta apresentou problemas relacionados ao tempo de mudança de um estado para outro devido às incertezas do momento em que o usuário mudava a corrente e/ou a tensão de valor. Isso provocou aleatoriedade na atuação dos indicadores de falta.

Após diversas análises nos recursos disponíveis na caixa de teste F6150 da Double, verificou-se também a possibilidade de executar os testes por meio de rotinas já prontas no software ProTest. Tais rotinas, denominadas Macros, permitiram então elaborar situações de teste padronizadas e automáticas para os ensaios dos dispositivos indicadores de falta. Tal conjunto de teste foi composto de evolução de carga, correntes pulsadas com amplitude variável e crescente, religamento sem sucesso e religamento com sucesso. 
Uma série de testes abrangendo diferentes ajustes, posições de instalação, quantidades de IFs instalados na linha foram realizados.

Para os indicadores de cabo da Linetroll $110 \mathrm{E} \mu$ foram adotados os ajustes conforme apresentado na Tabela 4.32.

TABELA 4.32 - Ajuste dos indicadores da Linetroll 110E $\mu$.

\begin{tabular}{|c|c|c|c|c|c|c|c|c|c|}
\hline \multirow{2}{*}{ Ajuste } & \multirow{2}{*}{$\mathbf{N}^{\mathbf{o}}$ de série } & \multicolumn{6}{|c|}{ Ajuste das chaves } \\
\cline { 3 - 9 } & & $\mathbf{1}$ & $\mathbf{2}$ & $\mathbf{3}$ & $\mathbf{4}$ & $\mathbf{5}$ & $\mathbf{6}$ & $\mathbf{7}$ & $\mathbf{8}$ \\
\hline 1 & 5620801469 & 0 & 0 & 0 & 0 & 0 & 0 & 0 & 0 \\
\hline 2 & 5620801443 & 0 & 1 & 0 & 0 & 0 & 0 & 0 & 0 \\
\hline 3 & 5620801304 & 0 & 0 & 1 & 0 & 0 & 1 & 1 & 0 \\
\hline 4 & 5620801466 & 0 & 0 & 0 & 1 & 0 & 0 & 0 & 0 \\
\hline 5 & 5620801479 & 0 & 0 & 1 & 1 & 0 & 0 & 0 & 0 \\
\hline 6 & 5620801405 & 0 & 0 & 1 & 1 & 0 & 1 & 1 & 0 \\
\hline 7 & 5620801466 & 0 & 0 & 0 & 0 & 0 & 0 & 1 & 0 \\
\hline 8 & 5620801405 & 0 & 0 & 0 & 1 & 0 & 0 & 1 & 0 \\
\hline 9 & 5620801479 & 0 & 0 & 1 & 0 & 0 & 0 & 0 & 0 \\
\hline 10 & 5620801510 & 0 & 1 & 0 & 0 & 0 & 0 & 1 & 0 \\
\hline 11 & 5620801443 & 0 & 1 & 0 & 1 & 0 & 0 & 0 & 0 \\
\hline 12 & 5620801489 & 0 & 1 & 0 & 1 & 0 & 0 & 1 & 0 \\
\hline
\end{tabular}

Para os indicadores da Linetroll contendo os ajustes $3,6,7,8,10$ e 12 foram habilitados o rearme automático. O conjunto de ajuste 6 , ilustrado pela Tabela 4.32, representa o ajuste empregado na Distribuidora em questão.

Os IFs com os ajustes descritos na Tabela 4.32 foram submetidos aos seguintes testes:

- Teste $1 \rightarrow$ Evolução de carga por meio de degrau de corrente.

- Teste $2 \rightarrow$ Corrente pulsadas com amplitude variável e crescente.

- Teste $3 \rightarrow$ Religamento sem sucesso na quarta tentativa de religamento sob falta (Macros executados em seqüência).

- Teste $4 \rightarrow$ Religamento com sucesso (Macros executados em seqüência).

Os parâmetros utilizados na montagem das rotinas de teste são apresentados na Seção 4.10.1.

Os resultados dos testes estão registrados na Tabela 4.33. Vale destacar que foi considerado o arranjo descrito na Seção 4.6. 
TABELA 4.33 - Resultados dos testes dos IFs Linetroll 110E $\mu$.

\begin{tabular}{|c|c|c|c|c|c|}
\hline \multirow{2}{*}{ Ajuste } & \multirow{2}{*}{ N. de Série } & \multicolumn{4}{|c|}{ Testes } \\
\hline & & 1 & 2 & 3 & 4 \\
\hline 1 & 5620801469 & Atuou Ind. & Não Atuou & Êxito & Êxito \\
\hline 2 & 5620801443 & Atuou Ind. & Não Atuou & Não Atuou & Não Atuou \\
\hline 3 & 5620801304 & Êxito & Não Atuou & Êxito & Êxito \\
\hline 4 & 5620801466 & Êxito & Êxito & Êxito & Êxito \\
\hline 5 & 5620801479 & Atuou Ind. & Êxito & Êxito & Êxito \\
\hline 6 & 5620801405 & Êxito & Êxito & Êxito & Êxito \\
\hline 7 & 5620801466 & Êxito & Êxito & Êxito & Êxito \\
\hline 8 & 5620801405 & Êxito & Êxito & Êxito & Êxito \\
\hline 9 & 5620801479 & Atuou Ind. & Êxito & Exito & Exxito \\
\hline 10 & 5620801510 & Exxito & Não Atuou & Não Rearmou & Éxito \\
\hline 11 & 5620801443 & Atuou Ind. & Êxito & Não Atuou & Não Atuou \\
\hline 12 & 5620801489 & Exxito & Exxito & Exxito & Exxito \\
\hline
\end{tabular}

Vale destacar que "êxito" representa o funcionamento correto segundo o seu ajuste, considerando também tempo de bloqueio, sinalização na ocorrência de uma falta e ainda o rearme automático no restabelecimento normal do sistema para os IFs com essa última opção habilitada na programação dos mesmos.

Foram também realizados outros testes para o ajuste 6 , conforme apresentado posteriormente. Um dos testes assemelha-se ao Teste 4 (Religamento Com Sucesso) variando-se apenas o pulso de corrente ao final do Macro SEC01, ou seja, o parâmetro $\mathrm{F}$ para valores de 0 a $8 \mathrm{~A}$. Desses testes, verificou-se que o indicador com ajuste de di/dt igual a 12 A começou a sinalizar com variações de corrente (di/dt) a partir de 8,82 A, o que representa uma situação de atuação indevida.

Outro teste que foi submetido os IFs Linetroll $110 \mathrm{E} \mu$ foi quanto à instalação de diversos indicadores no condutor conforme a Seção 4.7. Foram instalados quatro indicadores próximos como ilustrado pela Figura 4.39. 


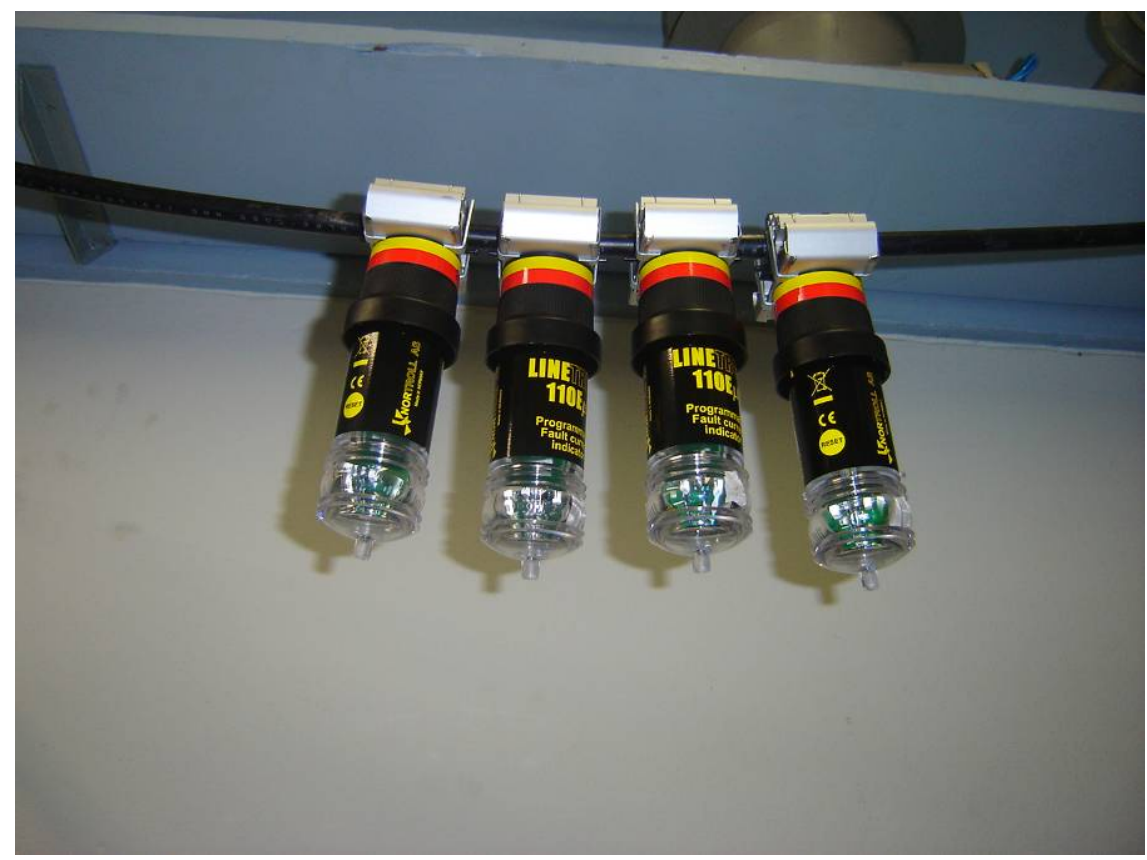

FIGURA 4.39 - Foto com quatro indicadores de falta próximos.

TABELA 4.34 - Resultados de testes para indicadores muito próximos.

\begin{tabular}{|c|c|c|c|c|c|}
\hline \multirow{2}{*}{ Ajuste } & \multirow{2}{*}{ N. de Série } & \multicolumn{4}{|c|}{ Testes } \\
\cline { 3 - 6 } & & $\mathbf{1}$ & $\mathbf{2}$ & $\mathbf{3}$ & $\mathbf{4}$ \\
\hline 1 & 5620801469 & Exxito & Atuou Ind. & Não Atuou & Êxito \\
\hline 2 & 5620801443 & Atuou Ind. & Exxito & Não Rearmou & Não Rearmou \\
\hline 3 & 5620801304 & Éxito & $\hat{E} x i t o$ & Não Atuou & Não Atuou \\
\hline 4 & 5620801405 & $\hat{E} x i t o$ & $\hat{E x x i t o}$ & $\hat{E} x i t o$ & Êxito \\
\hline
\end{tabular}

O comportamento aleatório observado para este ensaio evidenciou que a proximidade entre dispositivos indicadores de falta provoca deformação no campo elétrico monitorado pelos mesmos.

A mesma instalação foi repetida, porém, foi considerada uma distância de 25 cm entre os 4 indicadores conforme a Figura 4.40. 


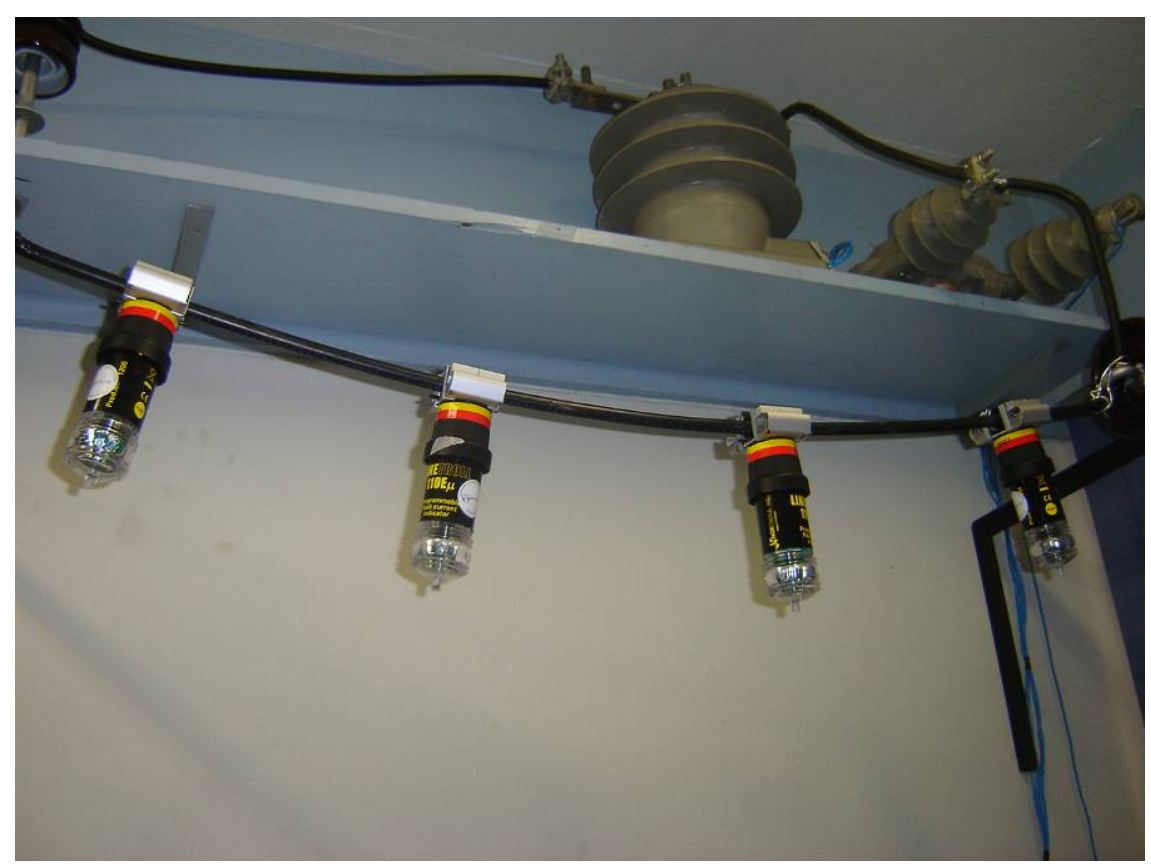

FIGURA 4.40 - Foto com quatro indicadores de falta distanciados de $25 \mathrm{~cm}$.

TABELA 4.35 - Resultados para IFs considerando uma distância entre eles.

\begin{tabular}{|c|c|c|c|c|c|}
\hline \multirow{2}{*}{ Ajuste } & \multirow{2}{*}{ N. de Série } & \multicolumn{4}{|c|}{ Testes } \\
\cline { 3 - 6 } & & $\mathbf{1}$ & $\mathbf{2}$ & $\mathbf{3}$ & $\mathbf{4}$ \\
\hline 1 & 5620801469 & Êxito & Êxito & Êxito & Êxito \\
\hline 2 & 5620801443 & Êxito & Êxito & Êxito & Êxito \\
\hline 3 & 5620801304 & Êxito & Exxito & Exxito & Exxito \\
\hline 4 & 5620801405 & Êxito & Êxito & Éxito & Exxito \\
\hline
\end{tabular}

Verificou-se que os indicadores atuam corretamente. Com isso, comprova-se a influência entre os indicadores no funcionamento adequado dos mesmos. Tal conclusão conduziu a elaboração de testes como variação angular na instalação do IF e mudança na defasagem angular entre a tensão e corrente.

Como descrito na Seção 4.8, foi montado o arranjo que contempla a variação angular na instalação dos indicadores de falta conforme mostra a Figura 4.41. 


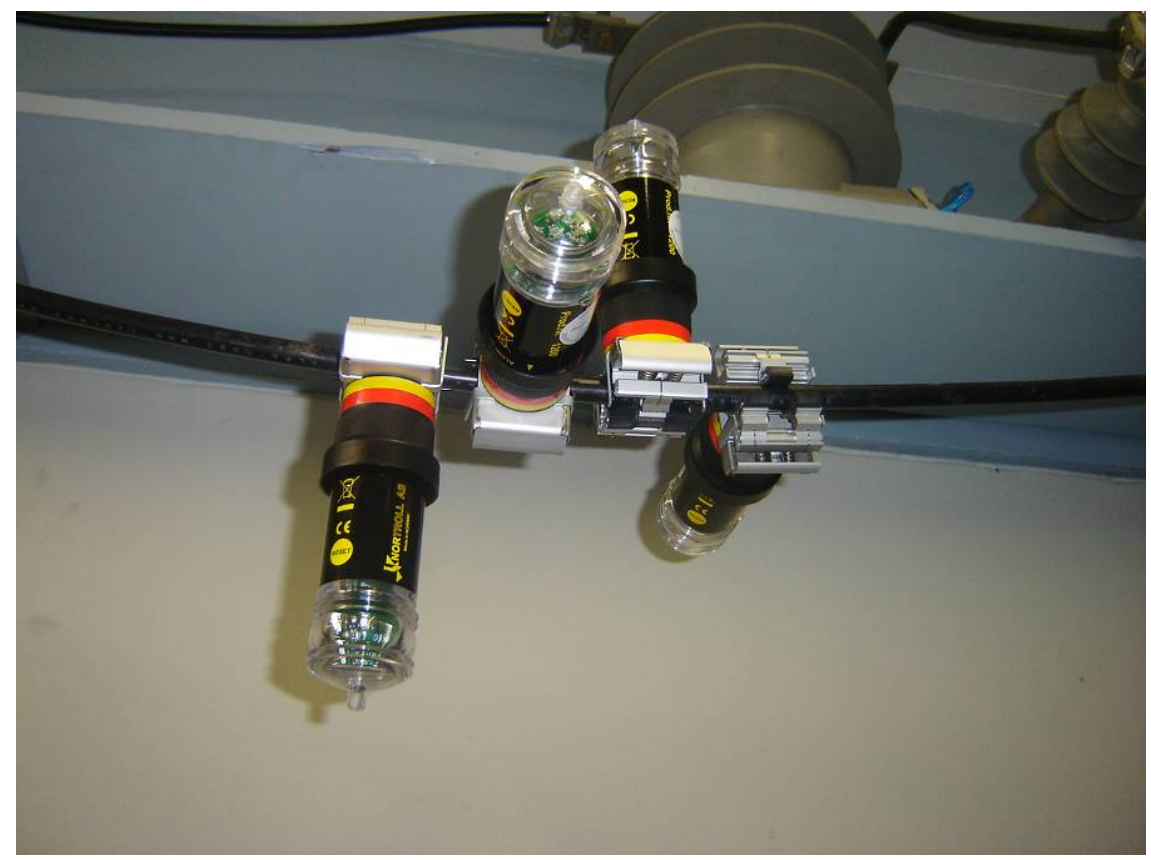

FIGURA 4.41 - Diferentes posições de instalação do IFs.

Os resultados para tal arranjo podem ser conferidos pela Tabela 4.36.

TABELA 4.36 - Variação da posição angular de instalação.

\begin{tabular}{|c|c|c|c|c|c|}
\hline \multirow{2}{*}{$\begin{array}{c}\text { Ângulo de } \\
\text { Instalação }\end{array}$} & \multirow{2}{*}{ N. de Série } & \multicolumn{4}{|c|}{ Testes } \\
\cline { 3 - 6 } & & $\mathbf{1}$ & $\mathbf{2}$ & $\mathbf{3}$ & $\mathbf{4}$ \\
\hline $0^{\circ}$ & 5620801469 & Êxito & Êxito & Êxito & Êxito \\
\hline $90^{\circ}$ & 5620801479 & Êxito & Êxito & Êxito & Êxito \\
\hline $180^{\circ}$ & 5620801304 & Êxito & Êxito & Éxito & Êxito \\
\hline $270^{\circ}$ & 5620801405 & Êxito & Êxito & Êxito & Êxito \\
\hline
\end{tabular}

Pela Tabela 4.36, verificou-se funcionamento correto dos Linetroll $110 \mathrm{E} \mu$ para os quatro testes.

Testes considerando variação de defasagem entre a tensão e corrente também foram avaliados. Os resultados são apresentados na Tebela 4.37, 4.38, 4.39 e 4.40 .

TABELA 4.37 - Variação na defasagem angular entre a tensão e corrente de $0^{\circ}$.

\begin{tabular}{|c|c|c|c|c|}
\hline \multirow{2}{*}{ N. de Série } & \multicolumn{4}{|c|}{ Testes } \\
\cline { 2 - 5 } & $\mathbf{1}$ & $\mathbf{2}$ & $\mathbf{3}$ & $\mathbf{4}$ \\
\hline 5620801469 & Êxito & Exxito & Êxito & Êxito \\
\hline 5620801304 & Êxito & Exxito & Êxito & Êxito \\
\hline 5620801405 & Exxito & Éxito & Êxito & Éxito \\
\hline 5620801479 & Êxito & Exxito & Exxito & Êxito \\
\hline
\end{tabular}


TABELA 4.38 - Variação na defasagem angular entre a tensão e corrente de $90^{\circ}$.

\begin{tabular}{|c|c|c|c|c|}
\hline \multirow{2}{*}{ N. de Série } & \multicolumn{4}{|c|}{ Testes } \\
\cline { 2 - 5 } & $\mathbf{1}$ & $\mathbf{2}$ & $\mathbf{3}$ & $\mathbf{4}$ \\
\hline 5620801469 & Exxito & Exxito & Exito & Exito \\
\hline 5620801304 & Êxito & Exxito & Exxito & Exxito \\
\hline 5620801405 & Êxito & Êxito & Éxito & Éxito \\
\hline 5620801479 & Êxito & Êxito & Éxito & Éxito \\
\hline
\end{tabular}

TABELA 4.39 - Variação na defasagem angular entre a tensão e corrente de $180^{\circ}$.

\begin{tabular}{|c|c|c|c|c|}
\hline \multirow{2}{*}{ N. de Série } & \multicolumn{4}{|c|}{ Testes } \\
\cline { 2 - 5 } & $\mathbf{1}$ & $\mathbf{2}$ & $\mathbf{3}$ & $\mathbf{4}$ \\
\hline 5620801469 & Exxito & Exxito & Exito & Exito \\
\hline 5620801304 & Êxito & Exxito & Exxito & Exxito \\
\hline 5620801405 & Êxito & Exxito & Exxito & Exxito \\
\hline 5620801479 & Êxito & Éxito & Éxito & Éxito \\
\hline
\end{tabular}

TABELA 4.40 - Variação na defasagem angular entre a tensão e corrente de $270^{\circ}$.

\begin{tabular}{|c|c|c|c|c|}
\hline \multirow{2}{*}{ N. de Série } & \multicolumn{4}{|c|}{ Testes } \\
\cline { 2 - 5 } & $\mathbf{1}$ & $\mathbf{2}$ & $\mathbf{3}$ & $\mathbf{4}$ \\
\hline 5620801469 & Êxito & Êxito & Exxito & Exito \\
\hline 5620801304 & Êxito & Êxito & Exxito & Exxito \\
\hline 5620801405 & Êxito & Exxito & Exxito & Exxito \\
\hline 5620801479 & Êxito & EExito & Éxito & Exxito \\
\hline
\end{tabular}

Para as Tabelas 4.37, 4.38, 4.39 e 4.40 foi considerada a tensão como referência angular. Dos resultados obtidos para a variação angular, verificou-se funcionamento correto dos dispositivos testados.

Alguns modelos dos fabricantes de indicadores de cabo LOFA e SCHWEITZER também foram estudados em laboratório. Os testes desenvolvidos para os ensaios desses fabricantes são os mesmos adotados para os IFs da Linetroll, excetuando-se apenas nos parâmetros das Macros. Tais alterações foram necessárias para atender condições específicas de funcionamento de cada modelo de indicador de falta. Os parâmetros são apresentados na Seção 4.10. Os resultados referentes aos ensaios do modelo SEL Auto Ranger são mostrados a seguir. 
TABELA 4.41 - Resultados de teste para o SEL Auto Ranger.

\begin{tabular}{|c|c|c|c|c|}
\hline \multirow{2}{*}{ N. de Série } & \multicolumn{4}{|c|}{ Testes } \\
\cline { 2 - 5 } & $\mathbf{1}$ & $\mathbf{2}$ & $\mathbf{3}$ & $\mathbf{4}$ \\
\hline 07050006 & Êxito & Exxito & Êxito & Exito \\
\hline
\end{tabular}

TABELA 4.42 - Resultados de teste para o LOFA RTA-A.

\begin{tabular}{|c|c|c|c|c|}
\hline \multirow{2}{*}{ N. de Série } & \multicolumn{4}{|c|}{ Testes } \\
\cline { 2 - 5 } & $\mathbf{1}$ & $\mathbf{2}$ & $\mathbf{3}$ & $\mathbf{4}$ \\
\hline 07050006 & Exxito* $^{*}$ & Não Atuou & Não Atuou & Não Atuou \\
\hline
\end{tabular}

* não atuou para níveis de corrente de carga

Para todos os testes, o SEL Auto Ranger apresentou êxito na sinalização em situações de falta e rearme automático devido ao retorno das condições normais da linha.

Com relação ao dispositivo indicador de falta do fabricante LOFA, modelo RTA-A, cabe ressaltar que o mesmo não possui possibilidade de ajuste pelo usuário. Para tais dispositivos foram aplicados os testes conforme descrito na Seção 4.10.4, porém, não houve atuação dos mesmos. No Teste 1 não houve atuação do dispositivo como era esperado, porém, há incertezas com relação a resposta do dispositivo frente a essa situação, pois para os outros testes ocorreu falha no seu funcionamento.

Procedimentos semelhantes foram adotados para o LOFA ICO que também não atuou em nenhum dos ensaios abordados na Seção 4.10.5.

Dentre as não atuações averiguadas em situações de falta nos modelos da LOFA, conclui-se que estes dispositivos não funcionam segundo as especificações do fabricante.

Cabe ressaltar também que os fabricantes indicam alguns testes para verificação do funcionamento dos dispositivos como: verificação da bateria e rearme manual por imã. Foi verificado em laboratório que tais testes não garantem que o dispositivo está funcionamento corretamente. 
De forma geral, para todos os testes laboratoriais realizados, tem-se uma avaliação segundo a Figura 4.42 .

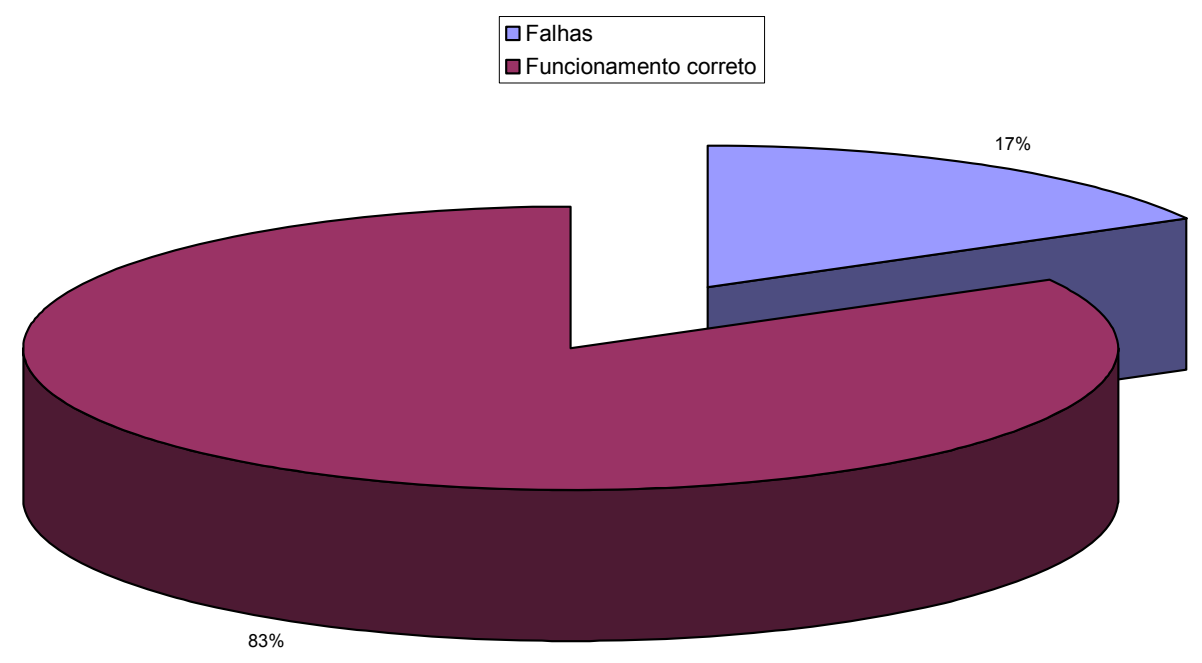

FIGURA 4.42 - Resultados dos ensaios referentes aos indicadores de cabo.

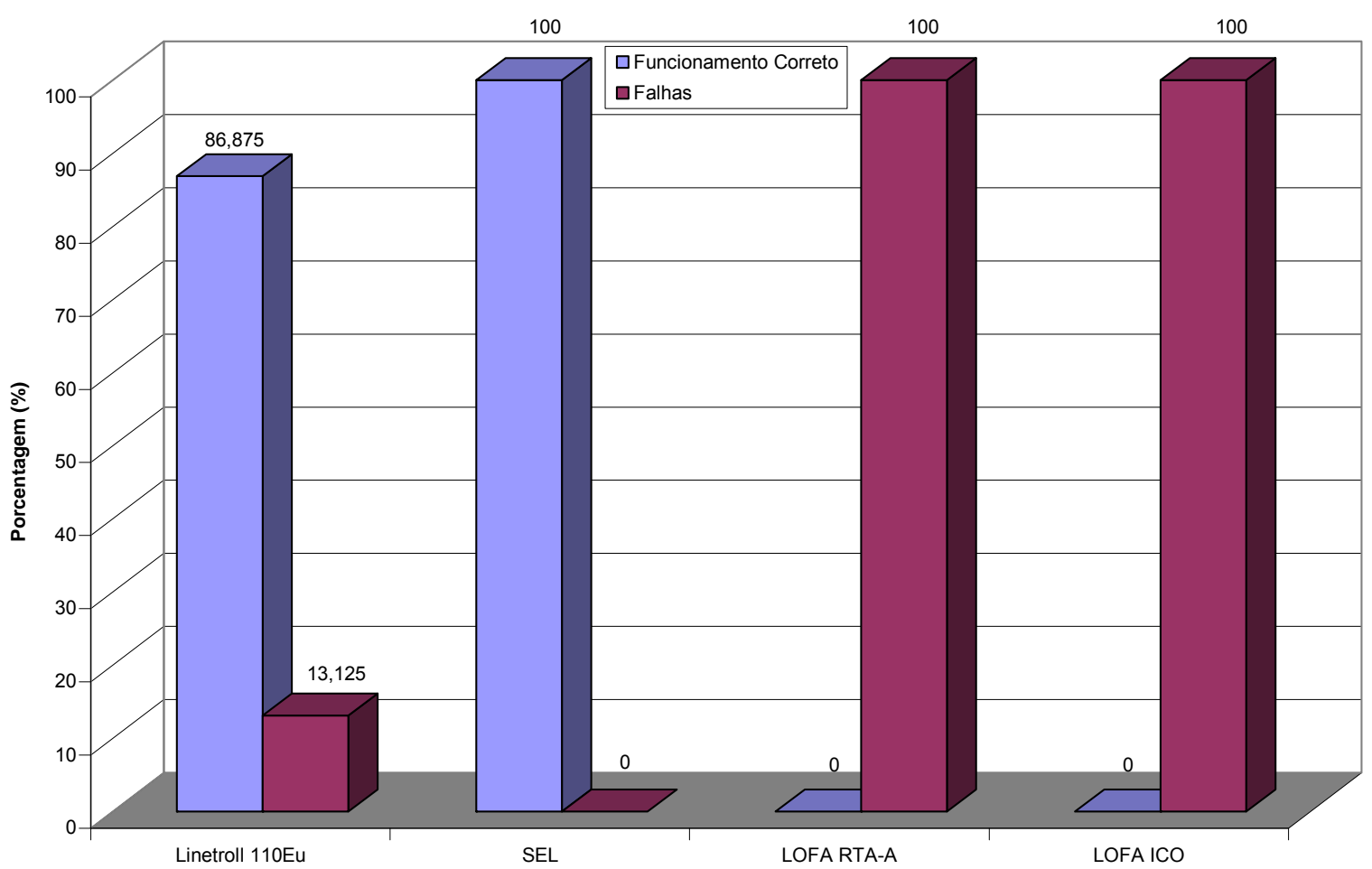

FIGURA 4.43 - Resultados dos Ensaios referentes aos IFs de cabo por modelo.

Por meio da Figura 4.42 e 4.43, é possível observar a compilação de todos os resultados gerais obtidos nos ensaios dos dispositivos indicadores de falta instalados no cabo. O modelo SEL Auto Ranger apresentou $100 \%$ de acertos frente 
aos testes que foi submetido. Por outro lado, os modelos Lofa RTA-A e ICO apresentaram $100 \%$ de falhas.

\subsection{Resultados Referentes aos Ensaios dos Indicadores de Faltas de Poste}

Nessa seção serão apresentados os resultados obtidos em ensaios laboratoriais dos indicadores de falta instalados em postes: Linetroll $111 \mathrm{k}$ e o Linetroll 3100. Os testes foram os mesmos aplicados nos indicadores de falta instalados em cabo. Com relação à montagem laboratorial, foi necessário considerar a distância de instalação do dispositivo à linha conforme já descrito na Seção 4.9. Vale lembrar que os indicadores de falta instalados em postes foram submetidos a ensaios monofásicos.

Primeiramente, foi testado o Linetroll $111 \mathrm{k}$ com a programação das chaves apresentadas na Tabela 4.43 .

TABELA 4.43 - Conjunto de ajuste para o IF Linetroll 111k.

\begin{tabular}{|c|c|c|c|c|c|c|c|c|c|c|c|c|c|}
\hline \multirow{2}{*}{ Ajuste } & \multirow{2}{*}{$\begin{array}{c}\mathbf{N}^{\mathbf{0}} \mathbf{d e} \\
\text { série }\end{array}$} & $\mathbf{1}$ & $\mathbf{2}$ & $\mathbf{3}$ & $\mathbf{4}$ & $\mathbf{5}$ & $\mathbf{6}$ & $\mathbf{7}$ & $\mathbf{8}$ & $\mathbf{9}$ & $\mathbf{1 0}$ & $\mathbf{1 1}$ & $\mathbf{1 2}$ \\
\hline 1 & 72242491 & 1 & 0 & 0 & 0 & 0 & 1 & 0 & 0 & 1 & 0 & 0 & 1 \\
\hline 2 & 72242491 & 1 & 0 & 0 & 0 & 0 & 1 & 0 & 0 & 0 & 0 & 0 & 1 \\
\hline 3 & 72242491 & 1 & 0 & 0 & 0 & 0 & 1 & 0 & 0 & 1 & 1 & 0 & 1 \\
\hline 4 & 72242491 & 1 & 0 & 0 & 0 & 0 & 1 & 0 & 1 & 1 & 0 & 0 & 1 \\
\hline 5 & 72242491 & 1 & 0 & 0 & 0 & 0 & 1 & 0 & 1 & 0 & 0 & 0 & 1 \\
\hline 6 & 72242491 & 1 & 0 & 0 & 0 & 0 & 1 & 0 & 1 & 1 & 1 & 0 & 1 \\
\hline 7 & 72242491 & 0 & 1 & 0 & 0 & 0 & 1 & 0 & 0 & 1 & 0 & 0 & 1 \\
\hline
\end{tabular}

O conjunto de ajuste 1 ilustrado pela Tabela 4.43 representa o ajuste empregado pela Distribuidora nos indicadores Linetroll 111k. Os ajustes 2 e 3 contemplam derivações dos ajustes utilizados pela Distribuidora com variação no tipo de rearme. Já o conjunto de ajustes 4 a 6 são derivados do conjunto 1 com variações no tipo de rearme, porém, considerando o Tripping dos disjuntores 
habilitado. E, por fim, o conjunto de ajuste 7 representa o ajuste utilizado na Distribuidora, excetuando-se apenas na programação da sensibilidade para 7A.

Foram-se aqui ensaiados apenas o ajuste 1 da Tabela 4.43. Os resultados para o ajuste 1 são apresentados na Tabela 4.44 .

TABELA 4.44 - Resultados referentes ao indicador de poste Linetroll 111k.

\begin{tabular}{|c|c|c|c|c|c|}
\hline \multirow{2}{*}{$\begin{array}{c}\text { Distância de } \\
\text { Instalação (m) }\end{array}$} & \multirow{2}{*}{ N. de Série } & \multicolumn{4}{|c|}{ Testes } \\
\cline { 3 - 6 } & & $\mathbf{1}$ & $\mathbf{2}$ & $\mathbf{3}$ & $\mathbf{4}$ \\
\hline 0,92 & 72242491 & Êxito & Exxito & Não Atuou & Êxito \\
\hline 1,22 & 72242491 & Êxito & Atuou Ind. & Êxito & Êxito \\
\hline
\end{tabular}

Dentre os resultados de teste do Linetroll $111 \mathrm{k}$, observou-se a não atuação para a situação de falta do Teste 3 e distância de instalação de 0,92. Tal comportamento pode ser explicado pelo fato de não ter sido considerada uma distância recomendada pelo fabricante ou pelo sistema laboratorial ser monofásico.

Para o Linetroll 3100 foi considerado o ajuste segundo a Tabela 4.45. Os resultados de ensaios obtidos para esse ajuste estão registrados na Tabela 4.46.

TABELA 4.45 - Ajuste adotado no Linetroll 3100.

\begin{tabular}{|c|c|}
\hline Número do banco de chaves & Posição das chaves \\
\hline Banco de chaves SW1 & 11000000 \\
\hline Banco de chaves SW2 & 11100000 \\
\hline Banco de chaves SW3 & 00000000 \\
\hline
\end{tabular}

TABELA 4.46 - Resultados referentes ao indicador de poste Linetroll 3100.

\begin{tabular}{|c|c|c|c|c|c|}
\hline \multirow{2}{*}{$\begin{array}{c}\text { Distância de } \\
\text { Instalação (m) }\end{array}$} & \multirow{2}{*}{ N. de Série } & \multicolumn{4}{|c|}{ Testes } \\
\hline & & 1 & 2 & 3 & 4 \\
\hline 0,92 & 07050006 & Éxito & Exxito & Éxito & Não Atuou \\
\hline 1,22 & 07050006 & Éxito & Exxito & Êxito & Exxito \\
\hline
\end{tabular}

Como observado no Linetroll 111k, o modelo 3100 não atuou em algumas situações, sob as mesmas suposições levantadas para o modelo $111 \mathrm{k}$.

A Figura 4.44 apresenta os resultados referentes ao desempenho dos indicadores de poste frente aos testes laboratoriais. 


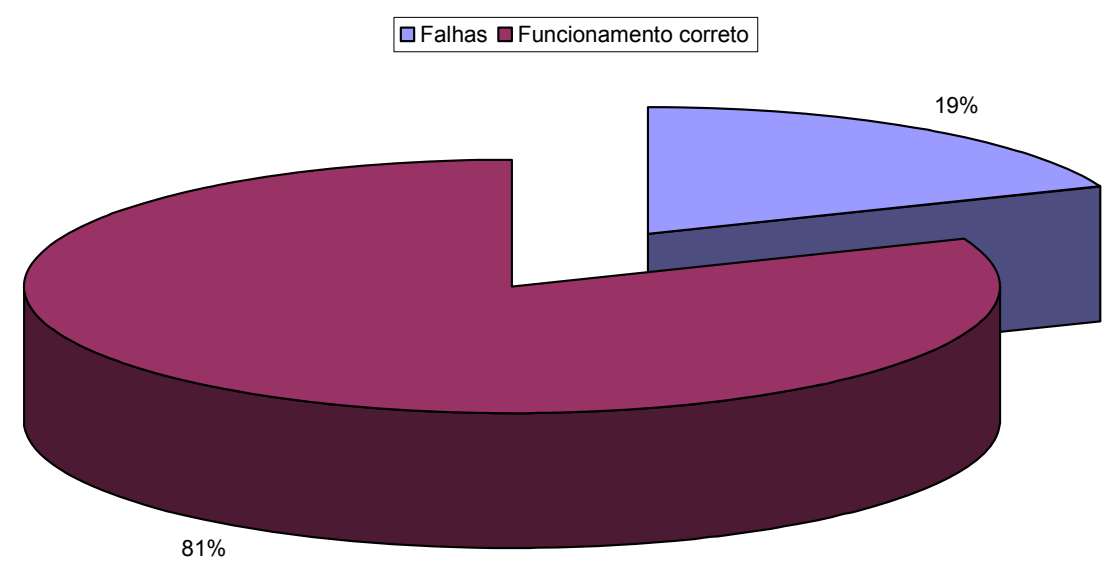

FIGURA 4.44 - Resultados referentes aos indicadores de poste.

Com relação aos resultados por modelo de IF de poste, observa-se pela Figura 4.45 que o modelo Linetroll 3100 teve desempenho superior ao Linetroll $111 \mathrm{k}$.

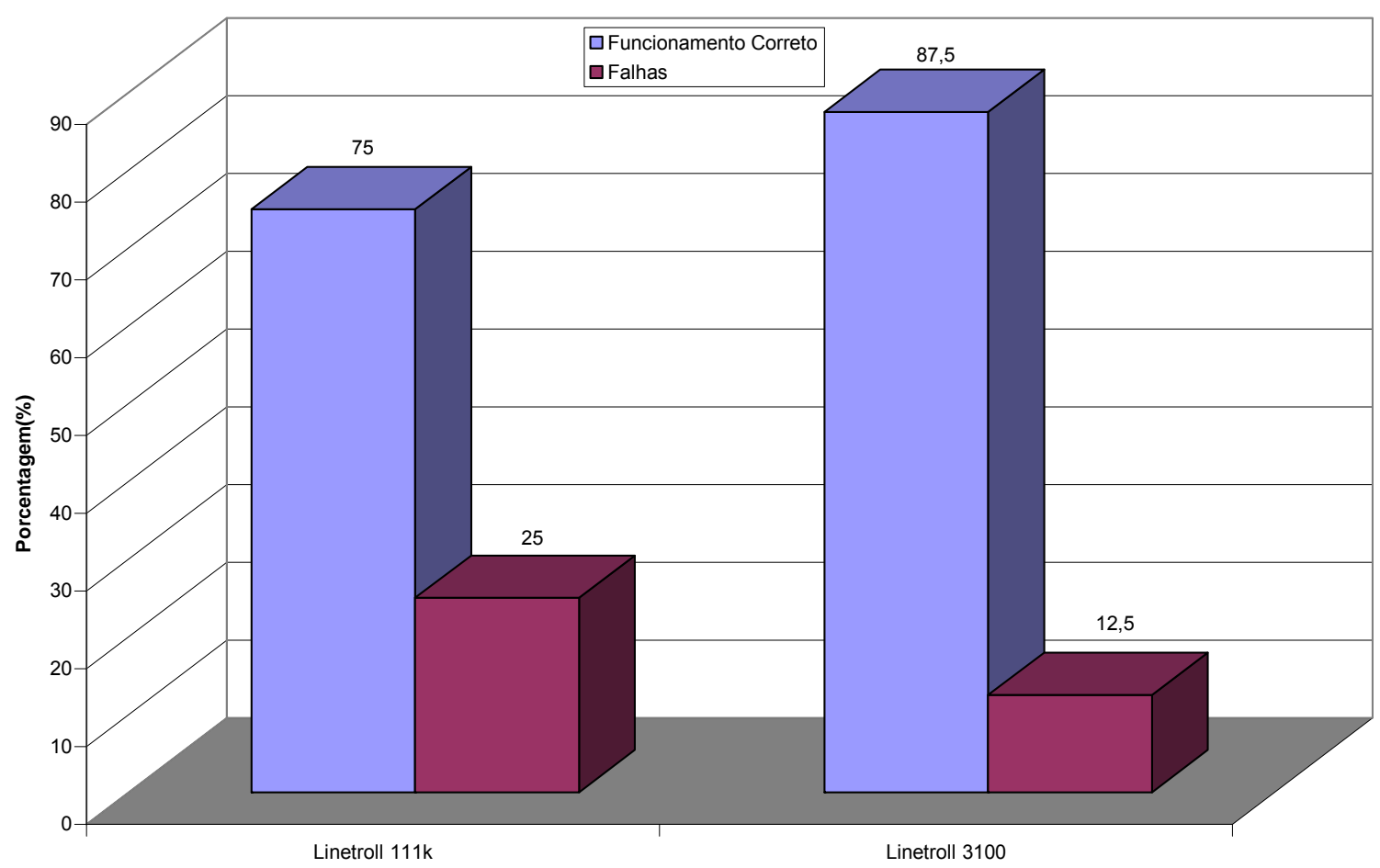

FIGURA 4.45 - Resultados referentes aos indicadores de poste por modelo.

Pode-se observar que os resultados gerais foram semelhantes aos obtidos nos ensaios realizados com os indicadores de cabo. 


\section{Conclusões}

Neste trabalho foi apresentada uma nova sistemática para realização de ensaios laboratoriais monofásicos a fim de complementar os testes padronizados realizados por fabricantes de IFs e também aqueles referenciados em norma.

O objetivo da pesquisa foi então identificar aspectos operacionais que colaboram para as falhas de tais equipamentos, quando submetidos às situações semelhantes àquelas encontradas em campo, por intermédio de ensaios automatizados e com repetibilidade.

Os resultados obtidos mostraram a eficiência da metodologia desenvolvida em detectar falhas de operação dos IFs.

Adicionalmente, a fim de validar a metodologia proposta, diversos ensaios experimentais foram realizados em laboratório e tiveram por objetivo verificar a aderência do método desenvolvido, assim como levantar os possíveis pontos de não atuação dos indicadores de faltas.

Tais ensaios também contemplaram os aspectos presentes na norma IEEE Std 495 (2007). Vale ressaltar que, em laboratório, não foi possível estudar o comportamento trifásico das linhas e a proximidade entre os indicadores instalados em condições reais de distância.

Os ensaios realizados para os indicadores de falta instalados em poste utilizaram apenas uma fase, sendo que os mesmos permitiram verificar que tais dispositivos são fortemente influenciados pelo desbalanço do sistema e posição de instalação em relação à linha. 
De forma geral, os ensaios indicaram que o teste recomendado pelos fabricantes para verificação do funcionamento do dispositivo não é suficiente, pois a garantia de funcionamento só é verificada quando os indicadores de falta são ensaiados sob condições reais de tensão e corrente. Além disso, alguns fabricantes não apresentaram o comportamento da bateria para operações contínuas de sinalização de faltas.

Por meio do aparato experimental automatizado desenvolvido para ensaios laboratoriais, torna-se então possível inserir os parâmetros, bem como a repetibilidade, que serão submetidos os IFs para verificar os seus desempenhos, sendo todo o aparato projetado para sistemas monofásicos.

Como trabalhos futuros, o aparato poderá agora ser expandido para sistemas trifáficos. Outra frente de pesquisa relaciona-se ao desenvolvimento de outras Macros a fim de identificar diversas outras situações que envolvem o comportamento dos indicadores de faltas junto ao sistema elétrico de distribuição de energia elétrica. 



\section{Referências Bibliográficas}

ANEEL (AGÊNCIA NACIONAL DE ENERGIA ELÉTRICA), PRODIST (Módulo 8) Qualidade da Energia Elétrica, 2011

ANGERER, F., "OH and UG fault indication via radio networks", IEEE/PES Transmission and Distribution Conference and Exposition, vol. 2, pp. 991-992, 2001.

ARAVENA, J.L.; CHOWDHURY, F.N., "A new approach to fast fault detection in power systems", Proceedings of International Conference on Intelligent Systems Applications to Power Systems - ISAP'96, pp. 328-332, 1996.

BAKER, G.; STEINER, J. P.; ROCKWELL, D., "Performance of on-line fault distance monitor for distribution cable circuits", IEEE Transmission and Distribution Conf. and Exposition, vol. 2, pp. 979-981, 2001.

BALDWIN, T.; RENOVICH Jr, F.; SAUDERS, L.F., "Directional ground-fault indicator for high-resistance grounded systems", IEEE Transactions on Industry Applications, vol. 39, no. 2, pp. 325-332, 2003.

$\mathrm{CHO}, \mathrm{N}$;; HA, B., "The results of the field test in distribution automation system for the Korea Utility", Proceedings of Power System Technology - POWERCON, vol.1, pp. 48-52, 1998.

CHOI, T.; KOH, I.-S.; KIM, B.-H.;SONG, W.-S.;JANG, W.-S., "PC-based remote control and fault location system for distribution line", IEEE Power Engineering Society - Winter Meeting, vol. 2, pp. 1085-1090, 1999. 
DUC-PHAM, C.; RAISON, B.; ROGNON, J.-P.; BONNOIT, S.; MANJAL, B., "Optimization of fault indicators placement with dispersed generation insertion", IEEE Power Engineering Society - General Meeting, pp. 1530-1537, 2005.

FALAGHI, H.; HAGHIFAM, M.R.; OSOULI TABRIZI, M.R., "Fault indicators efFICts on distribution reliability indices", $18^{\text {th }}$ International Conference on Electricity Distribution - CIRED2005, pp. 1-4, 2005.

IEEE Std 495, IEEE Guide for Testing Faulted Circuit Indicators, IEEE, 2007.

KIM, C.H.; KIM, H.; KO, Y.H.; BYUN, S.H.; AGGARWAL, R.K.; JOHNS, A.T., "A novel fault-detection technique of high-impedance arcing faults in transmission lines using the wavelet transform", IEEE Transactions on Power Delivery, vol. 17, no. 4, pp. 921-929, 2002.

KRAJNAK, D.J., "Faulted circuit indicators and system reliability", Rural Electric Power Conference, pp. A4/1 - A4/4, 2000.

SANTOS, N.R.; SILVA, I.N.; FLAUZINO, R.A.; SPATTI, D.H., "Optimized Selection Approach of Transformer Protection Devices against Atmospheric Discharges Using Expert System", IEEE Power Engineering Society - General Meeting, Calgary (Canadá), 6p., 2009.

SILVA, I.N.; FLAUZINO, R.A.; RODRIGUES, J.F., "Uma aplicação de redes neurais artificiais em projetos de aterramento elétrico", IV Simpósio Brasileiro de Automação Inteligente, pp. 692-697, 1999.

SOUDI, F.; TOMSOVIC K., "Optimized distribution protection using binary programming", IEEE Transactions on Power Delivery, vol. 13, no. 1, pp. 218-224, 1998. 
SOUZA, D.M.B.S.; ASSIS, A.F.; SILVA, I.N.; USIDA, W.F., "Efficient fuzzy approach for allocating fault indicators in power distribution lines", IEEE Transmission and Distribution Conference and Exposition, pp. 1- 6, 2008.

SOUZA, D.M.B.S., Abordagem Baseada em Lógica Fuzzy para Alocação de Indicadores de Faltas em Sistemas de Distribuição de Energia Elétrica, Dissertação de Mestrado (USP/EESC/SEL), 2009.

SOUDI, F.; TOMSOVIC, K., "Optimal distribution protection design: quality of solution and computational analysis", International Journal on Electric Power and Energy Systems, vol. 21, pp. 327-335, 1999.

SOUDI, F.; TOMSOVIC, K., "Optimal trade-offs in distribution protection design", IEEE Transactions on Power Delivery, pp. 292-296, 2001.

TANG, Y.; WANG, H.F.; AGGARWAL, R.K.; JOHNS, A.T., "Fault indicators in transmission and distribution systems", Proceedings of Electric Utility Deregulation and Restructuring and Power Technologies, pp. 238-243, 2000.

USIDA, W.F., Sistema Inteligente para Alocação Eficiente de Dispositivos Indicadores de Falta em Alimentadores de Distribuição, Tese de Doutorado (USP/EESC/SEL), 2011.

ZAHRA, F.; JEYASURYA, B.; QUAICOE, J. E., "High-speed transmission line relaying using artificial neural networks", Electric Power Systems Research, no. 53, pp. 173-179, 2000.

ZHANG, H.F.; PAN, Z.C.; SANG, Z.Z., "Fault locating in ungrounded and compensated systems", Eighth IEE International Conference on Developments in Power System Protection, vol. 2, pp. 469-472, 2004. 